This document is downloaded from DR-NTU (https://dr.ntu.edu.sg) Nanyang Technological University, Singapore.

\title{
An analysis of journalism convergence in legacy media organisations \& online news start-ups
}

Chua, Sherwin Kim Hee

2018

http://hdl.handle.net/10356/73167

https://doi.org/10.32657/10356/73167

Nanyang Technological University

Downloaded on 26 Apr 2023 22:50:45 SGT 

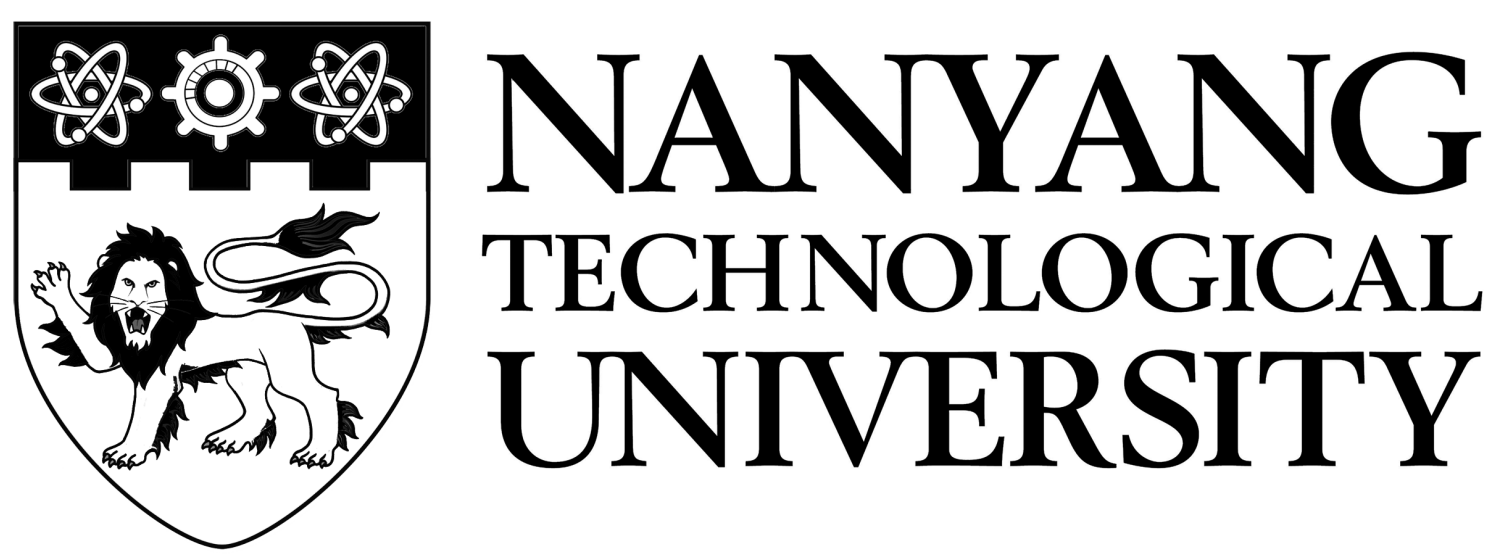

AN ANALYSIS OF JOURNALISM CONVERGENCE IN

LEGACY MEDIA ORGANISATIONS \&

ONLINE NEWS START-UPS

בֶב

SHERWIN CHUA KIM HEE

$\stackrel{\text { ำ }}{\Theta}$

WEE KIM WEE SCHOOL OF COMMUNICATION AND INFORMATION 


\section{AN ANALYSIS OF JOURNALISM CONVERGENCE IN \\ LEGACY MEDIA ORGANISATIONS \& ONLINE NEWS START-UPS}

SHERWIN CHUA KIM HEE

WEE KIM WEE SCHOOL OF COMMUNICATION AND INFORMATION

A thesis submitted to the Nanyang Technological University in partial fulfilment for the degree of Master of Mass Communication 


\begin{abstract}
Journalism convergence scholarship has been criticized for failing to keep pace with the rapid transformations in newsrooms. Multidimensional news convergence frameworks, in particular, have been critiqued for being inadequate in explaining convergence for two reasons. Firstly, they have become outdated as journalism has been evolving at a blistering pace in tandem with advancements in communication technology. Secondly, they remain focused on large, traditional media organisations, and has neglected online news start-ups.

This thesis proposes an updated multidimensional news convergence framework that includes five dimensions - business convergence; technological convergence; convergence of contents; professional convergence; and convergence with the audience - and applies it to the examination of legacy media and digital news start-ups in Singapore. Through three case studies that include one legacy newspaper (The Straits Times) and two digital news start-ups (The Middle Ground and The Online Citizen), in-depth interviews with 19 journalists, and a content analysis of 762 online news articles, this study finds that both types of organisations similarly exhibit most of the news convergence characteristics outlined by the news convergence paradigm. However, nuanced dissimilarities in each organisation have been observed. These include the manner in which resources are allocated to enhance their digital capabilities, their platform publishing strategies and work processes, and the degree to which they require their journalists to be polyvalent in journalistic skills.

This study has also observed new traits of convergence that better explain current journalistic praxes in the news companies. To meet the demands of online journalism, each company has evolved new, distinct traits and practices that enhance their multimedia digital news production and distribution, such as leveraging on novel
\end{abstract}


social media features - including live videos, incorporating new communication technologies in news construction, and experimenting with intra- and interorganisation collaborative journalism. 


\section{ACKNOWLEDGEMENTS}

To my academic supervisors, Dr Debbie Goh, Dr Trisha Lin and Professor Hao

Xiaoming. For your patience, guidance and never giving up on me.

To the staff of The Middle Ground, The Online Citizen and The Straits Times.

For generously sharing your time, thoughts and experiences with me.

To the examiners, for your invaluable advice on refining my research.

Most importantly, to Mabel, my wife.

For being my pillar of support and intellectual sounding board. Your clarity of thought always astounds me.

Thank you. 


\section{TABLE OF CONTENTS}

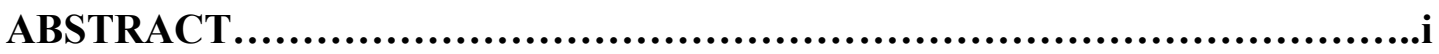

ACKNOWLEDGEMENTS............................................................ii

TABLE OF CONTENTS..............................................................iv

LIST OF TABLES.....................................................................

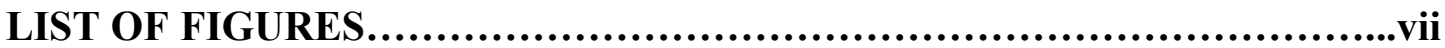

CHAPTER ONE: INTRODUCTION.............................................1

1.1 Towards an Updated Typology of News Convergence.....................2

1.2 Singapore's Journalism Landscape .......................................

1.3 Research Objectives and Significance..................................... 6

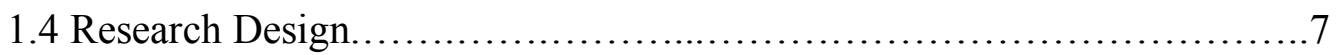

1.5 Research Context: Singapore General Election 2015....................8

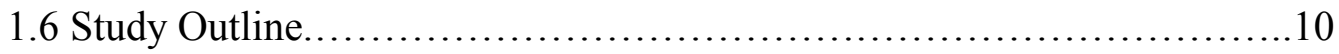

CHAPTER TWO: LITERATURE REVIEW....................................11

2.1 The State of Legacy Media and News Start-ups............................11

2.2 Defining Journalism Convergence.......................................

2.3 An Updated News Convergence Framework.............................23

CHAPTER THREE: METHODOLOGY.........................................29

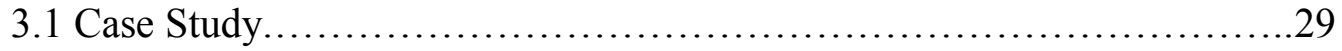

3.2 Data Collection I: Semi-structured, In-depth Interviews.....................34

3.3 Data Collection II: Content Analysis......................................36

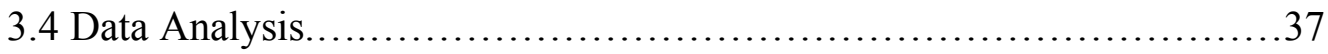

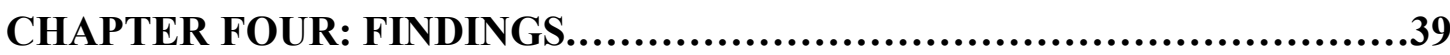

4.1 Business Convergence..................................................

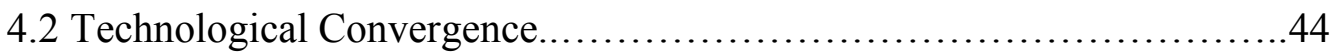


4.3 Convergence of Contents. 49

4.4 Professional Convergence.............................................52

4.5 Convergence with The Audience...................................60

4.6 New Characteristics of Journalism Convergence.........................69

CHAPTER FIVE: DISCUSSION AND CONCLUSIONS.......................77

5.1 Relevance of the Systemic Approach.....................................77

5.2 New Characteristics of Convergence................................. 80

5.3 Contributions to Research........................................ 83

5.4 Limitations and Future Studies....................................... 85

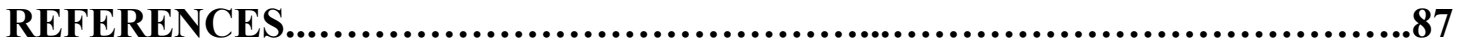

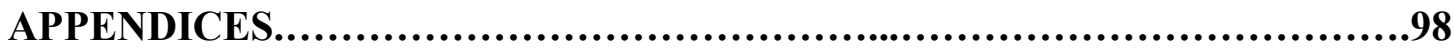

Appendix A: Background Information of Interviewees.................... 98

Appendix B: Interview Guide....................................... 100

Appendix C: Informed Consent Form................................. 103

Appendix D: Code Book............................................. 104

Appendix E: The Opinion Collaborative Ltd.

Business Registration Details. 107 


\section{LIST OF TABLES}

Table 2.1

Table 2.2

Table 4.1

Table 4.2

Table 4.3

Table 5.1
Common Traits of Journalism Convergence Among

Three Systemic Typologies

Updated Framework of News Convergence For Analysing

Legacy Newsrooms and Digital News start-up. .25

Comparison of GE2015 Multimedia Stories Published by ST,

TMG and TOC on their websites.

Comparison of GE2015 Stories Published by ST, TMG and

TOC that Contained a Social Media Sharing Function .64

Comparison of GE2015 Stories Published by ST, TMG and TOC that Included Readers' Social Media Posts. .64

Existing Characteristics of Journalism Convergence in ST,

TMG and TOC .78

New Characteristics of Journalism Convergence in ST, TMG and TOC .81 


\section{LIST OF FIGURES}

Figure 3.1

Figure 3.2

Figure 3.3

Figure 4.1

Figure 4.2

Figure 4.3

Figure 4.4

Figure 4.5

Figure 4.6

Figure 4.7

Figure 4.8

Figure 4.9

Figure 4.10

Figure 4.11

Figure 4.12

Figure 4.13
ST's digital desk organisational chart

at the time of this study 31

TMG's organisational chart at the time of this study.

TOC's organisational chart during GE2015...................34

ST's news hub. .40

TMG's newsroom. .42

ST's website with a Twitter-like feed, "ST Now". 46

Example of how TMG used "creative ways" to include videos in its news without having to produce original content. .51 ST's Assistant political desk editor doubling as a commentator for one of ST's videos .53

TOC executive editor doubles as a commentator for one of

TOC's videos

Examples company-sanctioned ST Twitter accounts for selected journalists. .62

Example of ST story with embedded social media post........65

Example of TMG story with embedded social media post......66

Example of TOC story with embedded social media post......67

ST's Chartbeat board projected in middle of its newsroom.....68

Example of TMG's 'doorstop' interviews on Facebook.........73

TMG's interactive stories during GE2015.....................75 


\section{CHAPTER 1: INTRODUCTION}

Journalism "as a practice, product and profession” (Spyridou et al, 2013, p.77) is presently in a state of flux and undergoing fundamental changes (García-Avilés, Meier \& Kaltenbrunner, 2017). One significant trend to emerge from this period of transition is the decline of traditional news media and the concurrent flourishing of entrepreneurial online journalism start-ups (Bruno \& Nielsen, 2012; Carlson \& Usher, 2016; Deuze, 2017; Usher, 2017b). Scholars and industry observers have opined that the challenges that legacy journalism is facing in terms of antiquated business models, declining profitability, shrinking staff strengths, outdated news practices and a reduction in journalistic quality have been borne out of the perfect storm of economic, technological and social change catalysed by the growth of the Internet (Carlson \& Usher, 2017; García-Avilés, Meier \& Kaltenbrunner, 2017; Ward, 2016).

Amid the tumultuousness of the transitions journalism is experiencing, one important area of journalism research investigates how media convergence impacts news companies. These studies examine how news organisations are altering their structures and adjusting their practices to meet the demands of the digital news environment (Avilés et al., 2007; Cottle \& Ashton, 1999; Infotendencias Group, 2012; Kamalipour \& Friedrichsen, 2017; Lee-Wright, 2010). However, critics argue that existing research inadequately explains news convergence because: (a) journalism continues to evolve at a blistering pace and existing frameworks are outdated; and (b) current research remains focused on legacy media organisations and pays little attention to how convergence has impacted smaller digital news start-ups (Konieczna, 2014; Manfredi \& Artero, 2014; Scolari, Navarro, Pardo \& Mico, 2007). This thesis, therefore, aims to fill the research gap by investigating whether existing frameworks are adequate in explaining news convergence in both news start-ups and traditional 
media organisations. It also seeks new characteristics of convergence that may better explain current online journalism praxes.

\subsection{Towards an Updated Typology of News Convergence}

While there is no universally accepted definition of news convergence, it is regarded as the "combination of technologies, products, staffs and geography among previously distinct provinces of print, broadcast and online journalism" (Singer, 2004, p.3). This definition is derived from the concept of media convergence that is described as a phenomenon that influences "the media system, shaping the different dimensions of communication: technological, professional, structural and operational" (García-Avilés, Kaltenbrunner \& Meier, 2014, p.573).

Several studies have offered theoretical concepts and definitions that aim to capture the essence of how convergence has impacted news organisations. In the 1990s, against the backdrop of the budding digital revolution in the mass media (Kumar \& Thomas, 2006), a group of researchers studied the impact of digitalisation in newsrooms. They proposed that changes in news companies and journalism practices were the result of advancements in communication technology such as the emergence of the Web and personal mobile devices (Cottle \& Ashton, 1999; Pavlik, 1996; Winseck, 1998). Throughout most of the 2000s, however, other theorists argued against the technologically deterministic framework that was developed in the previous decade. Instead, they investigated how journalists in media organisations collaborated with each other to produce content for multimedia platforms and proposed that the transformations in most news companies involved a longitudinal process with multiple phases that culminated in "full convergence" (Dailey, Demo \& Spillman, 2005, p.153). Yet, a third paradigm was proposed by journalism scholars 
who viewed convergence as a system. They criticised the process-centric model for its linear and "deterministic logic" (Infotendencias Group, 2012, p.27), and its sweeping assumption that all news organisations would move towards, and eventually achieve, full convergence (Erdal, 2011). These researchers stressed that journalism convergence was a complex and multi-faceted phenomenon that could be better understood by examining its characteristics, and how changes in one characteristic influences every element within the system (Domingo et al., 2007; Gordon, 2003; Kolodzy, Grant, DeMars \& Wilkinson, 2014; Singer, 2006).

More recently, the Infotendencias Group (2012) introduced an updated framework of journalism convergence that leveraged upon the multidimensional approach. Based on a country-wide study of Spanish newsrooms, the researchers analysed convergence in traditional news organisations and proposed four dimensions of convergence - Business Convergence, Technological Convergence, Convergence of Contents and Professional Convergence. More specifically, the study took into account the latest developments in journalism, such as new multiplatform news production software that fostered greater integration and collaboration between news departments; new forms of logistical arrangements in news organisations as they re-structure to meet the demands of the online news environment; new content management systems that facilitate multitasking for journalists; and new digital communication tools and social media platforms that are being used in the production and dissemination of multimedia news.

Although being the more widely accepted approach in journalism convergence research thus far (Salaverria, 2012, Torres, 2013; Westlund, 2013), the Infotendencias Group's (2012) typology is not without its shortcomings. First and foremost, critics have highlighted that like its predecessors, this framework still maintains its roots in 
large, legacy media organisations and neglects how convergence has impacted smaller digital news start-ups. Moreover, research has shown that online news start-ups displayed different convergence characteristics from legacy media organisations, such as evolving their own journalistic norms and practices (Konieczna, 2014; Manfredi \& Artero, 2014; Scolari, Navarro, Pardo \& Mico, 2007). Secondly, researchers who adopt the multidimensional approach cannot agree on exactly which dimensions are the most important in understanding how news convergence influences both large and small news organisations (Infotendencias Group, 2012; Larrondo, Domingo, Erdal, Masip \& Van den Bulck, 2014; Menke et al., 2016). Thirdly, journalism scholars have also pointed out that reducing journalism convergence to a few ideal types and characteristics over-simplifies the dynamics of news convergence and ignores its multi-faceted nature (Infotendencias Group, 2012). Lastly, recent studies in journalism innovation have found that despite possessing less resources than traditional media organisations, online news start-ups are taking the lead in responding to the demands of news in the digital environment (Boyles, 2016; Bruno \& Nielson, 2012; Carlson \& Usher, 2016). This fosters room for new dimensions of convergence to emerge that need to be scrutinised.

Despite its blind spots, the Infotendencias Group's (2012) newer framework remains an effective model for guiding journalism convergence research for the following reasons: (a) it analyses business convergence in greater detail than earlier models and provides deeper insights into media management tactics of news companies; (b) it places greater emphasis on how convergence processes within organisations are intricately interrelated to each other and, therefore, outlines a more multifaceted and less deterministic approach than earlier theoretical approaches; (c) it is more sensitive towards how news professionals are altering and adapting their work 
practices to suit the digital news environment; and (d) it takes into account the latest technological developments in journalism (Pew Research Center, 2012; Reuters Institute, 2012; Salaverria, 2012, Torres, 2013; Westlund, 2013). This study, therefore, leverages on this approach - and includes relevant elements from earlier frameworks that have been omitted in this new paradigm - to investigate convergence processes in legacy news media organisations and digital news start-ups.

\subsection{Singapore's Journalism Landscape}

This study examines legacy media organisations and independent digital news start-ups in Singapore. Due to governmental regulations that pose as significant barriers to entry for new participants, Singapore's journalism industry is dominated by two state-controlled legacy media companies - Singapore Press Holdings (SPH) and MediaCorp (George, 2015; Lau, Lin \& Low, 2013). The former corporation publishes a stable of newspapers and magazines, including the national English-language broadsheet, The Straits Times; while the latter focuses on television and radio broadcasting, and the production of one English-language newspaper and several magazine titles. Since the early 2000 s, in response to greater demand for online news by consumers and to exploit business opportunities in the digital environment, both SPH and MediaCorp have been aggressively improving their websites and online versions of their newspapers and news products (Lau, Lin, \& Low, 2013).

Although both mainstream media companies continue to be leading sources of news in Singapore (Goh, 2017), the number of independent online news start-ups and socio-political blogs have been flourishing since 2006 (George, 2012; Lau, Lin, \& Low, 2013; Salleh, 2015; Tan, Tng \& Yeo, 2015). According to a study by the Institute of Policy Studies in Singapore (Samsudin, 2017), the number of active socio- 
political online news sites and blogs peaked at around 240 during the country's general election in 2015. Some of the more prominent ones include The Middle Ground, The Online Citizen, Independent.sg and Mothership.sg (Goh, 2017). Described by George (2012) as small, nimble and "less formally organised and bound by professional norms and standards than mainstream news media organisation" (p.164), these start-ups play a complementary role to the mainstream media by providing alternative perspectives (Atton, 2009; Chua, 2017). Furthermore, in terms of journalistic practices, these news start-ups represent new approaches to news production and distribution (Carlson \& Usher, 2016) that are "distinct from the trappings of traditional journalism" (Usher, 2017b, p.3).

\subsection{Research Objectives and Significance}

This research has two objectives. The first is to determine the extent to which the legacy media-based multidimensional framework explains journalism convergence in both traditional mainstream newsrooms and digital news start-ups, given their differences in business operations and editorial practices (Atton, 2009; Carlson \& Usher, 2016; George, 2012; Usher, 2017). The second objective is to identify new characteristics of convergence in both types of news organisations vis-à-vis their news practices in the digital news climate.

These objectives are significant for several reasons. Firstly, by applying the multidimensional framework in the investigation of journalism convergence in both legacy news media and online news start-ups, this research deepens our understanding of the approach and determines its relevance as a scholastic framework. Secondly, earlier studies on convergence in newsrooms focused mainly on legacy media companies (Edge, 2004; Keshvani, 2000) and have not thoroughly examined how the 
phenomenon influences online news start-ups. By critically examining these entrepreneurial media companies, we are able to observe, compare and enrich our comprehension of how convergence impacts both types of news organisations. Thirdly, by seeking new dimensions of news convergence in both types of media companies, this exploratory study aims to bolster our understanding of current journalism trends and practices that are continually evolving to keep pace with technological advancements in today's digital media environment.

To meet the research objectives, this study aims to answer the following questions:

RQ1:Based on the multidimensional framework, what existing characteristics of journalism convergence may be observed in legacy mainstream organisations and digital news start-ups?

RQ2: What new characteristics are needed to explain journalism convergence in legacy mainstream organisations and digital news start-ups?

\subsection{Research Design}

This case study selects three news organisations in Singapore - The Straits Times, a 172-year-old legacy mainstream newspaper; The Middle Ground, a two-yearold digital news start-up; and The Online Citizen, a decade-old online news start-up.

As this research aims to examine journalism convergence in traditional news organisations and digital news start-ups, one 175-year-old mainstream newspaper and two comparatively newer online news sites were chosen. They represent three unique cases that have distinct organisational characteristics in terms of funding models, business strategies, operations, size, culture, and leadership. Their distinct traits that 
make them suitable cases for comparing and contrasting existing dimensions of news convergence within each newsroom, and for exploring new ones.

This study conducted semi-structured, in-depth interviews with a total of 19 journalists, including editors, reporters, sub-editors, video journalists, videographers and digital graphic illustrators from the three news companies. The interviews were conducted between December 2015 and June 2016 in the respective newsrooms, and furnished a total of 940 minutes of data. Additionally, data from a content analysis of 762 online news articles published by the three news organisations during Singapore's last parliamentary general election (GE2015) from 1 to 12 September 2015 was used to triangulate the interview findings in relation to the characteristics of convergence.

\subsection{Research Context: Singapore General Election 2015}

Singapore's $13^{\text {th }}$ general election in 2015 officially began on Nomination Day, 1 September 2015, when the political parties announced their interest in contesting for specific constituencies, and culminated on Polling Day, 11 September, when the voting results were announced. GE2015 was a significant election for the following reasons.

Firstly, it was the first time since Singapore's independence in 1965 that every constituency was contested (Chew, 2015; Lee, 2016). GE2015 was also the second election - the first being GE2011 - in the country's modern history that local opposition parties managed to mount a viable challenge to the dominant People's Action Party (PAP) that has been the incumbent government since 1965 (Oliver \& Oswald, 2017). Secondly, the election prior to GE2015 in 2011 was the worstperforming for the PAP since independence when it won $60 \%$ of the popular vote (Goh \& Pang, 2012). The success of the opposition that year - and in two by-elections in 2012 and 2013 - coupled with the online buzz that was generated by non-PAP 
politicians leading up to GE2015 led many to believe that the incumbent party would continue to lose ground (Lee, 2016, Soon \& Samsudin, 2016). Thirdly, with Singapore having one of the world's highest internet and mobile device penetration rates in the world (Goh \& Pang, 2012), online news and social media were expected to play instrumental roles in influencing the outcome of GE2015. This was a trend that began in GE2011 and was predicted to continue in GE2015 (Zhang, 2016). During GE2011, it was observed that an unprecedented number of people were writing about the elections via online blogs and on social media (Zhang \& Pang, 2016). After the 2011 elections until GE2015, the local online news environment evolved dramatically. The number of independent online news sites continued to proliferate, while the mainstream mass media were aggressively taking steps to strengthen their digital portals (Zhang, 2016; Zhang \& Pang, 2016). On social media, several scholars who have studied Singapore's recent elections have opined that in addition to being a more widely used platform for political expression, it was a tool that was increasingly utilised by local journalists, commentators and politicians during elections to debate issues, influence public opinion, and gain insights about the electorate (Goh \& Pang, 2012; Lee 2015; Zhang, 2016; Zhang \& Pang, 2016).

On top of the factors that made GE2015 a significant one, this researcher also learnt earlier that same year through preliminary interviews that all three newsrooms were introducing changes to their operations and ramping up their production of digital multimedia news in preparation for increased news coverage during the election. These reasons made it timely to study the news organisations' output during the election period and interview the news professionals shortly after the election so they could discuss and reflect on the details of the newsroom changes. 


\subsection{Study Outline}

The second chapter of this dissertation reviews the research literature on legacy news organisations, digital news start-ups and journalism convergence by outlining the relevant significant theories and studies. The third chapter presents the methodology of this study, while Chapter 4 deep dives into the findings of this thesis. The discussion, conclusions, limitations of this research, as well as recommendations for future research on journalism convergence are covered in Chapter 5. 


\section{Chapter 2: Literature Review}

This thesis investigates existing and new dimensions of journalism convergence in legacy media organisations and online news start-ups. Before reviewing the literature on news convergence, this chapter will provide an overview of current trends regarding traditional news companies and journalism start-ups.

\subsection{The State of Legacy Media and News Start-ups}

The rise of the Web has provided the platform for the emergence of a global start-up culture in the field of journalism. Since the beginning of the $21^{\text {st }}$ century, there has been a burgeoning in the number of small-scale, online-only news companies that distinguish themselves from traditional media organisations in a variety of ways (Stamp, 2015; Usher, 2017b). While some of these start-ups are profit driven and staffed by professional journalists, others are non-profit outfits that rely on volunteers and freelance content producers (Naldi \& Picard, 2012). Despite the differences in their approaches to journalism, Boyles (2016) and Usher (2017b) observe that most entrepreneurial news ventures share the following common characteristics that are distinct from traditional journalism: they possess little overheads and a few staff; have flat organisational hierarchies; rely on algorithms and digital editorial customisation more than human news judgement; have evolved their own newsroom cultures that thrive on chance-taking and creativity; and receive funding from external sources such as investors or large companies rather than banks and traditional funding streams.

For this study, the identification of online news start-ups follows that of Bruno and Nielsen (2012) and Deuze (2017). They are small news organisations that are not affiliated with legacy news media; built primarily around an online presence; and produce original content that is journalistic - in other words, they "identify with 
journalism as it has historically been practised... and [deliver] news that users will regard as journalism" (Bruno \& Nielsen, 2012, p.4). George (2016) provides a lucid definition of journalism as "the use of observation, investigation, and analysis, to report and comment on current affairs, in order to help people comprehend change and engage in collective self-determination" (p.32).

Given the differences in structure, culture and practices between legacy news media and online news start-ups, this thesis aims to uncover and understand whether convergence has manifested similarly or dissimilarly in both types of journalistic organisations. Simultaneously, it also seeks to identify new dimensions of convergence, if any, in these companies.

\subsection{Defining Journalism Convergence}

Scholars and industry observers have been analysing journalism convergence for three decades and have presented three broad definitions. In the 1990s, against the backdrop of the budding digital revolution in the mass media (Kumar \& Thomas, 2006), researchers focused on analysing the phenomenon as a product (García-Avilés et al., 2007). Academics such as Pavlik (1996, 1999) and Winsek (1998) examined the emergence of new communication technologies and the Internet as a multimedia information superhighway. They argued that the World Wide Web and digitalisation blurred the lines between the different forms of traditional media, and was the main driving force behind the surge in quantity of online multimedia content. In the beginning of the $21^{\text {st }}$ century, concurrent with the introduction of Web 2.0 and social media, convergence scholars theorised that the Internet removed the barrier between media producers and consumers by allowing both groups to directly interact with each 
other, and facilitated a "participatory culture" that replaced "passive spectatorship" among audiences (Jenkins, 2006, p.3).

Another definition conceptualised convergence in journalism as a process that occurs in multiple phases (Applegren, 2004; Dailey et al., 2005; Lawson-Borders, 2005). Specifically, Dailey et al. (2005) proposed a five-stage model of news convergence that illustrated the degree of cooperation and integration between staff who produced news for different platforms within news companies. Ranging from low to high degrees of integration, the first two stages, "cross-promotion" and "cloning" described the republishing of content from one platform to another with little or no editing. The third stage, "coopetition", involved both cooperation and competition between two platforms. The fourth stage was "content sharing" and it explained how platforms share and repurpose content. The last stage, "full convergence", illustrated how hybrid teams from different platforms fully cooperate in producing news content. Dailey and his colleagues (2005) stressed that all newsrooms would need to gradually experience the various stages before achieving total integration.

Although both the convergence-as-product and convergence-as-process paradigms have had influential methodological consequences for news convergence research (Menke et al., 2016), they possess several flaws. Both approaches have been criticised by social constructivist communication scholars as being overly technologically deterministic as they place too much emphasis on the role of technology in media convergence (Boczkowski, 2004; Gordon, 2006; Jenkins, 2006, 2014). Moreover, critics of the convergence-as-process framework observe that its linear, unidimensional logic over-generalises and assumes that all news organisations will eventually move towards full convergence (Erdal, 2007, 2011). Further empirical research showed that instead of a linear progression, news organisations exhibited 
characteristics of several continuum stages simultaneously (Doudaki \& Spyridou, 2014; Erdal 2011).

\subsubsection{Convergence as a system}

Constructivist researchers, on the other hand, posited that convergence is not merely a result of technological advancement. Scholars who advocate this approach agree that a thorough understanding of convergence can only be attained through a broad, all-round approach that examines how every element of the complex, interconnected system exerts a reciprocal influence on each other (Domingo et al., 2007; Gordon, 2003; Infotendencias Group, 2012; Singer, 2004). Although there is disagreement on which element wields the most influence, most agree that the elements that should be examined include an organisation's technologies, products, content, staffs, geography, business strategy, and interaction with their audiences (Domingo, 2008; Infotendencias Group, 2012).

In his study of the transformations that took place in US newsrooms in the late 1990s and early 2000s, Gordon (2003) outlined five aspects of journalism convergence. The first, ownership convergence, refers to situations when one company (or person) owns several media outlets of different types. The second aspect, tactical convergence, involves all the cross-promotional activities performed by media of different types that do not necessarily require cross-ownership of the outlets involved. The third aspect, structural convergence, refers to the changes within the media outlets, including alterations to newsroom layouts and journalists' job descriptions. The fourth aspect, information-gathering convergence, highlights the multimedia skills that journalists require to effectively produce news in a technologically driven environment. The fifth aspect, story-telling convergence, emphasises how journalists must reconceptualise the manner in which they produce 
stories and capitalise on the unique strengths of multiple mediums - print, audio and video - in getting their messages across to their audience. Based on his typology, Gordon (2003) underscores that one or more aspects of convergence may be observed in almost all news organisations - from media conglomerates in the US such as News Corp and AOL-Time Warner to smaller newspaper publishers such as The Tampa Bay Times and the Minneapolis Star-Tribune.

Similar to Gordon's model is Domingo et al.'s (2007) four dimensions of journalism convergence, which the authors developed from a study of 58 Spanish news organisations. They stressed that every convergence project has its own unique contextual factors that influence its development and outcomes and should not be avoid over-simplified into a 'continuum', nor thought of it as a simple technologydriven process. Instead, they proposed that convergence taps into "technological innovation to achieve specific outcomes in specific settings" (p. 3), and that no two convergence projects are identical.

Domingo and his colleagues organised journalistic convergence into four dimensions. The first, integrated production, looks at the physical reorganisation of newsrooms, the implementation of digitised networked systems that facilitate cooperation between news workers, and the degree of cooperation between them when producing content for multiple mediums. The second dimension, multi-skilled journalists, examines the degree of multi-skilling a journalist requires according to three categories: (a) media multiskilling - whether a journalist has the skills needed to produce content for different mediums of news; (b) issue multiskilling - whether a journalist possesses the knowledge needed to work on news that covers different thematic areas; and (c) technical multiskilling - whether a journalist is responsible for and equipped with the know-how to perform tasks required at different stages of the 
news production process. The third dimension, multiplatform delivery, studies the strategies related to how news content is either produced, adapted or cloned for distribution across several platforms, including both traditional and digital channels. The fourth dimension, the Active Audience, analyses the degree of audience participation that a news organisation allows in its production process. The researchers catalogued a total of eight most common Active Audience features used by Spanish news media on their websites. They included: journalists' blogs; user-submitted photos, user-submitted videos; audiences' blogs, news about their audience; interviews with their audience; the inclusion of audiences' comments in op-ed articles; and a section that allowed audiences to leave their comments at the end of news articles. The study found that while most news organisations merely included simple features such as a comments section, others were more proactively engaging their audiences by encouraging them to submit contributions for publication, or tasking their journalists and editors to directly engage their audiences in discussion on internet forums.

\subsubsection{A multidimensional approach to news convergence}

In 2012, Domingo and his colleagues reviewed their work and proposed an updated typology (Infotendencias Group, 2012). This newer framework identifies four main types of journalism convergence, leverages on Domingo et al.'s (2007) earlier research, and includes aspects of Gordon's (2003) definition. Table 2.1 (next page) illustrates the common traits among the three typologies. 


\begin{tabular}{|c|c|c|c|}
\hline Gordon (2003) & $\begin{array}{l}\text { Domingo et al. } \\
(2007)\end{array}$ & $\begin{array}{c}\text { Infotendencias } \\
\text { Group (2012) }\end{array}$ & $\begin{array}{l}\text { Common traits of news } \\
\text { convergence }\end{array}$ \\
\hline $\begin{array}{l}\text { Tactical and } \\
\text { Structural } \\
\text { Convergence }\end{array}$ & $\begin{array}{l}\text { Integrated } \\
\text { Production }\end{array}$ & $\begin{array}{l}\text { Business } \\
\text { Convergence: } \\
\text { Centripetal }\end{array}$ & $\begin{array}{l}\text { More strategic } \\
\text { collaboration between } \\
\text { departments in the news } \\
\text { organisation; } \\
\text { Reorganisation of } \\
\text { newsrooms for } \\
\text { multimedia operations }\end{array}$ \\
\hline $\begin{array}{l}\text { Ownership } \\
\text { Convergence }\end{array}$ & & $\begin{array}{l}\text { Business } \\
\text { Convergence: } \\
\text { Centrifugal }\end{array}$ & $\begin{array}{l}\text { News businesses } \\
\text { diversifying their } \\
\text { operations horizontally } \\
\text { and vertically }\end{array}$ \\
\hline \multirow[t]{2}{*}{$\begin{array}{l}\text { Story-telling } \\
\text { Convergence }\end{array}$} & \multirow[t]{2}{*}{$\begin{array}{l}\text { Multiplatform } \\
\text { Delivery }\end{array}$} & $\begin{array}{l}\text { Technological } \\
\text { Convergence: } \\
\text { Multiplatform }\end{array}$ & \multirow{2}{*}{$\begin{array}{l}\text { - } \\
\text { multimedia content that is } \\
\text { delivered via multiple } \\
\text { platforms - traditional } \\
\text { and digital }\end{array}$} \\
\hline & & $\begin{array}{l}\text { Convergence of } \\
\text { Contents }\end{array}$ & \\
\hline \multirow[t]{2}{*}{$\begin{array}{l}\text { Info-gathering } \\
\text { Convergence }\end{array}$} & $\begin{array}{l}\text { Multi-skilled } \\
\text { Professionals }\end{array}$ & $\begin{array}{l}\text { Professional } \\
\text { Convergence: } \\
\text { Functional, } \\
\text { Thematic and } \\
\text { Polyvalence of } \\
\text { Media }\end{array}$ & $\begin{array}{l}\text { Journalists must be able } \\
\text { to multi-task and be } \\
\text { multi-skilled to produce } \\
\text { multimedia content for } \\
\text { multiple platforms }\end{array}$ \\
\hline & Active Audience & & - $\quad$ Not applicable \\
\hline
\end{tabular}

Table 2.1 Common Traits of News Convergence Among Three Multidimensional Typologies.

The first type of convergence, Business Convergence, analyses the corporate strategies of a news organisation. Within this aspect, two main strategies are outlined Centripetal Business Convergence and Centrifugal Business Convergence. The first strategy highlights how news organisations are integrating their previously mediumspecific production processes and finding new ways to reorganise their newsrooms to promote greater cross-desk, cross-media collaboration to meet the "requirements of the new digital platforms" (Infotendencias Group, 2012, p. 31). The second strategy, Centrifugal Business Convergence, is further sub-divided into horizontal and vertical diversification. Horizontal diversification focuses on how news companies that previously owned only one platform have now diversified to publish news on multiple mediums. Legacy news organisations such as CNN and The New York Times, for 
instance, which only published news on one medium, now produce content for the online platform (Chyi \& Lee, 2013; Usher, 2017). Vertical diversification, on the other hand, refers to how news companies are expanding into businesses "present throughout the value chain of entertainment and news products" (Infotendencias Group, 2012, p. 31). Media organisations such as US-based Fox Entertainment Group, for example, operates radio and television news networks, distributes and produces film and television programs, on top of publishing print and digital magazines (Holt, 2011).

The second type of convergence, Professional Convergence, focuses on skills polyvalence and refers to the multimedia and multi-tasking expertise of a journalist. It is further divided into three sub-categories: (a) functional polyvalence - the overall multiplication of practical duties of a journalist; being able to produce multimedia news content; and being familiar with different parts of the news production process for several mediums; (b) thematic polyvalence - the need for a journalist to be able to cover news across a broad range of topics; and (c) media polyvalence - the requirement for a journalist to work "like a classic freelancer" (Infotendencias Group, 2012, p.33) for several brands and media that belong to his or her organisation (Martins, 2015; Torres, 2013). On journalists' attitudes towards polyvalence, the framework highlights that news workers would be resistant towards the additional workload because of the drastic alterations to their work patterns and a lack of compensation.

The third type, Convergence of Contents, draws attention to the "hybridized" (Infotendencias Group, 2012, p. 35) nature of online news content. Here, the researchers observe that it is common for media organisations that disseminate news online to incorporate multimedia news in their coverage. Moreover, when it comes to 
significant news events, such as elections, large media corporations that own a variety of brands across a variety of media tend to logistically coordinate their news coverage beforehand.

The fourth type is Technological Convergence, which places emphasis on "cross-media" and "multiplatform" (Infotendencias Group, 2012, p. 31) news production. The Spanish researchers observed that news corporations were adopting new production processes that included multimedia content management systems that allowed them to publish news simultaneously on multiple platforms. One of the consequences of technological convergence is a higher degree of collaboration between previously distinct newsrooms (or sections within a newsroom) that produced content for separate mediums and platforms.

In short, the complexities of convergence is captured in the definition proposed by Domingo and his colleagues:

Convergence in journalism is a multidimensional process which, facilitated by the widespread implementation of digital communication technologies, affects the technological, business, professional and editorial aspects of the media, fostering the integration of tools, spaces, working methods and languages that were previously separate, in such a way that journalists can write contents to be distributed via multiple platforms, using the language that is appropriate in each medium (Infotendencias Group, 2012, p. 29-30).

\subsubsection{Blind spots in the multidimensional framework}

Despite being the more widely accepted approach in journalism convergence research thus far (Infotendencias Group, 2012), the updated multidimensional framework is not without its blind spots. First, critics have noted that like the earlier 
multidimensional paradigms, one major limitation of this typology is that it still has roots in legacy media organisations. Researchers who have examined small onlineonly news start-ups posit that they are nimble, flexible and represent an entrepreneurial mind-set to journalism that share little or no resemblance to large, mainstream media corporations. A study of small news projects in Spain by Manfredi and Artero (2014) demonstrated that their country's news start-ups displayed different characteristics from legacy media organisations. One key feature that was common among news start-ups was that despite the fact many of the small news businesses were helmed by journalists who were formerly working at legacy news organisations, they were able to effectively leverage on technology and move away from traditional models of journalism by evolving new companies that were nimbler and more effective in responding to the demands of the digital era. Manfredi and Artero (2014) concluded that while convergence has created problems for the media giants, these small companies were thriving because they had adopted a modus operandi that was different and much more in-tune with the new digital economy than their larger counterparts. Another Spanish study that focused on polyvalent journalism in Catalan newsrooms (Scolari et al., 2008) found that multi-tasking was already a common and accepted practice for journalists who worked in smaller newsrooms. Larger traditional media, however, faced resistance from their employees when trying to implement the same polyvalent culture in their newsrooms. The researchers concluded that resistance was more common in larger legacy media enterprises than small news start-ups, and that the transition from a univalent culture to polyvalent one turned out to be conflictive and unstable. One other investigation of a small, non-profit US news website found that journalists who worked in smaller newsrooms with limited resources (compared to the established legacy media) tended to innovate their own 
norms and practices that were dissimilar from those related to traditional journalism (Konieczna, 2014). The research found that even though many of the websites' reporters and editors had worked at traditional organisations before, they eventually had to evolve new routines because they faced a different set of challenges and situations. As such, it would be inadvisable to assume that the convergence patterns that exist in media giants are automatically applicable to small-scale news start-ups.

Another blind spot in the multidimensional model is the lack of agreement among scholars on exactly which categories and characteristics are essential in understanding news convergence (Infotendencias Group, 2012). Among researchers who have employed the multidimensional framework to study large news organisations, two distinct views may be observed. On the one hand, there are those who agree that all four areas of convergence are relevant and inter-related. On the other hand, there are critics who insist that not all are applicable to understanding the process of news convergence. One study that adheres to the former perspective is Larrondo et al.'s (2014) research of four European public service broadcasters in the UK, Spain, Norway and Belgium. The study found that although some variations did exist, journalism convergence in the media organisations that were investigated generally followed a similar basic pattern outlined by the four types of convergence proposed by the Infotendencias Group (2012). Contrary to Larrondo et al.'s (2014) research, a study of six European newsrooms (Menke et al., 2016) concluded that convergence dynamics in newsrooms did not showcase any clear pattern, but were instead distinctly different in each newsroom because it was highly influenced by cultural and contextual factors. It further stressed that not all four types of convergence may be relevant in studying news convergence. Similarly, Torres' (2013) analysis of 12 Spanish newsrooms also found that of all the convergence parameters, 
"professional polyvalence is the key to understanding convergence processes in Spain" (p. 31). She added that because the news organisations in her study had, to varying degrees, reorganised their operations to deliver multimedia news, their news workers consequently faced increasing pressure and responsibility to acquire skills that allowed them to produce and manage content for different mediums.

Yet another problem of the model is its tendency to oversimplify the dynamics of journalism convergence. Despite its elegance and simplicity, the typology's authors self-reflexively cautioned that their four-dimension framework may still be too simplistic in capturing the myriad of convergence-related transformations that are currently taking place in news organisations. The researchers stressed that due to the "complexity", "instability” and "polymorphic” (Infotendencias Group, 2012, p. 29) nature of journalism convergence, investigators have experienced - and will continue to experience - difficulties in reaching a consensus on how to define, conceptualise, and study the phenomenon. As such, the authors pointed out that the framework they proposed served the function of a working definition that represented "a step in the study of convergence in journalism, not a finishing line" (p. 35).

One other shortcoming is the omission of a dimension that examines how newsrooms engage their audiences - a characteristic of convergence that was included in Domingo et al.'s 2007 framework as the Active Audience. Scholarship on audiences have shown that audience participation has become a "key strategic question" (GarciaAvilés, Kaltenbrunner \& Meier, 2014, p. 582) for both traditional and online news start-ups (Bruno \& Nielsen, 2012). On top of examining existing Active Audience features that were noted by Domingo et al. (2007), this study proposes that new digital technologies such as social media and editorial analytics - quantitative data that provides insights into audience behaviour on a news organisation's website and social 
media accounts (Cherubini \& Nielsen, 2016) - serve as new direct and indirect methods for newsrooms to include and engage their audiences in the news construction process, and must be examined in greater detail. Tremblay (2017) argues that social networking, which allows consumers to actively share and discuss news online, and provide direct feedback to news producers, has given audiences a significantly greater participatory role in journalism. On editorial analytics, scholars assert that it represents an indirect form of audience participation as journalists use the data to inform their editorial decisions and strategies in the long- and short-term (Cherubini \& Nielsen, 2016; Schlesinger \& Doyle, 2014)

\subsection{An Updated News Convergence Framework}

Despite its limitations, there are several merits of the Infotendencias Group's (2012) typology that make it an effective framework for guiding journalism convergence research. The Infotendencias Group's (2012) typology, which was developed based on numerous newsroom studies that spanned over a decade, has been identified as one of the most holistic typologies thus far that promotes rigorous theoretical reflection on the various dimensions of news convergence (Salaverria, 2012; Torres, 2013) in the following ways: Firstly, unlike earlier multidimensional approaches, the most recent typology analyses news organisations' corporate strategies by deep-diving into Business Convergence. This is crucial as it not only provides insights into the media management tactics of news companies, but also facilitates scrutiny of how media industries are navigating the digital news environment as a whole (Karmasin, Diehl \& Koinig, 2016). Secondly, the typology places greater emphasis on how each aspect of journalism convergence is intricately related to each other. Hence, it takes a more multidimensional, less deterministic approach to 
understanding the phenomenon than Domingo et al.'s (2007) earlier iteration. Thirdly, the recent paradigm is more sensitive in understanding how news workers collaborate with each other and how newsrooms coordinate their resources to respond to the new demands of the digital news environment. It also takes into account journalists' response to professional polyvalence, an aspect that was missing in the previous typology. Lastly, the new typology takes into account the significant technological developments since 2007, such as the rise in online news consumption and via mobile devices, and the increasingly influential role of social media in news (Pew Research Center, 2012; Reuters Institute, 2012; Westlund, 2013), that have had, and continue to have, a significant impact on journalism.

This thesis, therefore, is guided by the updated framework of news convergence that includes the four dimensions of convergence outlined by the Infotendencias Group (2012), and an additional dimension of Convergence with the Audience (Table 2.2, next page). It aims to examine journalism convergence in legacy media organisations and news start-ups, and also seeks to identify news dimensions. 


\begin{tabular}{|c|c|}
\hline $\begin{array}{l}\text { Dimensions of } \\
\text { Convergence }\end{array}$ & Characteristics \\
\hline \multirow{3}{*}{$\begin{array}{c}\text { Business } \\
\text { Convergence }\end{array}$} & Centripetal \\
\hline & Centrifugal (horizontal) \\
\hline & Centrifugal (vertical) \\
\hline $\begin{array}{l}\text { Technological } \\
\text { Convergence }\end{array}$ & Multi-platform news production and dissemination \\
\hline \multirow{2}{*}{$\begin{array}{l}\text { Convergence } \\
\text { of Contents }\end{array}$} & Multimedia news \\
\hline & Sharing of content from affiliated media brands \\
\hline \multirow{4}{*}{$\begin{array}{l}\text { Professional } \\
\text { Convergence }\end{array}$} & Polyvalence: Functional \\
\hline & Polyvalence: Thematic \\
\hline & Polyvalence: Media \\
\hline & Positive towards polyvalence \\
\hline \multirow{5}{*}{$\begin{array}{l}\text { Convergence } \\
\text { with The } \\
\text { Audience }\end{array}$} & $\begin{array}{l}\text { Using social media to involve readers in the news } \\
\text { construction process }\end{array}$ \\
\hline & Directly engage readers on social media \\
\hline & $\begin{array}{l}\text { Including social media sharing functions on websites' } \\
\text { articles }\end{array}$ \\
\hline & Embedding readers' social media posts in web stories \\
\hline & Use of analytics as an indirect audience engagement tool \\
\hline
\end{tabular}

Table 2.2 Updated Framework of News Convergence For Analysing Legacy newsrooms and Digital News start-ups

Based on this framework, this thesis examines if Business Convergence in relation to centripetal (newsroom integration) and centrifugal (vertical and horizontal diversification) aspects are similar or different for both types of news organisations. This study aims to find out if small digital news start-ups possess the resources to diversify their operations laterally and vertically, what strategies they adopt in relation to editorial integration, and how are they similar 
or dissimilar to large news corporations. It also aims to shed more light on the factors that influence their business strategies.

The literature suggests that Technological Convergence is a norm among media organisations (Infotendencias Group, 2012). This thesis examines if this suggestion is applicable to both traditional media organisations and digital news start-ups. If so, do they adopt similar approaches in the management of multiple platforms? The original typology remains vague in the application of the definition of "multiplatform". It is used both to differentiate "media platforms" such as radio, television, print and online (p. 33), and also channels within a medium, such as email, RSS feeds and social media, which it terms as "new digital platforms" (p. 31). For clarity, this study adopts a definition of cross media by Veglis (2012), who posited that "platforms" and "channels" should be different entities. He explained that media platforms refer to specific mediums print, web, television and radio. Channels, on the other hand, "do not represent different categories of technology... but various methods for publishing news" (p. 211). For instance, a news company's website, mobile application, Facebook, and Twitter accounts represent four separate channels, even though they are all on the online platform.

Convergence of Contents - the "multimodal nature of cybermedia" (Infotendencias Group, 2012, p. 34) - has been observed to be placing pressure on news organisations to constantly produce and deliver multimedia content via their digital platforms. This, in turn, influences media giants that possess several news mediums and editorial departments to combine and coordinate their resources towards the production of multimedia news for their online channels. The original study by the Infotendencias Group (2012) did not examine how this aspect of convergence may be 
applicable to smaller news businesses that do not possess the financial and manpower resources to own several mediums and editorial departments. This thesis aims to fill this gap in the research by proposing two poignant questions: (a) whether the concept of Convergence of Contents is applicable to news start-ups; and (b) what strategies do they adopt to manage the production and delivery of multimedia content for their online channels? This study will also analyse the news articles on each organisation's website for evidence of multimedia content.

Professional Convergence has been observed to have had a significant impact on the work of journalists (Infotendencias Group, 2012). News companies now place immense value on workers who are able to use a variety of multimedia production tools to deliver multi-format news that cover a spectrum of topics. With respect to this dimension, this thesis aims to investigate how Professional Convergence affects media corporations and smaller newsrooms, explore whether advantages of professional polyvalence exist, and understand the attitudes of journalists' towards professional polyvalence in both types of news organisations. Although its merits were not discussed in the Infotendencias Group's (2012) study, other research has underscored the positive aspects of professional polyvalence, which include greater work satisfaction, greater autonomy and increased levels of efficiency and productivity (Dickinson, Matthews \& Saltzis, 2013; Lin, 2012; Raviola \& Hartmann, 2009).

The Infotendencias Group (2012) omitted the examination of audience engagement from its typology. Domingo et al. (2007), however, argued that the digital environment allows for new and novel avenues of engagement between journalists and their audience, and it is crucial that convergence studies examine these "new possibilities offered by the media to promote [audience] involvement" (p. 12) in the news construction process. Therefore, this thesis proposes that the dimension of 
Convergence with The Audience be included into the new framework. Adapting from Domingo et al.'s (2008) study, this research will investigate the presence (or absence) of the following new audience engagement features on the news organisations' websites: social media sharing tools; the embedding of audiences' social media content in news stories; and reader comments section at the end of news articles. Furthermore, this research will investigate how journalists from both the traditional news organisations and online start-ups leverage on social media and editorial analytics to engage their audiences.

Therefore, this thesis presents a case study of three newsrooms in Singapore that includes one legacy organisation and two online-only news start-ups, and is structured around the following research questions:

RQ1:Based on the multidimensional framework, what existing characteristics of journalism convergence may be observed in legacy news organisations and digital news start-ups?

RQ2: What new characteristics are needed to explain journalism convergence in legacy news organisations and digital news start-ups? 


\section{Chapter 3: Methodology}

This thesis employs a case study approach, combining semi-structured, indepth interviews with content analysis. To investigate existing and new dimensions of convergence in news organisations, three newsrooms - one legacy newspaper and two digital news start-ups - in Singapore were chosen as unique cases to facilitate comparison among them.

\subsection{Case Study}

Case study refers to an empirical research method that "investigates a contemporary phenomenon within its real-life context" (Yin, 2009, p. 13) with the objective of generating in-depth understanding of specific cases, rather than attempting to reach generalizable conclusions (Baxter \& Jack, 2008). For this thesis, semi-structured, in-depth interviews with news professionals and a content analysis of their news output were used to examine news convergence in their newsrooms. The interviews with the news professionals focused on gathering insights into how the five dimensions of news convergence in this study's framework manifested in each newsroom, and elicit information about new dimensions of convergence. The content analysis looked for evidence of news convergence in the newsrooms' online articles. Both sets of data provided a stronger basis on which evidence and findings could be triangulated. Rather than relying on just one data collection technique, this dual-prong approach ensured that news convergence was examined from "a variety of lenses which allow for multiple facets of the phenomenon to be revealed and understood" (Baxter \& Jack, 2008, p. 544). 


\subsubsection{Multiple cases}

In choosing the cases for this study, this researcher employed theoretical sampling, a method that selects cases "because they are particularly suitable for illuminating and extending relationships and logic among constructs" (Eisenhardt \& Graebner, 2007, p. 27). The three Singapore newsrooms - The Straits Times (ST), a 172-year-old legacy newspaper; The Middle Ground (TMG), a two-year-old online news start-up; and The Online Citizen (TOC), a decade-old online-only news website - represent three unique cases that have distinct organisational characteristics in terms of funding models, business strategy, operations, size, culture, and leadership. Their distinct traits make them suitable cases for comparing and contrasting existing dimensions of news convergence within each newsroom, and for exploring new ones. The following sub-sections provide a background of the three cases:

\subsubsection{The Straits Times (ST)}

ST was founded in 1845 . It is currently owned by local public-listed media giant Singapore Press Holdings (SPH), which also publishes other newspapers and magazines, and owns three radio stations at the time of this study. With both print and digital versions, ST is the country's most-read English newspaper, boasting a daily reach of about 1.8 million people (Zaccheus, 2015). When this study was conducted, the newspaper employed about 300 people, and dedicated 30 staff (referred to as "digital desk") to oversee its online news operations. The online team includes a digital editor, deputy editors, section editors, social media editor, web and multimedia journalists and a digital infographics unit (Figure 3.1, next page).

For over two decades, ST has been gradually transforming its newsroom from a print-focused newspaper to a multimedia, multi-platform news organisation (Keshvani, 2000a). Since the inception of its website in 1995 until the late 2000s, ST 
continually invested in newer content management systems that integrated print and digital content; redesigned its production workflow to incorporate more automation; reviewed its hiring policies to employ more multimedia journalists; started a New Media Unit to oversee the production of digital multimedia content; and experimented with updated methods of delivering news to its online audience (Keshvani, 2000b). More recently, ST's editor, Warren Fernandez (2015), revealed in an op-ed published by his newspaper that some of the more recent changes included dismantling both the mental and physical walls that separated print and online content; introducing a new cross-platform workflow that integrated both print and digital departments within the newsroom; training its print staff to be proficient in multimedia production while ramping up its video content capabilities; and introducing an in-house innovation unit to keep abreast of news-related technological developments. Additionally, SPH deputy CEO, Patrick Daniel, stressed that ST's transformation was still a work-in-progress, vis-à-vis the relentless pace of technological advancements and digital disruptions the newspaper continues to face (Teng, 2016).

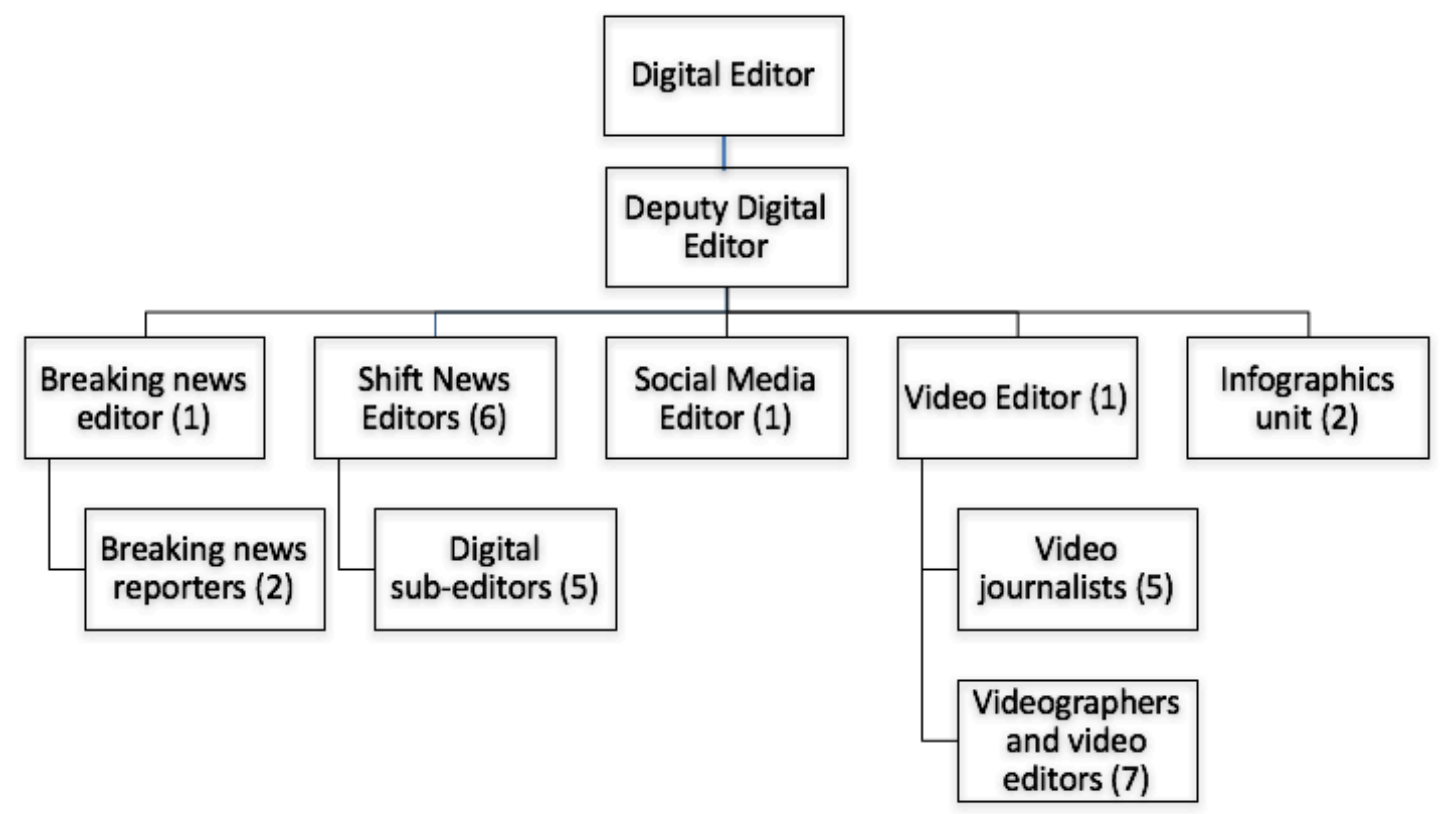

Figure 3.1 Organisational chart of the digital desk at The Straits Times at the time of this study. 


\subsubsection{The Middle Ground (TMG)}

Launched in June 2015, TMG is a for-profit digital news start-up and was cofounded by former senior ST editor, Bertha Henson, who had spent 27 years at the newspaper. According to Henson's (2015) personal blog, TMG's editorial philosophy is grounded in providing middle-income Singaporeans with original, interesting, insightful, balanced and objective news. The company's emphasis on journalistic quality may be seen in its hiring policy. At the time of this study, except for the news interns, TMG was staffed by a team of full-time, part-time and freelance journalists, video journalists, and graphic designers, of whom most had prior news or multimedia content production experience (Figure 3.2, next page). The TMG news editor, incidentally, was a journalist and copy editor at The Straits Times for seven years.

Commercially, TMG relies on a semi-subscription model that gives subscribers access to exclusive content, including videos, polls and certain op-ed articles. It also has a video unit that works on both editorial and commercial video projects.

According to Tan, Tng and Yeo (2015), TMG's website was ranked among the top 10 most popular news sites in Singapore during GE2015. More recently, data from digital market research company SimilarWeb ranked it eleventh based on the average number of monthly unique visitors from June to August 2017. 


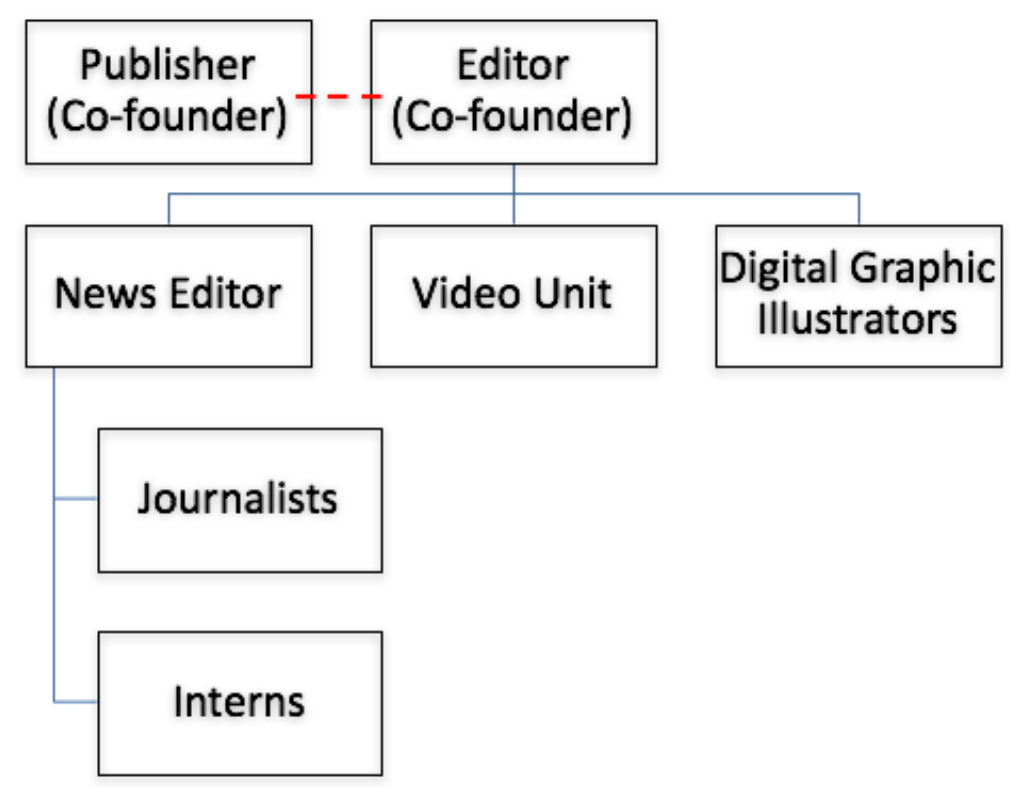

Figure 3.2 Organisational chart of The Middle Ground at the time of this study.

\subsubsection{The Online Citizen (TOC)}

TOC was one of the local pioneers in the arena of online news start-ups. The non-profit news platform began operations in 2006 as a community blogging platform for local political matters and is now one of Singapore's leading alternative news websites (George, 2015). Positioning itself as a counter-balance to the governmentcontrolled mainstream media, TOC's articles are well-researched and often delve into official statistics to highlight alternative perspectives on issues (George, 2012).

The news website has over the last decade maintained the characteristics of an online news start-up. In an interview with The Straits Times, TOC editor Terry Xu said that the news website has remained a lean outfit since (Figure 3.3, next page) its inception and has been staffed by no more than three or four full-time editors (Sim, 2016). It has always relied on volunteer journalists, photographers and videographers to contribute content, and continues to do so (The Online Citizen, 2017). During GE2015, TOC had four full-time editors. However, at the time of this study the 
website was managed solely by its executive editor as the other editors had left the organisation.

Funding-wise, TOC was financially supported by its then-parent company The Opinion Cooperative Ltd until December 2015, when the news website announced that both entities would part ways and TOC would seek its own funding (Hicks, 2015a). As a source of income, TOC has been providing citizen journalism training workshops and organising seminars for social activists. During GE2015, TOC launched an online crowd-sourcing campaign to raise $\mathrm{S} \$ 50,000$ to defray the cost of hiring journalists who provided election-related news coverage (Hicks, 2015b).

During GE2015, TOC's website was ranked the eighth most visited local news site (Tan, Tng \& Yeo, 2015). As of August 2017, SimilarWeb ranked it as Singapore's ninth most popular news website based on the average number of unique visitors for the prior three months.

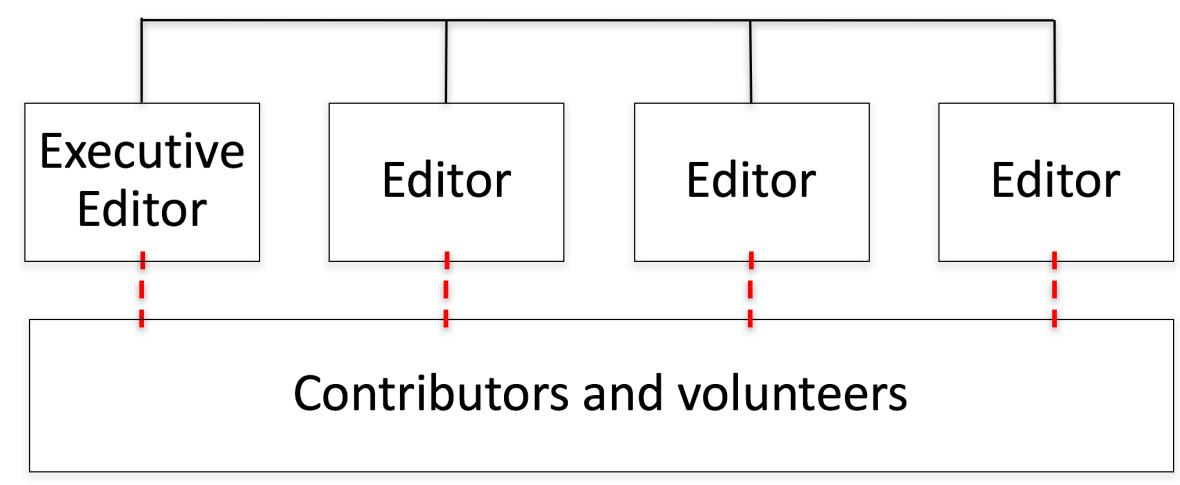

Figure 3.3 Organisational chart of The Online Citizen during GE2015.

\subsection{Data Collection I: Semi-structured, In-depth Interviews}

The semi-structured, in-depth interview allows researchers to deep-dive into interviewees' perceptions and how they attach meaning to certain phenomena (Wengraf, 2001). Another advantage is the flexibility it provides in terms of allowing interviewers to alter the phrasing and sequence of questions, as well as ask probing 
ones (Berg \& Lune, 2012). As such, semi-structured, in-depth interviews with news professionals are ideal for studying a complex topic such as news convergence because it allows them to "reflectively communicate their experiences" (Lindlof \& Taylor, 2011, p. 173) and offer insights into their organisational practices and cultures. Using snowball sampling, this study conducted semi-structured, in-depth interviews with 19 news professionals - 10 from ST, 6 from TMG and 3 from TOC including editors, journalists, digital graphic illustrations and videographers (Appendix A). Ranging from about 30 minutes to 110 minutes per session, the interviews commenced three months after the end of GE2015 and were conducted in the respective newsrooms between December 2015 and May 2016. When the interviews were completed, a total of 940 minutes of data was collected.

Prior to the interviews, a two-page interview protocol was prepared (Appendix B) and sent to the interviewees via email a week before the interviews were done. The open-ended questions in the interview protocol were developed with the aim of eliciting responses from the interviewees that would elucidate both existing and new dimensions of convergence in their news organisations, and provide answers to the research questions of this thesis. The interviewees were asked to describe their news practices, routines, corporate strategy and work culture in relation to the five dimensions of convergence - Business Convergence, Professional Convergence, Convergence of Contents, Technological Convergence, and Convergence with The Audience - outlined in this study's research framework. Moreover, the semi-structured nature of the interviews allowed for the flexibility of additional probing questions to be asked, especially when an interesting anecdote was shared or when clarification was needed. 
During each interview, respondents were asked to sign a form of informed consent (Appendix C). After which, the interviews were digitally tape recorded while hand-written notes were also taken simultaneously. All recorded interviews were then transcribed by this researcher.

\subsection{Data Collection II: Content Analysis}

During GE2015, specifically from 1 September to 12 September 2015, a content analysis of the news articles on each organisation's website was conducted. At the end of each day during the specified period, this researcher would access the daily archives of published stories on each website and catalogue the URL of every online article. In total, 762 online news articles were captured.

Each digital story was then analysed for features that served as evidence of two dimensions of convergence - Convergence of Contents and Convergence with The Audience. Of the five dimensions of convergence in this study's framework, the content analysis focused on these two dimensions because Business Convergence and Professional Convergence were not characteristics that could be observed in the news output. Although features of Technological Convergence, specifically multiplatform news dissemination, could have been examined in the content analysis, it was beyond the capabilities of this researcher to catalogue every story that was published on each of the news organisations' channels - social media platforms, mobile apps, emails and RSS feeds. The following sub-sections describe how the website news articles were coded and analysed.

\subsubsection{Coding for features of Convergence of Contents}

The research literature underscores that news companies are feeding their digital publications with more multimedia stories (Infotendencias Group, 2012). 
Hence, this content analysis counted the number of media - text, photo, video, audio clips - in each online story. Subsequently, each article that had two or more different types of media was coded as a multimedia story. The number of multimedia stories produced by each website was then compared against the total number of stories they published during GE2015 to gauge the degree of emphasis each news organisation placed on Content Convergence.

\subsubsection{Coding for features of Convergence with The Audience}

This study adapts from Domingo et al.'s (2008) framework that examined eight Active Audience features that journalists included in their online news websites to engage their readers. This thesis streamlined and updated the framework to take into account the capabilities of social media platforms as a new method of engaging the audience. The features classify into three categories. The first category was social media sharing functions. News stories that allowed readers to directly share the story on their social media platforms with the click of a mouse were classified in this category. The second category was social media content from readers. Articles that featured readers' social media posts in the copy were classified in this category. The third category was reader comments section. Stories with a section that allowed readers to leave their comments at the end of articles were included into this category.

\subsection{Data Analysis}

To analyse the interview data, this study is guided by the logic of open, repetitive inductive analysis from the constant comparative approach of grounded theory (Corbin \& Strauss, 2015). According to Corbin and Strauss, constant comparison in grounded theory does not aim to make generalisations but theoretical explanations. Furthermore, this iterative analytical strategy provides an opportunity to 
gain new insights and allow fresh concepts and relationships to emerge from the data (Saldana, 2009). The advantages of this analytical strategy are consistent with the premise of the case study approach, which advocates a thorough understanding of specific cases rather than attempt to reach generalizable conclusions.

After the interviews were transcribed, this researcher first read through the transcripts to familiarise himself with the data before it was coded. Simultaneously, he also referred constantly to the relevant literature, interview questions and research questions to spot themes related to the characteristics of journalism convergence.

Thereafter, the interview data was coded based on the characteristics of journalism convergence outlined in this study's theoretical framework. Themes related to Technological Convergence, Business Convergence, Professional Convergence, Convergence of Contents and Convergence with The Audience were highlighted. Simultaneously, issues raised by interviewees that did not adhere to this study's research framework were also coded as potentially new characteristics of convergence (Appendix D). This process of coding the transcripts based on existing and new emergent codes, and looking for patterns and relationships between them was done iteratively and manually until the point of theoretical saturation - when a researcher "has continued sampling and analysing data until no new data appear and all concepts in the theory are well-developed" (Morse, 2004). Eventually, a total of 43 codes were developed.

The next chapter presents the findings of this study. 


\section{CHAPTER 4: FINDINGS}

This chapter is divided into two parts. The first part (sections 4.1 to 4.5 ) answers RQ1, which asks: Based on the multidimensional approach, what existing characteristics of journalism convergence may be observed in the legacy mainstream organisations and digital news start-ups? It investigates the characteristics of convergence exhibited by The Straits Times (ST), The Middle Ground (TMG) and The Online Citizen (TOC).

The second part (section 4.6) answers RQ2: What new characteristics are needed to explain journalism convergence in legacy mainstream organisations and digital news start-ups? This section identifies new traits of news convergence exhibited by the three newsrooms.

\subsection{Business Convergence}

\subsubsection{Centripetal Business Convergence}

All three newsrooms displayed aspects of Centripetal Business Convergence. However, while legacy newsroom ST has had to make changes to its physical and resource set-up, online news start-ups TMG and TOC incorporated elements of Centripetal Business Convergence from the beginning.

ST modelled the key characteristics of Centripetal Business Convergence in several ways. Firstly, it reorganised its physical newsroom layout in 2013 and introduced a "news hub" in the middle of its newsroom that allowed both the digital and newspaper editors to be seated next to each other (Figure 4.1, next page), and moved the digital department (referred to as the "digital desk") closer to the hub. The digital news editor explained that prior to this, the digital desk editors were seated separately from the print editors, and the digital department was located at a corner of 
the newsroom. With the news hub, both digital and print editors would be able to "chip in and comment at almost every stage [of the news production process]" (S1, personal communication, 10 December 2015).

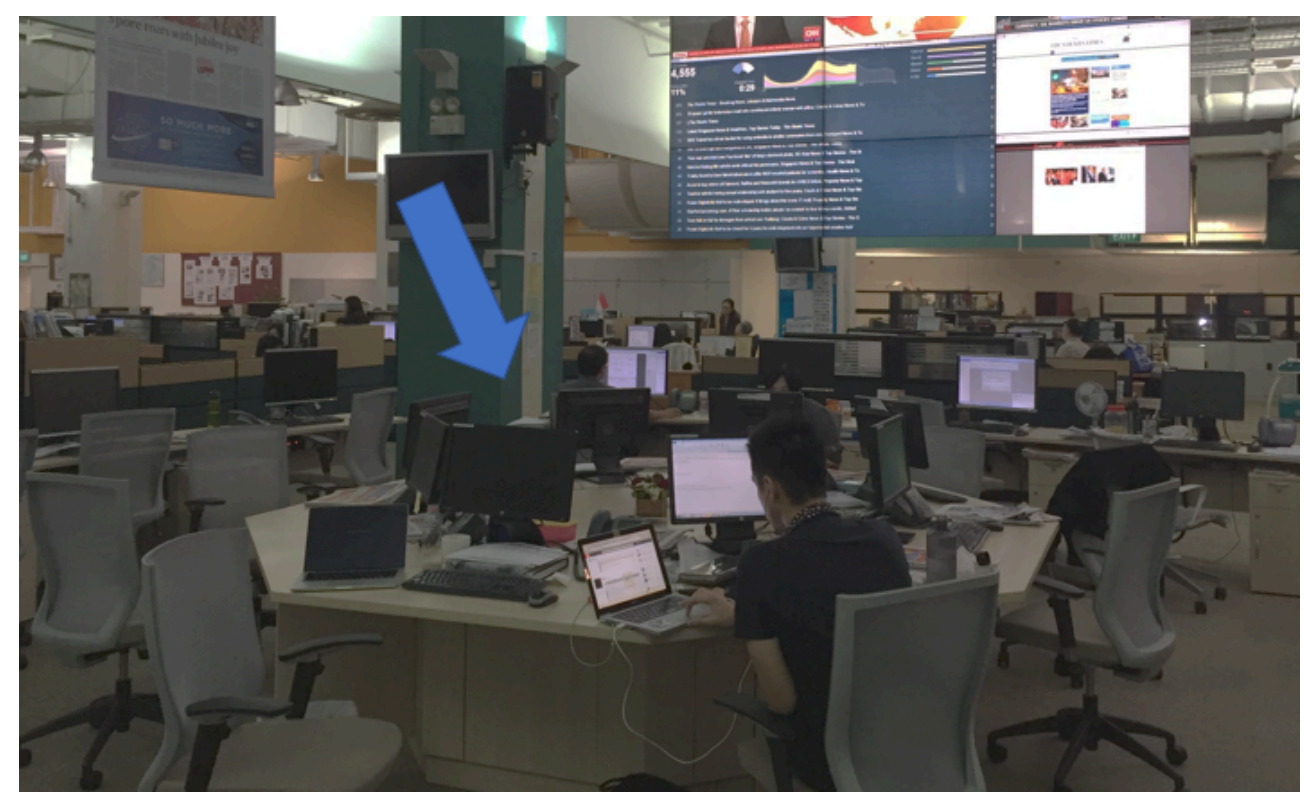

Figure 4.1 ST's news hub (arrow indicates 'hub' where digital and newspaper editors sit).

Secondly, ST had invested a significant amount of resources in enhancing its capabilities in online videos and digital interactive graphics. The legacy news publication had started a separate video unit to produce documentary-style current affairs content in 2014 by tapping on existing video journalists and production staff that were previously with another department within the company. The video team, formerly located on another floor, was moved into the ST newsroom to facilitate more efficient coordination between video staff and the ST editors and reporters. One of the video journalist said: "It's quite clear that they want us to be more integrated into ST's ecosystem" (S6, personal communication, 5 April 2016). To boost its interactivegraphics production capabilities, ST formed a team of web designers and coders 
comprising of new hires as well as staff who were transferred from SPH Digital another department in-charge of producing digital advertising-related content.

Thirdly, the newspaper experimented with a cross-brand effort for the first time during GE2015. ST's website featured a segment that contained daily election-news videos that were co-produced by a broadcast journalist from its affiliated radio station under Singapore Press Holdings. ST's digital news editor explained that the broadcast journalist was a former TV news presenter and had the skills and experience required to help produce and host the online shows for ST. He added that "it may pave the way for similar types of collaborative projects" (S1, personal communication, 10 December 2015) with other brands owned by SPH.

TMG's newsroom, measuring about a tenth of the area of an Olympic-sized swimming pool, was designed to facilitate collaboration and improve efficiency among its staff (Figure 4.2, next page) from the beginning. There are no partitions in the newsrooms and the editorial staff and editors sit side-by-side each other, a feature similar to ST's news hub. The publisher explained:

"When we started this, we knew that to survive in the digital news business, we needed to act and react fast. We wanted an outfit with minimal hierarchy and red-tape” (T1, personal communication, 21 January 2016). 


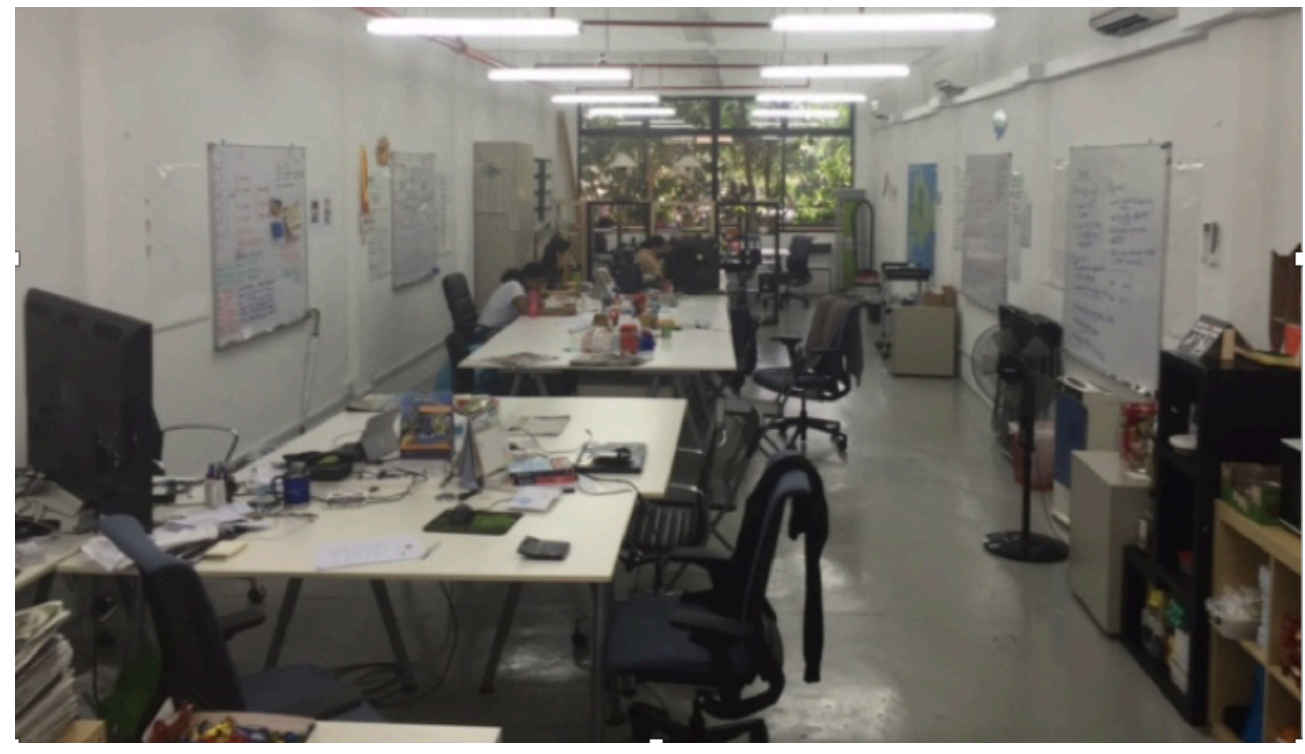

Figure 4.2 TMG's newsroom.

TMG was also set up with "no beats" in mind to achieve greater collaboration among its staff. Its news editor, who had spent seven years at ST as a journalist, emphasised that he had realised that modern newsrooms "had to move out of the print mindset" to respond to the demands of online news, and that TMG was established "without that baggage" of a legacy media organisation (T3, personal communication, 11 January 2016).

When it came to producing multimedia content, on top of relying on its journalists to shoot simple photos and videos using their mobile phones, TMG had set up a separate video unit to produce documentary-style videos for its online channels and relied on pulling together "shared resources" between its news and video teams. TMG's news journalist explained that the video unit staff had to work closely with its news staff for two main reasons. First, the video unit staff were not "news-trained", and had to consult the news journalist in matters of editorial content production. Second, the news journalists had to frequently double-up as video journalists because the production unit is just a small two-person team. 
Like TMG, TOC incorporated elements of Centripetal Business Convergence

right from the start. Its editors explained that although they were each in-charge of specific areas of content, there were no clear beats as each other's work areas overlapped. They said the executive editor managed video production, political news and the social media channels; the commentaries editor took charge of the opinioneditorial articles and stories contributed by volunteers and bloggers; two of the editors were responsible for activism-related news and articles by volunteers and bloggers, and assisted the executive editor with political news. They stressed that TOC's work arrangement was a highly collaborative one where if one journalist was busy, another would help by taking on some of the workload. The commentaries editor explained that "it really was nothing like the mainstream media where you [had] to jump through hoops to get one story approved" (O3, personal communication, 2 June 2016).

\subsubsection{Centrifugal Business Convergence}

With regard to horizontal Centrifugal Business Convergence, the legacy media and online news start-ups varied. ST, which was originally a newspaper-focused business, exhibited characteristics that were closely congruent with the literature as it was the only one of the three newsrooms that had diversified into producing news for both the print and online platforms (Keshvani, 2000a). As online-only publications, TMG and TOC, however, engaged in a variation of horizontal Centrifugal Business Convergence. They did not diversify their businesses to include traditional media platforms such as print, TV or radio. Instead, they "diversified" their operations by expanding their digital distribution channels and increasing the amount of multimedia content distributed via those channels. This is a new characteristic of convergence that is discussed in the second part of this chapter under section 4.6.1. 
On vertical Centrifugal Business Convergence, ST did not exhibit traits

outlined by the research literature. It should be noted, however, that vertical

Centrifugal Business Convergence was left to the domain of its parent company, SPH, which has assets in digital and traditional media advertising, book and magazine publishing, events and exhibition management, Internet services, properties, education and healthcare (Singapore Press Holdings, 2017).

TMG and TOC, on the other hand, displayed characteristics of vertical Centrifugal Business Convergence. TMG had diversified its businesses vertically into commercial video production. TMG's publisher said TMG's video unit produced both editorial news videos for its website and engaged in commercial projects involving corporate videos and advertisements. He added that TMG had invested a "hefty sum" (T1, personal communication, 21 January 2016) of money into buying professional video equipment and hiring the production team. Hence, engaging in commercial video projects helped to defray those cost.

When TOC separated from its parent company The Opinion Collaborative Ltd in December 2015, the non-profit news website had to seek alternative sources of funding. It has since began diversifying its operations to include organising citizen journalism workshops and forums for social activists.

\subsection{Technological Convergence}

Of the three newsrooms, ST's news production and diffusion strategies most closely reflected the multiplatform approach outlined by the literature on Technological Convergence. TMG and TOC, on the other hand, were online-only newsrooms that did not by definition practice multiplatform journalism. They did, however, adopt a variation of the multiplatform strategy, which involved creating and 
distributing multimedia content via multiple online channels. They also put in place a workflow that prioritised the channels through which their content was disseminated.

ST introduced a four-stage, multiplatform workflow in 2013 that integrated the digital and print platforms. The first stage is related to producing and publishing breaking news on ST's digital platforms. The ST staff explained that the breaking news editor and her team at the digital desk are consistently monitoring various potential sources of news, including the Internet, social media, wire news agencies, and broadcast news. When something newsworthy happens, the breaking news editor (or digital duty editor) would assemble a "crack news team" (S1, personal communication, 10 December 2015). According to the editors, whether a story is newsworthy is decided largely based on traditional news values, such as prominence, impact, and uniqueness of the story. ST's associate news editor explained:

"We usually look at a few things, like how many people will it affect, how major is the news, whether people will be interested... Like right now, if there was an announcement that involves big money, big ticket announcements, it will get big coverage... or court stories. If the details are interesting and shocking, we will play it up" (S8, personal communication, 20 May 2016). ST's senior digital desk editors explained that the crack news team usually consists of a just two or three staff from the digital desk, including the breaking news editor (or a duty editor), a breaking news reporter, and a digital sub-editor. This team are the "first responders" in breaking news situations. The ST digital editor said:

"It's a small team, but they are in-charge of breaking the news first on digital to buy the key reporter time to get to the ground. They write the news slugs, do the format, headlines, put in pictures if possible... but focus on the main news point. 
That's it. That's just to give the story the first push... get the ball rolling" (S1, personal communication, 10 December 2015).

The priorities of the "crack news team" include: alerting all ST journalists of the breaking news situation via the use of Telegram, an instant messaging app used by most of the ST staff; gathering information from the various news sources; and publishing a short story consisting of a few lines on "ST Now" (Figure 4.3) - a section on its website that is dedicated to breaking news and is similar to a Twitter feed before posting the content on its social media platforms.

Once "ST Now" has been updated, the newsroom's content management system would automatically send a "breaking news alert" push notification to readers who have downloaded the ST news app on their mobile devices. Thereafter, the social media editor would publish the news on their Facebook and Twitter accounts.

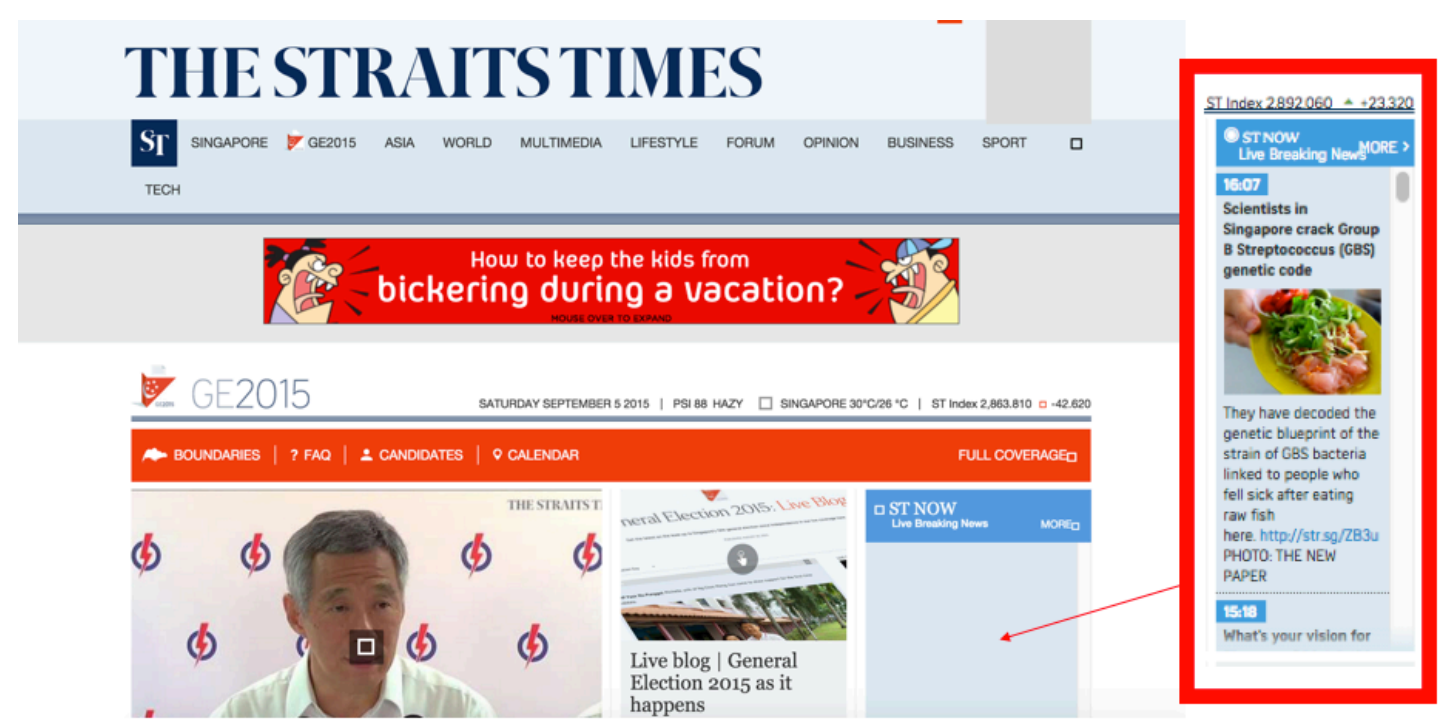

Figure 4.3 ST's website with a Twitter-like feed, "ST Now", for breaking news.

The second stage entails the print reporter getting to the scene and "feeding the ‘crack news team' with information” (S10, personal communication, 9 June 2016), including photos, videos, and audio recordings - to piece together a longer story for 
ST's website. After which, new blurbs would be posted on its social media platforms. Reporters at the news scene communicate with the editors and digital desk journalists in the newsroom via Telegram.

The third stage includes the print editors deciding which online stories should be further developed for the following day's newspaper. The associate news editor of the newspaper added that when an online story is prepared for print, it is updated, reangled, and given "more voice and quotes" (S8, personal communication, 20 May 2016).

The fourth stage kicks in when the newspaper editors feel that a print story is worth commissioning into a longer opinion-editorial article that would be published both in print and online, and promoted on its social media accounts.

Similar to ST's practice, TMG's and TOC's production and dissemination strategies also prioritised their different online channels. However, unlike ST which breaks news on its website first, TMG and TOC generally publishes breaking news on their social media channels first.

There are two variations to TMG's news workflow. The first involves nonbreaking news, which most of the journalists said was the more common type of news for TMG because it did not have sufficient human resource to cover breaking news on a regular basis. In such instances, the story is first published on its website and then simultaneously pushed on it social media accounts, Facebook and Twitter. TMG's news editor explained:

"We get most of our (web) traffic from social media, most from Facebook. So, whatever we publish on our website, we must also push out on our social media platforms" (T3, personal communication, 11 January 2016). 
When TMG covers breaking news, on occasions such as the 2015 General Elections (GE2015), it adopts a different workflow that includes updating Twitter first, followed by Facebook, before writing a longer story for its website. The news editor commented on the process:

"For breaking news situations, we update Twitter more often because it's limited by 140 characters, so it was like a stream of live updates. We update Facebook every 10 or 15 minutes because there, we're able to write more, attach a video, give more details. If you look at our website, I guess it's most akin to print. There's still a lot more analysis, a lot of copy editing, the newsroom processes that take place before we put up stories on the website" (T3, personal communication, 11 January 2016).

TOC's news workflow is like TMG's. Per its executive editor, TOC focuses on producing multimedia features and long-form analytical stories, and not breaking news due to a lack of staff. Its usual workflow includes first publishing stories on its website, then posting those stories on its social media accounts simultaneously.

When TOC covers breaking news events, such as the political rallies during GE2015, it prioritises Facebook over its website and Twitter. One of the TOC editors explained that during such events, any new developments would first be updated on its Facebook page. A longer, more detailed story is only written for its website when sufficient information can be gathered. Once the story is published on its website, TOC's social media accounts would then also be updated simultaneously, and the posts would contain hyperlinks to the stories on its website. She said:

"Most of our readers are on Facebook. We get more referral traffic to our website from Facebook too, so we don't do much on Twitter. During the GE2015 rallies, for instance, we were at several rallies shooting videos and 
photos, and frantically updating our Facebook account as the politicians were speaking" (O2, personal communication, 20 April 2016).

\subsection{Convergence of Contents}

\subsubsection{Multimedia content}

The content analysis examined the total number of online multimedia articles each newsroom produced during GE2015. Each article that contained two or more types of media - text, photo, video, audio clip - was considered a multimedia story. Table 4.1 presents the number of multimedia stories each website produced.

The results reveal that more than $80 \%$ of all digital stories each website published during GE2015 were multimedia, indicating a high degree of Convergence of Contents. TOC produced the highest percentage of multimedia stories $(96.8 \%)$, while ST's and TMG's output of multimedia articles were $95.1 \%$ and $80.8 \%$ respectively.

\begin{tabular}{|l|l|c|l|}
\hline & $\begin{array}{l}\text { No. of } \\
\text { multimedia } \\
\text { stories }\end{array}$ & $\begin{array}{l}\text { Total no. of } \\
\text { stories published } \\
\text { on website }\end{array}$ & $\begin{array}{l}\text { Percentage of } \\
\text { multimedia } \\
\text { stories compared } \\
\text { to total no. of } \\
\text { stories }\end{array}$ \\
\hline The Straits Times & 430 & 452 & $95.1 \%$ \\
\hline $\begin{array}{l}\text { The Middle } \\
\text { Ground }\end{array}$ & 97 & 120 & $80.8 \%$ \\
\hline $\begin{array}{l}\text { The Online } \\
\text { Citizen }\end{array}$ & 184 & 190 & $96.8 \%$ \\
\hline
\end{tabular}

Table 4.1 Comparison of GE2015 Multimedia Stories Published by ST, TMG and TOC on their Websites

The interview data mirrored the high number of multimedia stories that was produced by the three newsrooms during GE2015 and reflected the importance the journalists had placed on multimedia news content. Most of them agreed it was 
important to have multimedia elements in their online news because their audience expected it. The ST associate news editor said:

“Increasingly, we've moved towards the thinking that where possible, there should be a multimedia package... I think increasingly, it has become the default rather than exception (S8, personal communication, 20 May 2016). The TMG publisher said although multimedia news production required a significant amount of resources that TMG did not possess, the publication's staff experimented with "several creative ways" to deliver multimedia content to its audience that required minimal video production efforts. Two such examples include: A story where the music video of a pop song was accompanied by its re-written lyrics that described the major political issues of GE2015 (Figure 4.4, next page); and an article that featured a video montage of several election rallies made by stitching a series of photographs together. TOC's journalists also stressed the importance of multimedia journalism. The commentaries editor said:

“Nowadays, you can't do just text alone. It's very hard. You need videos, photos, illustrations... all the fancy stuff, to keep your readers engaged" (O3, personal communication, 2 June 2016). 


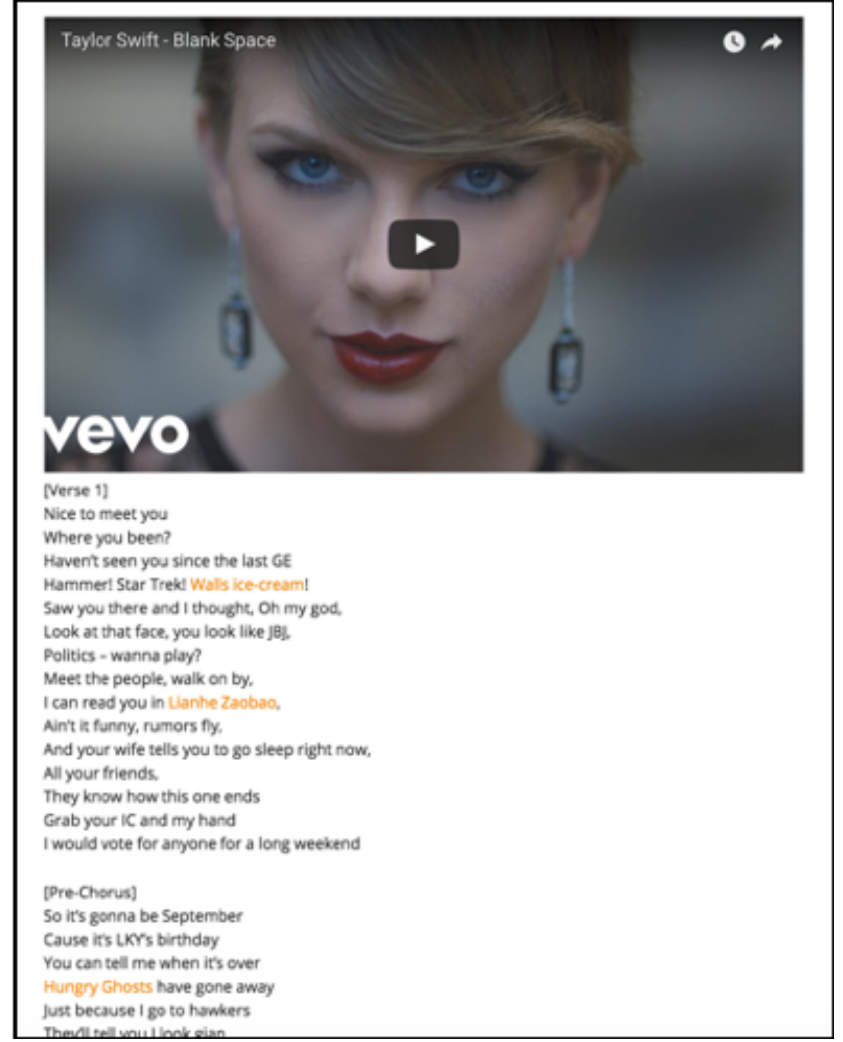

Figure 4.4 Example of how TMG used "creative ways" to include videos in its news without having to produce original content.

\subsubsection{Coordinated coverage}

On sharing content with other publications, the ST digital editor said although it had not included any news produced by other media brands owned by SPH in its GE2015 coverage, it does sometimes include other SPH publications' articles into its own newspaper and online platforms. He also mentioned that ST's content is shared with the other SPH newspapers, although he could not confirm if they were used. TMG and TOC, on the other hand, did not own other media outlets. However, the TMG and TOC editors revealed that due to their small operations, they relied on collaborations with external partners to produce content. This collaborative practice among the online news start-ups is a new characteristic of journalism convergence and is detailed in the second part of this chapter under section 4.6.3. 


\subsection{Professional Convergence}

\subsubsection{Functional polyvalence}

The characteristic of functional polyvalence featured strongly in all three newsrooms.

For ST, its newspaper reporters were required to write for both the print and digital platforms, in addition to producing simple multimedia content during breaking news events. Secondly, on top of having to oversee digital news production, the digital news editors were also in-charge of some technical aspects of the website, such as monitoring the site's UX and UI (user experience and user interface) and offering suggestions to improve them. According to the editors, these matters used to be the IT department's responsibility and they were not consulted on these areas because they do not possess professional IT knowledge. Thirdly, functional polyvalence in ST's newsroom was especially significant during major news events, such as the 2015 General Elections and the state funeral of Singapore's former prime minister Lee Kuan Yew, which both occurred in the same year. The digital editor explained that the two events were good examples of "all hands on deck" situations, when print editors and reporters had to assist the digital team with the production of special feature videos (Figure 4.5, next page). He added that some "were roped in as topic experts" during the pre-production and research stages, while others contributed as political commentators (S1, personal communication, 10 December 2015). Lastly, the ST video team said the professional culture in their unit was one that lauded employees for being familiar with all parts of the production process. An ST videographer recounted how members of his video team looked up to another younger, multiple awardwinning videographer who was not trained as a video journalist but learnt to "shoot, 
write, edit, do post-production work all by himself, without a video journalist" (S5, personal communication, 5 April 2016).

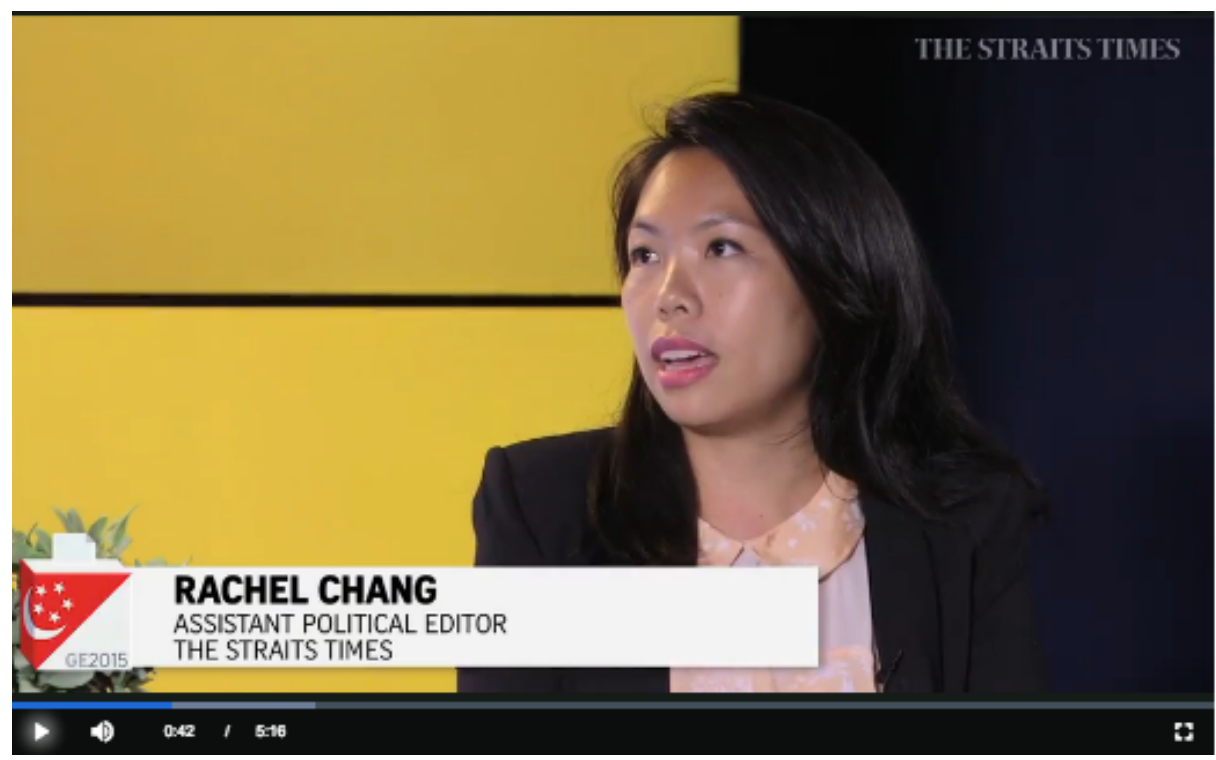

Figure 4.5 Assistant political desk editor doubling as a commentator for one of ST's videos.

TMG also exhibited characteristics of functional polyvalence. Firstly, TMG's online journalists were expected to occasionally produce simple multimedia content using their mobile phones. TMG's journalist said:

"We were told even before we were hired that we may have to shoot simple videos using our mobile phones. Even for those who are not familiar [with using mobile phones to shoot videos], they will get tips from others in the newsroom who are more digitally savvy" (T5, personal communication, 21 February 2016).

Secondly, the online journalists also occasionally functioned as video journalists for TMG's video unit, helping them to do background research, prepare scripts, and interview people, on top of having to write online stories to accompany the videos. Thirdly, TMG's online journalists were also tasked to sub-edit stories on a 
"rotating shift" on certain days of the week. Their sub-editing job included simple photo editing, adding hyperlinks into online stories and posting content on TMG's social media channels.

TOC's journalists also showed characteristics of functional polyvalence. Firstly, TOC's staff, freelancers and volunteers were expected to produce simple multimedia content - including videos, photos, audio and text - for the publication's website and social media channels. The executive editor said when he first started contributing articles to TOC in 2006, he had to shoot his photographs for his stories, include hyperlinks and sometimes edit articles. The digital publication's commentaries editor said although TOC could not be too selective when it came to assigning work to volunteers, they "tended to assign more work to those who could shoot videos, take photos and write well" (O3, personal communication, 6 April 2016). Secondly, when it came to the production of professional videos, the executive editor worked with several multimedia-production savvy volunteers (Figure 4.6, next page), on top of his other editorial duties. Thirdly, in addition to coordinating and editing multimedia content and stories from volunteers and freelancers, the four TOC editors were also involved in producing their own stories for the publication's online channels. 


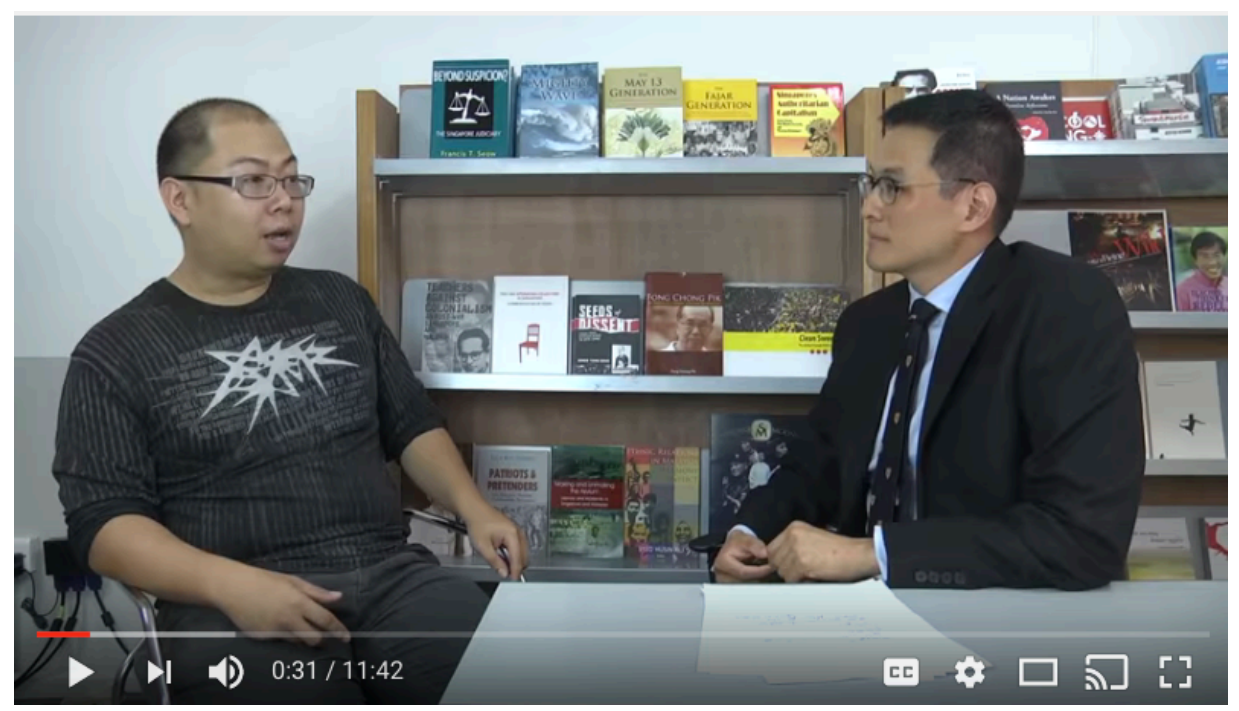

Figure 4.6 TOC executive editor (left) doubles as a commentator for one of TOC's videos.

On multimedia skills, most of the editors from all three newsrooms said they did not require all their journalists to be extremely proficient in multimedia news production.

For ST, the digital editor said reporters only needed to shoot "very basic video and photos using their mobile phones" (S1, personal communication, 10 December 2015). The associate editor elaborated that "maybe because [ST] still [has] a big newsroom that allows [it] to demarcate duties", it was not specifically looking for journalists who could single-handedly produce an entire multimedia package, but someone who was just "familiar and willing to use smart phone technology" (S8, personal communication, 20 May 2016).

Likewise, TMG's news editor said that he expected his journalists to possess a "decent level of multimedia skills, such as being able to shoot simple photos and videos on the mobile phone... and have some knowledge of how social media platforms work" (T3, personal communication, 11 January 2016).

For TOC, not all the editors and volunteers were highly proficient in multimedia production. The commentaries editor explained that "for those who 
weren't, those who were [multimedia proficient] would help them out" (O3, personal communication, 2 June 2016).

However, the TOC editors mentioned that during significant news events such as GE2015, it usually faced difficulties getting enough multimedia savvy volunteers. To overcome this obstacle, the TOC executive editor explained that "sometimes, [TOC] pools volunteers with different skills together to cover a story" (O1, personal communication, 6 April 2016). This is a new characteristic of convergence that is discussed further in the second part of this chapter under section 4.6.4.

\subsubsection{Thematic polyvalence}

Staff from ST, TMG and TOC all displayed thematic polyvalence, albeit to varying degrees.

This study found that ST's print journalists were not as thematically polyvalent as its digital desk journalists. Excluding significant news events, the newspaper's print journalists were usually required to "cover, at most, two beats", although some of the more experienced journalists may handle more (S7, journalist, personal communication, 10 May 2016). The digital desk, on the other hand, required their journalists to be familiar with a wide range of issues, including "local news, politics, foreign news, lifestyle, sports and business" (S10, deputy digital editor, personal communication, 9 June 2016). The deputy digital editor explained that there were only three digital desk reporters and they were expected to write about any topic as they had to cover breaking news, plus work on any stories that were assigned to them by the various digital editors. She added that the digital sub-editors also worked shifts and had no specific beats. The video journalists, who were a part of the digital desk, were also required to produce video content that cut across a varied range of issues and were described as "generalists" by the video editor. 
Thematic polyvalence was highly prevalent in the TMG newsroom. Most of its staff, including its editors, were required to produce news that covered a wide range of issues ranging from politics and health to sports and entertainment. All the editorial and video unit staff who were interviewed said there were no beats in the TMG newsrooms, and one of the journalists emphasised that they had to "cover any story that was assigned to them, although [they] could propose topics that interested [them]" (T5, personal communication, 21 February 2016).

For TOC, thematic polyvalence was observed among its editors as their areas of responsibility frequently overlapped. Moreover, before any article was published online, they all read each other's stories (including contributions by volunteers and freelancers that each editor was responsible for) and offered their views on what changes should be made. When it came to producing documentary-style videos, TOC's executive editor had to be thematically polyvalent as he was the only one in the team who had the professional know-how. The commentaries editor explained:

"He [the executive editor] usually does the investigative journalism videos... from the political ones during the GE to reports on fish farmers who were affected by algae bloom (O3, personal communication, 2 June 2016).

\subsubsection{Polyvalence of media}

All three newsrooms exhibited characteristics of media polyvalence to different extents, with ST showing traits that were closest to the literature.

The ST journalists said they were not required but encouraged to produce original content for other media assets owned by SPH. The associate editor said some of its senior staff regularly contributed articles to several magazine titles managed by the company and vice-versa. The ST digital editor added that although it was a common practice for all the English publications under SPH to publish each other's 
content, each newsroom's journalists were not required to produce original content for the others. However, he cited an incident during GE2015 when a radio broadcast journalist assisted the newspaper in producing daily online political commentary videos as an example of cross-brand collaboration between SPH Radio and ST.

For TMG, the online journalists explained that they sometimes volunteered to help their video unit colleagues produce content for both editorial and commercial projects. However, they stressed that it was not a requirement.

For TOC, the executive editor explained that when its parent company, The Opinion Collaborative Ltd, was previously financially supporting the news site, he would on an ad-hoc basis assist them in him commercial video projects.

\subsubsection{Attitude towards polyvalence}

The journalists in all three organisations were positive towards polyvalence. Moreover, most of those who felt they lacked polyvalent skills were keen on improving through on-the-job training and professional courses.

Interviews with ST staff revealed that most of them acknowledged the importance of polyvalent skills and were keen to be proficient in it. The associate editor said one of the reasons why ST introduced the digital-print job rotation system was to familiarise the newspaper journalists to different aspects of ST's news production processes. Moreover, one of the journalists added:

"[Polyvalent skills are] very important now. There is a lot of focus on sending photos and videos back to the digital team during breaking news. It's like it's almost obligatory..." (S7, personal communication, 10 May 2016).

However, a few older journalists, despite being offered similar incentives and multimedia skills training, were resistant towards skills polyvalence. ST's breaking 
news editor exasperatedly recounted an incident when an older print reporter refused to use Telegram to send information back during a breaking news event:

"She didn't want to send information because she said she didn't know how to use Telegram, and she didn't want to. I offered her WhatsApp or email, but she refused those as well. She came back to the newsroom, slowly typed her story... got it cleared by her desk and print supervisors, and then told me to pick up the story from Hermes [ST's content management system]. It was too late! Everyone else [referring to competing news publications] already had their stories online" (S9, personal communication, 11 April 2016). The breaking news editor added that the older journalists were not as technologically savvy as the younger ones, and that many were struggling to keep up with the changes that have been introduced in the newsroom.

Although a few staff still remain negative towards polyvalence, ST's digital editor explained the newsroom's successful strategy in helping its staff accept the importance of skills polyvalence. The digital editor said most of the ST journalists were initially not supportive when told that they had to produce news for both the digital and print platforms, and shoot simple videos using their mobile phones. To mitigate the resistance, ST introduced a job rotation system that allowed print reporters to volunteer to work at the digital desk for stints of six months. He said: "This is still ongoing. Those who put their hand up for the stint were recognised. We make sure their efforts are rewarded during their performance appraisals... we wanted them to go back to the print side and evangelise about the [digital] effort... about the new skills they had learnt" (S1, personal communication, 10 December 2015). 
Two print journalists, S7 and S8, who had volunteered for this work arrangement both said their experiences at the digital had helped them understand ST's new workflow and the importance of digital news. ST's associate editor said the job rotation gave the print reporters an opportunity to realise that the print and digital desks need to "work a lot closer together, because you really need to sync the online with every other part of the newsroom (S8, personal communication, 20 May 2016).

For TMG and TOC, all the journalists acknowledged the importance of being polyvalent, especially for online news. Furthermore, even those who lacked polyvalent skills were trying to learn. TMG's consulting editor, said:

"Being able to multi-task, basic multimedia skills... for online news, of course they are important. But it's okay if some of them [the TMG staff] are not that good. They come in and learn on the job" (T2, personal communication, 11 January 2016).

One of the TMG journalists admitted he was not very proficient at multimedia production and covering a range of topics that were "outside his comfort zone" when he first joined the company. However, he realised that those skills were important "assets" to have and taught himself to be polyvalent by asking for advice from his colleagues. Similarly, TOC's executive editor said that having more journalists with polyvalent skills was important for a small online-news organisation such as his as it would help alleviate the heavy workload placed on the few staff who were effectively polyvalent (O1, personal communication, 6 April 2016).

\subsection{Convergence with The Audience}

This section illustrates the ways in which the newsrooms utilised social and digital media to interact and engage their readers. It also includes editorial analytics as 
an indirect tool that the newsrooms use to engage their audiences by understanding readers' content preferences.

\subsubsection{Using social media to involve readers in constructing news}

All the journalists who were interviewed for this study said they kept close tabs on issues, comments and posts that were trending on social media, including readers' posts on their publications' social media channels. Some of them claim these had occasionally proved to be good sources of information, story ideas and news leads, and updates about breaking news situations. The ST breaking news editor explained that ST relies heavily on its readers when news breaks because that is how "(ST) is

made aware of [such] news events" (S9, personal communication, 11 April 2016), and would use social media to get in touch with readers for interviews. Likewise, the ST associate editor stressed that "social media, Facebook, Twitter... are very much news gathering tools these days" (S8, personal communication, 20 May 2016). Most of the TMG and TOC staff said they too closely monitored their publications' social media channels and had on several occasions followed up on story ideas and leads provided by their readers.

\subsubsection{Directly engaging with readers on social media}

The journalists from all three newsrooms remained cautious about responding to readers' comments and questions on their respective publications' social media platforms. However, most of them who were interviewed believed that it was crucial to engage readers directly on social media.

For ST, social media engagement was left to its social media editor and several senior journalists who were hand-picked by the ST's management. The interviewees explained that these journalists were tasked with using company-sanctioned Twitter accounts to engage readers because they had "already developed reputations as topic 
experts" (S8, personal communication, 20 May 2016) and could help "cement ST as being an authority on certain issues" (S7, personal communication, 10 May 2017). The associate editor said these journalists were encouraged to post their own digital stories on social media, and engage their online followers by sharing their thoughts and opinions on issues related to their beats (Figure 4.7).
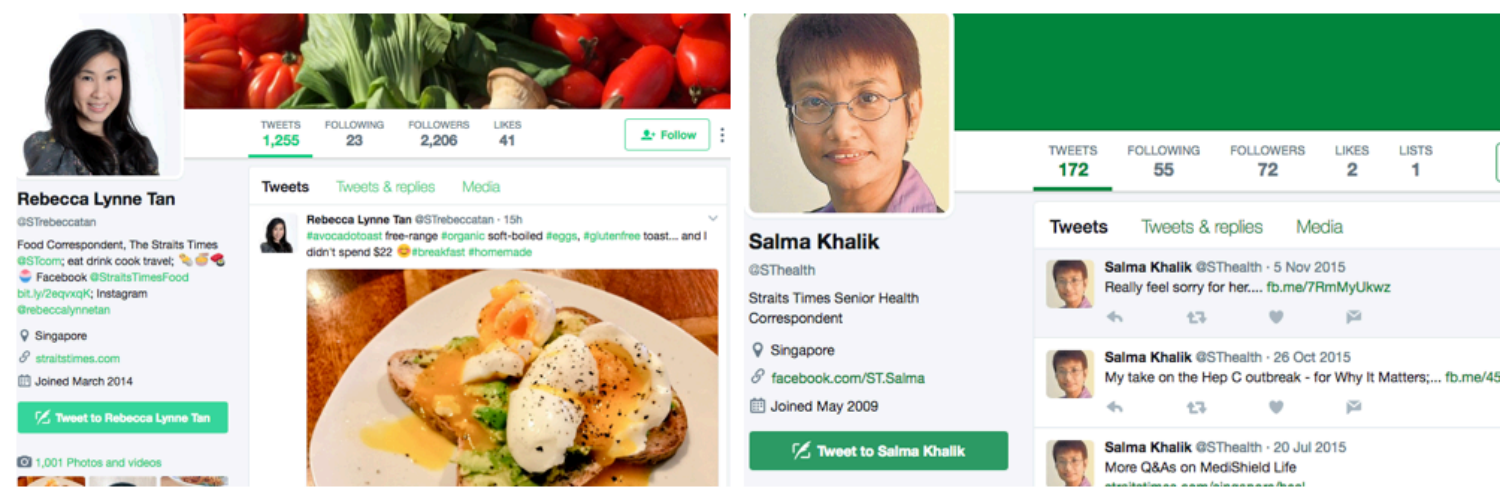

Figure 4.7 Examples company-sanctioned ST Twitter accounts for selected journalists.

However, the ST social media editor, who was in-charge of the newspaper's social media accounts, added he and most of his colleagues were very careful when responding to readers online. They never engaged readers in a debate as they "[did] not want to get caught in a heated argument”. Replying to comments were limited to highlighting factual errors or only when necessary to "mediate racist and nasty" remarks (S2, personal communication, 28 January 2016).

Like ST, the responsibility of replying readers for TMG is highly centralised and left mostly to the publisher. He explained that most online comments were just points of view and did not require a response. However, he stressed that questions from readers must always be answered. He added how engaging them directly online “was a very big part” of TMG's journalism as it not only helped build a relationship 
between TMG and its readers, but also differentiated his online publication from the legacy media:

"This is something that the classic approach to journalism did not include as old newsrooms kept journalists away from comments and interacting with readers" (T1, personal communication, 21 January 2016).

TOC's executive editor, who was one of the two journalists in-charge of responding to readers online, echoed the TMG publisher's sentiments. He expressed how engaging readers on social media and on TOC's website was not only something which the mainstream media lacked, but also unique to his publication:

"I think our readers know that unlike the mainstream media or other media, we are a place where you can debate, interact and engage with us editors and with each other (O1, personal communication, 6 April 2016).

\subsubsection{Including social media sharing functions on websites' articles}

Based on the content analysis, every GE2015 story that was published from 1 to 12 September on the ST, TMG and TOC websites contained a social media sharing button that allowed readers to share articles on their own social media platforms (Table 4.2, next page). Most of those interviewed said it was a "standard feature" now because most news websites had it, and it would be "weird" if they were absent. The ST digital editor further elaborated on how "social sharing was huge" and that the buttons which accompany each news article gave readers "an added convenience" to share ST's content (S1, personal communication, 10 December 2015). 


\begin{tabular}{|l|c|c|l|}
\hline & $\begin{array}{l}\text { No. of stories } \\
\text { that contained a } \\
\text { social media } \\
\text { sharing function }\end{array}$ & $\begin{array}{l}\text { Total no. of } \\
\text { stories published } \\
\text { on website }\end{array}$ & $\begin{array}{l}\text { Percentage of } \\
\text { stories that } \\
\text { contained a social } \\
\text { media sharing } \\
\text { function } \\
\text { compared to total } \\
\text { no. of stories }\end{array}$ \\
\hline The Straits Times & 452 & 452 & $100 \%$ \\
\hline $\begin{array}{l}\text { The Middle } \\
\text { Ground }\end{array}$ & 120 & 120 & $100 \%$ \\
\hline $\begin{array}{l}\text { The Online } \\
\text { Citizen }\end{array}$ & 190 & 190 & $100 \%$ \\
\hline
\end{tabular}

Table 4.2 Comparison of GE2015 Stories Published by ST, TMG and TOC that Contained a Social Media Sharing Function

\subsubsection{Embedding social media posts in online articles}

The content analysis found that all three newsrooms had very few stories during GE2015 that embedded readers' social media posts. Of all their online articles published during that period, 5.3\% of ST's stories included readers' social media posts, while TMG and TOC only had $0.8 \%$ and $7.3 \%$ respectively (Table 4.3 ).

\begin{tabular}{|l|c|c|c|}
\hline & $\begin{array}{l}\text { No. of stories } \\
\text { with embedded } \\
\text { social media posts }\end{array}$ & $\begin{array}{l}\text { Total no. of } \\
\text { stories published } \\
\text { on website }\end{array}$ & $\begin{array}{l}\text { Percentage of } \\
\text { online articles } \\
\text { with embedded } \\
\text { social media } \\
\text { compared to total } \\
\text { number of stories }\end{array}$ \\
\hline The Straits Times & 24 & 452 & $5.3 \%$ \\
\hline $\begin{array}{l}\text { The Middle } \\
\text { Ground }\end{array}$ & 1 & 120 & $0.8 \%$ \\
\hline $\begin{array}{l}\text { The Online } \\
\text { Citizen }\end{array}$ & 14 & 190 & $7.3 \%$ \\
\hline
\end{tabular}

Table 4.3 Comparison of GE2015 Stories Published by ST, TMG and TOC that Included Readers' Social Media Posts

The low numbers reflect the editors' sentiments, which emphasised the need to be highly selective about embedding social media posts in their stories (Figures 4.8, 4.9) because of issues in relation to the sources' credibility. The ST associate news editor explained: 
"We include them more nowadays to reflect [readers'] sentiment, or eyewitness' accounts... It helps give the story a voice... But we must be very careful to verify the credibility of the source (S8, personal communication, 20 May 2016).

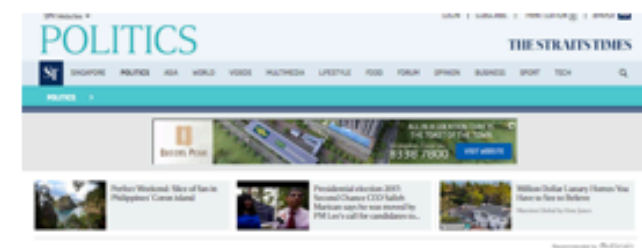

GE2015: Who's the most discussed politician or party on Twitter at half-time?

5. CANDIDATES FACES ON CAMPAIGN POSTERS ARE SO 2011

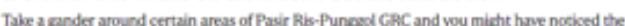

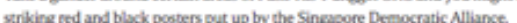

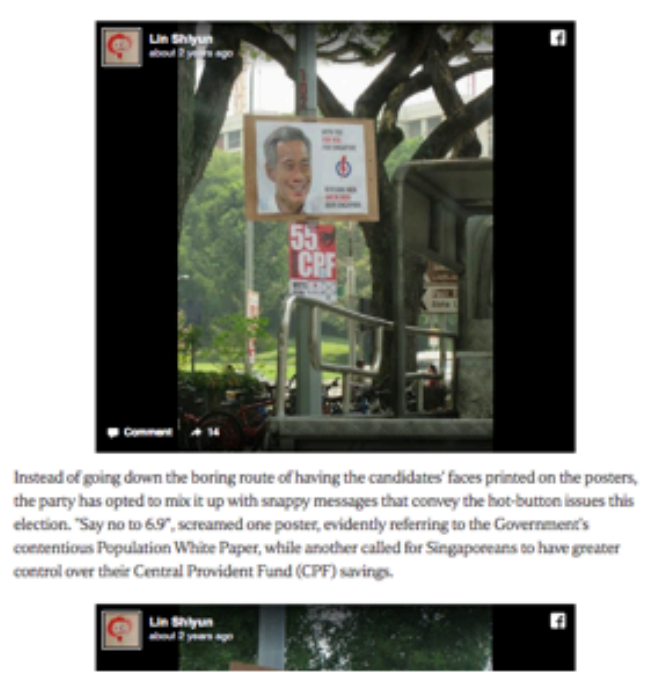

Figure 4.8 Example of an ST story that included readers' social media posts.

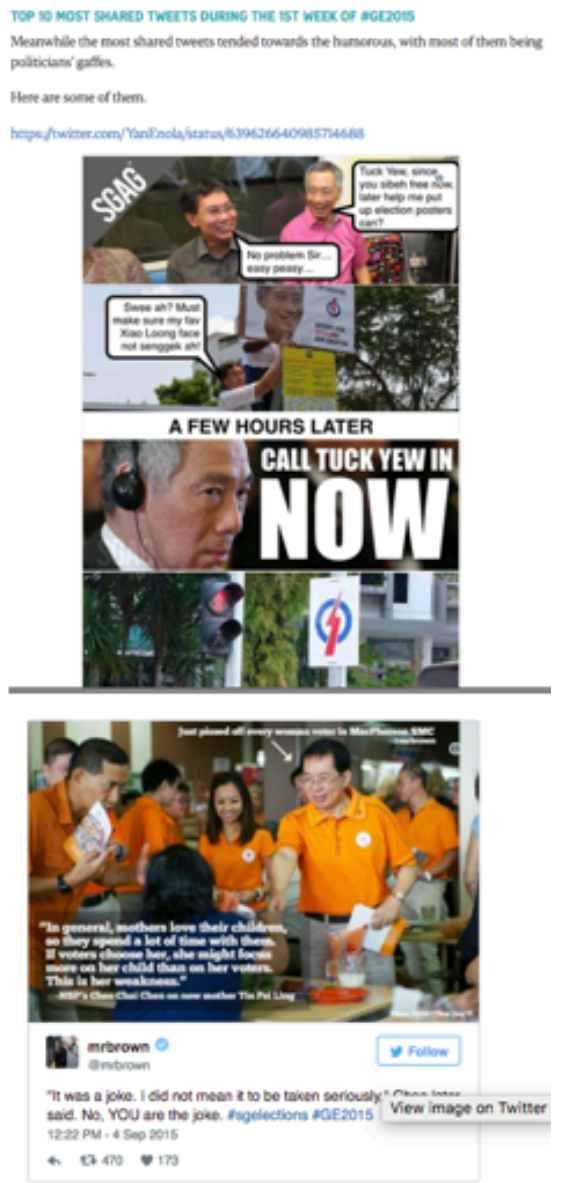

Likewise, TMG's news editor stressed they were cautious when including social media posts in stories. He added they only did so when the person could be verified as a credible source - someone whose identity and comments could be ascertained as authentic and factually accurate (T1, personal communication, 21 January 2016), and the post provided more depth to the reporting. He referred to one 
of TMG's stories published just before GE2015 when an opposition politician was accused of having an illicit affair. He explained:

"On the day when news broke...At 8pm, there were rumours about the affair... by 9 plus, it was all over [the news]. At around 10pm, he [the politician] posted a Facebook post about it... By then, there were reactions to [the mainstream media's] story and to [the politician's] post... it didn't make sense for us to report what was already all over the news. So, I did a fuller story for the website that included both the social media post by [the politician] and people's general reactions to the news, some of which were comments by our readers' on our social media channels" (T3, personal communication, 11 January 2016).

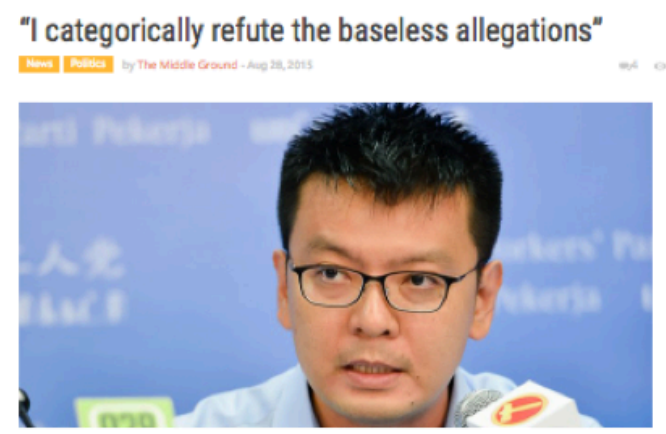

De Geh has said that he was an advisor to the student, who was pursuing a Masters degree from 2007 to 2009 at NuS. He added that they are stil in touch with each other, but that he did not know the supposed author of the emails. Resttion to the news anline have been largely in support of Dr Goh. whose own post thd attracted mere than 100 comments within the frat tou: On Twitter, one user

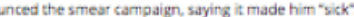

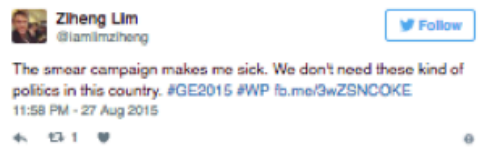

The Werker's Party has not addressed either the allegation or their tandidate's denial. Howerer, it ad post Dr Goh's denial on its Facebeok and Twitter pages. As for his wife? This was what she apparenty texced him atter he told her of the new:

*Forget it. Esther youre so threatening they need to stoop so law or they are so bah Ẽoco. I think your (all of you) time is better spent resting. Nathing to it You know its baund to happen gutter politics. No NEW candidate for the Workers' Party (WP?, De Dariel Geh, has ceme out to publicly refice allegations

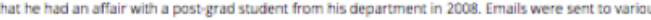

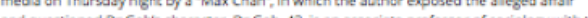

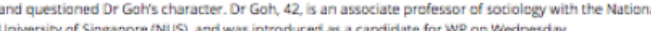

Despite the late hour, the story has gane viral quickly, as both online and mairstream medis ran on their websites Dr Goh's denial of the affair, which he posted on Facebook. As of 1am Friday, the post had garnered more than 500 Lkes and had been shared more than 200 times. reed to convince me. Make the meeting with Low chop chop. Tell him your wife sass you reed to sleep.
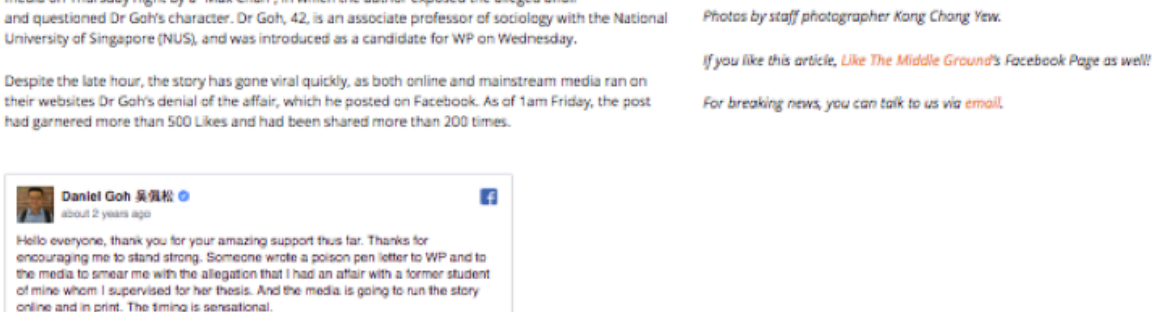

For breaking newa you can talk to us via emall.

Figure 4.9 Example of a TMG story that included a reader's social media post.

TOC's executive editor echoed similar sentiments as TMG's publisher, and expressed that embedding social media posts in articles was better than just paraphrasing comments. He said: 
"If our reader makes a valid point [with a social media post] and we feature it, all our other readers will know exactly who the source is, and they can engage the person if they want to. It makes our readers own what they say... it's more transparent... I think this is something that differentiates us and the mainstream media, and [our] readers know it. (O1, personal communication, 6 April 2016).

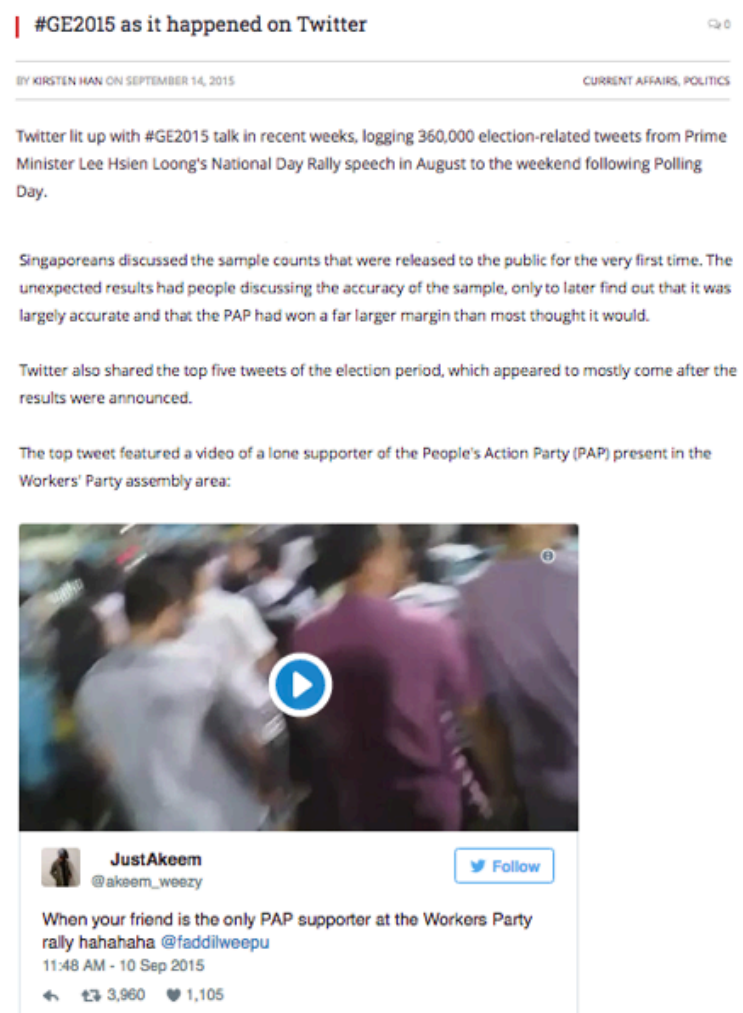

Figure 4.10 Example of a TOC story that included a reader's social media post.

\subsubsection{Editorial analytics as an indirect audience engagement tool}

For ST, it was found that its journalists were trying to find a balance between relying on news analytics to gauge their readers' interest and their own news judgement. TMG's and TOC's, however, did not rely on editorial analytics in their news decisions. 
During interviews with ST journalists in the publication's office, this researcher observed that the news website's metrics were projected onto a large screen in the middle of the newsroom (Figure 4.11). This suggests the importance that ST had placed on keeping track of the performance of its online news articles. When asked to what extent did ST rely on analytics to gauge readers' interest in stories, the ST editor said:

"The rule of thumb is 50-50: Fifty percent analytics; 50 percent news sense...

If I know that there is an important story that will not do well analytics-wise, but it is an important story, I would still keep it up there just because it is important" (S1, personal communication, 10 December 2015).

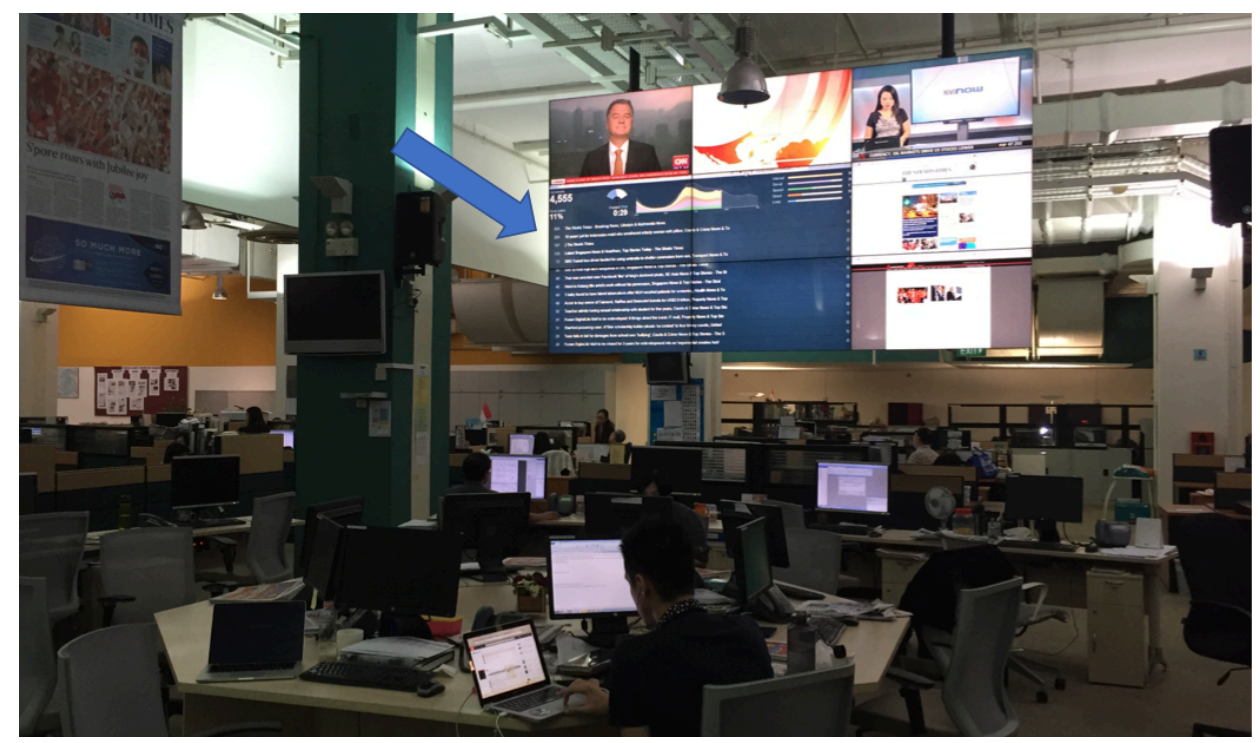

Figure 4.11 ST projects its website analytics (Chartbeat) onto a big screen in the middle of the newsroom.

For TMG, most of the journalists said they did not keep track of online news analytics. TMG's publisher explained that despite monitoring TMG's web and social media metrics, he did not factor them into his editorial decisions. He said: 
'It's only crucial if you're playing a numbers game. For us, it's a good-toknow. We don't serve traffic... the mission of journalism is not to generate traffic but to convey newsworthy information to readers" (T1, personal communication, 21 January 2016).

For TOC, its executive editor took an even more extreme view against the use of audience metrics:

“We don't bother. We only care about getting good stories out to our readers... I think that's the difference between us and the mainstream media. We are mostly funded by public donations, so we answer only to the public. The mainstream media has to sell advertisements, so they need to justify their numbers (O1, personal communication, 6 April 2016).

\subsection{New Characteristics of Journalism Convergence}

RQ2 asks what new characteristics are needed to explain journalism convergence in legacy mainstream organisations and digital news start-ups? This section answers this research question by identifying new traits exhibited by ST, TMG or TOC that were not discussed by the research literature.

\subsubsection{Proliferation of online news distribution channels}

All three newsrooms were found to have been increasing the number of online news diffusion channels.

For ST, at the time of this study, in addition to disseminating news on its websites, social media accounts, news app, email subscription service, and RSS feeds, it was exploring boosting the frequency of its news messaging service on the WhatsApp instant messaging app. The ST social media editor explained: 
"People nowadays are always going to consume news digitally. The question is whether your it's your brand, or someone else's... We need to continually invest in our online... and if we keep flooding the different online platforms with our news, we ensure ST remains the prominent brand..." (S1, personal communication, 10 December 2015).

Despite having less financial and human resources compared ST, both online news start-ups have been investing heavily in increasing the number of online channels via which they distribute news. At the time of this study, both digital news publications were already disseminating news on its websites, social media accounts, and RSS feeds. On top of those, TOC allowed readers to subscribe to a free email notification service every time a new story is published on its website, and TMG was considering offering a subscription-based daily email newsletter for its readers. However, the TMG publisher added that the various online channels were not only conduits for news distribution, but also different opportunities to engage its audience: "I don't see the new channels as just another platform to get the news out. I think they are new channels to engage readers on... There are new communication flows that exists in addition to the story itself, the story doesn't end with publishing it... So, we really need to be able to use all these available channels" (T1, personal communication, 21 January 2016).

\subsubsection{Leveraging on new digital communication tools}

Digital apps that allowed virtual group communication and the sharing of multimedia content featured prominently in the news production routines of the three newsrooms.

On top of the company's intranet messaging system, the ST journalists also relied on the Telegram app to communicate with each other, especially during 
breaking news events (as highlighted in point 4.1). Most of the ST staff agreed it has had a positive impact on the newsroom's efficiency. One of the reporters said ST started using Telegram during GE2015 as it had a desktop version that allowed its digital desk journalists to directly transfer multimedia content from the web application to ST's digital publishing software. He added it was a much more effective system than the previous one where information was exchanged only via email:

"People tend to miss their emails when there are too many. The good thing about Telegram is whenever you send updates there, everybody gets to see it... both print and digital. If someone misses it, someone else who saw it will shout out. It's easier for everyone to keep abreast of things and update stories accordingly" (S7, personal communication, 10 May 2016).

ST's digital editor further explained how Telegram was used by news editors to communicate with reporters when they were covering GE2015:

"During the GE, the editors talked very extensively on Telegram to the reporters on the ground and co-ordinate strategy, things like what should the reporter do, should he or she sit with the newsmaker, who to interview..." (S1, personal communication, 10 December 2015).

For TMG, its morning editorial meetings are conducted on a closed Facebook group as some of its staff work from home. Moreover, TMG's publisher said coordination for news production matters is always done via the closed Facebook group or the social media platform's chat function. Like ST, TMG's staff stress that such a method of online group communication helped minimise the amount of information that is overlooked and ensures that staff are kept updated about newsroom developments. 
For TOC, most of its staff, contributors and volunteers worked remotely and liaised and shared content with each other using a host of digital communication tools, including WhatsApp, Telegram, Facebook, SMS (short messaging service) and email. One of the TOC editors explained that during GE2015, most of the coordination between the editors and volunteers was done via WhatsApp, SMS and email (when the content was less time sensitive). She said:

"There was this big group, so you have it like in one big WhatsApp group...

[the volunteers] would send us their photos, videos and updates mostly on WhatsApp (O2, personal communication, 20 April 2016).

\subsubsection{Broadcasting live video news on websites and social media}

All three news organisations leveraged on the immediacy and video capabilities of social media and the Internet to deliver live breaking news. However, while TMG and TOC turned to social media, ST invested in sophisticated video broadcasting equipment to stream high-quality live footage via its website.

During GE2015, one of the TOC editors explained that they had asked a few volunteers to livestream video coverage of the election rallies via Periscope, an app that allows users to upload live video feeds using their mobile devices. She explained: "We thought it would be cool if TOC had livestreaming... we could be as fast as the mainstream media by going 'live'... but in the end, it didn't work out...we couldn't beat them. Theirs was professional and we realised there was no point in continuing as we didn't get a lot of followers. So halfway [through the GE], we dropped the idea (O2, personal communication, 20 April 2016). Likewise, TMG experimented with posting recorded "doorstop" (spontaneous) interviews with politicians on Facebook (Figure 4.12, next page). Like TOC, TMG's 
publisher also said that this was done to compete with the "live" news of the mainstream media:

"The broadcast media were crossing live all the time. Even ST had its Live Blog [a special General Election version of ST Now]... we had to try something new..." (T1, personal communication, 21 January 2016).

The news editor added:

“...Facebook and Twitter kind of became like, what I guess I could call mobile reporting that was 'live'...I would say we look at Facebook as an intermediary between the short, snappy bursts of reporting that was happening on Twitter, and the kind of deeper stories that we do on our website (T3, personal communication, 11 January 2016).
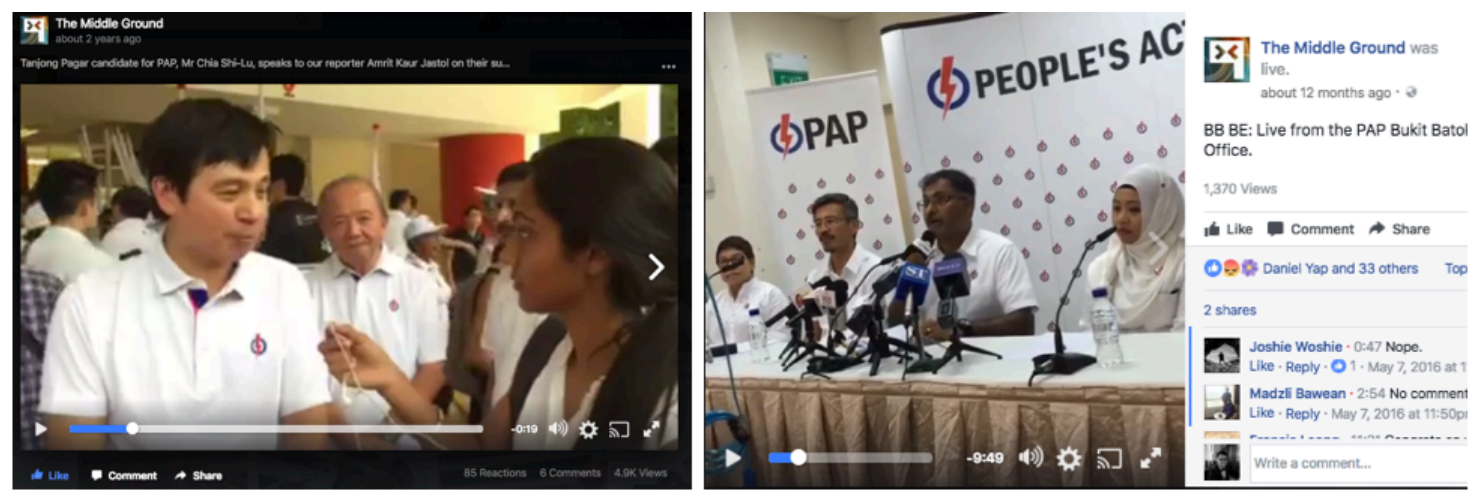

Figure 4.12 TMG's ‘doorstop' interview (left) on Facebook during GE2015, and its Facebook Live stream in May 2016.

The news editor also said that judging by the comments they had received on Facebook, the "experiment proved fruitful”. Later in May 2016, TMG covered a local constituency special election press conference and streamed a video of it on Facebook Live (Figure 4.12), which was only introduced by the social media company in April 2016 (Zuckerberg, 2016). 
Unlike TMG and TOC, ST did not use social media to stream live videos, but instead relied on its website and sophisticated video broadcasting equipment. During GE2015, ST devoted a significant amount of resources to its live video broadcasting capabilities hosted on its website. It had set up a microsite that livestreamed several election rallies over the Internet and, as per ST's videographer, had invested more than S\$60,000 in professional cameras and digital broadcasting equipment. He explained that ST was “doing [this] live thing, because nowadays, if you don't put more effort in going live, you will lose out because everybody is on it (S5, personal communication, 5 April 2016). ST's digital editor added that its video strategy online was key in competing with broadcast news during GE2015:

"One way we can match CNA [Channel News Asia, a Singapore TV news broadcaster] is through videos... First, we make sure all our reporters are comfortable shooting short videos and sending them back for the editors to push online... Then, we had our daily [political commentary] segments...not 'live' but close to real-time... and then we had our live coverage... we were able to flood social media and online with all these videos... Why? Because the thinking was: If I had the time to watch TV, I wouldn't be online" (S1, personal communication, 10 December 2015).

\subsubsection{Collaboration I: Co-producing content among online news start-ups}

During GE2015, while ST expanded its interactive digital graphics team, TMG and TOC both worked with external partners to include interactive features in their online articles. TOC's interactive GE2015 microsite was developed with another news website, The Vulcan Post, and a group of volunteers, of whom both did not charge TOC for their work. TMG included two interactive maps during its GE2015 coverage, of which one was a contribution by a data visualisation company (Figure 4.13). 


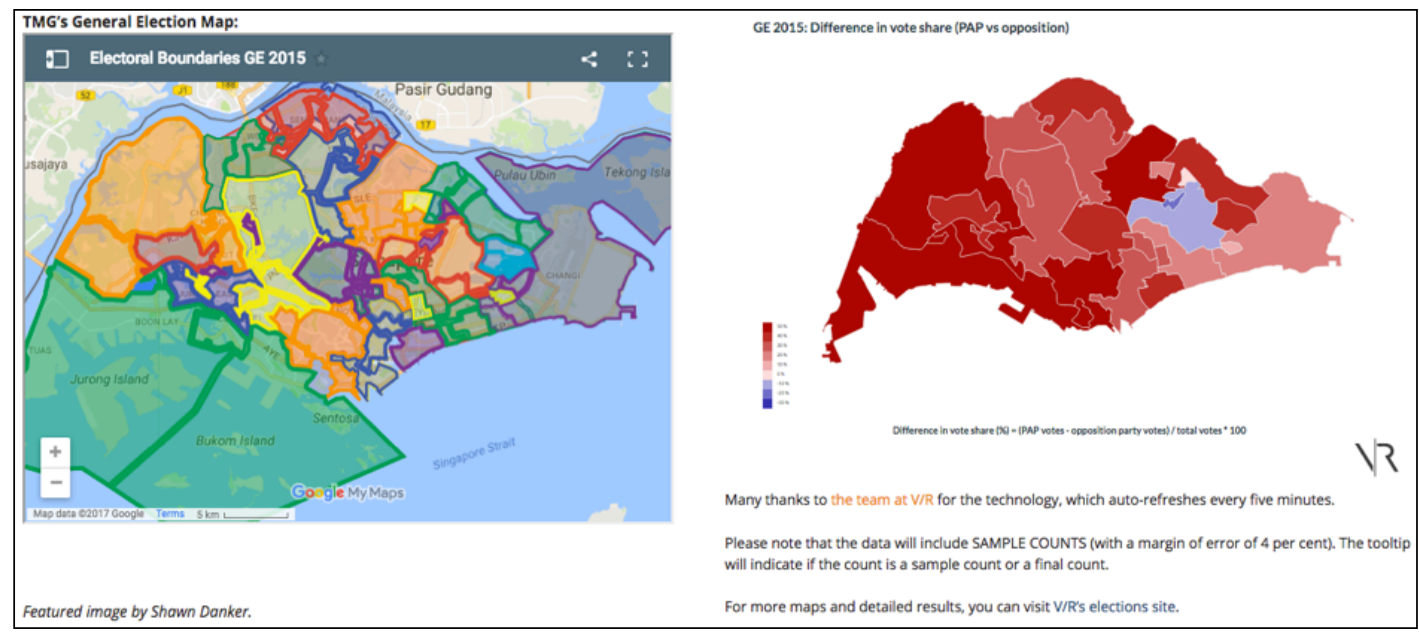

Figure 4.13 The only two interactive stories TMG featured during GE2015, of which one (right) was a contribution from a data visualisation company.

\subsubsection{Collaboration II: Pooling different media skills for multimedia content}

The TOC editors revealed that they usually had difficulties getting enough volunteers who were proficient in multimedia production during major news events, such as GE2015. The executive editor explained that in such cases, TOC would group volunteers who were proficient in different types of media together to produce a multimedia story. To illustrate, TOC had 16 volunteers who were divided into three teams to cover the election rallies during GE2015. According to one of the editors, each team had people who were only "good with videos, while others were more comfortable just taking photos, posting social media updates...or writing long-form articles" (O2, personal communication, 20 April 2016). She added that due to the volunteers' own schedules and preferences, members had to be rotated between teams over the election period. The editors acknowledged how this arrangement was not ideal as it made planning ad hoc and complicated, but also stressed that TOC "couldn't ask for the moon and the stars" (O3, personal communication, 20 April 2016) as it relied heavily on volunteers to ensure there was sufficient news content. 


\subsubsection{Collaboration III: Co-ordinating coverage}

On coordinating their news coverage during major events, TMG and TOC editors expressed interest in collaborating with other media organisations. TMG's publisher said that due to a lack staff, sharing resources was a feasible solution:

"We loathe to share a story with anyone else, that's just how journalism works... [but] given our limited resources, there could have been benefits from more sharing of content and coordinating our coverage. Sadly, not much was done (T1, personal communication, 21 January 2016).

TOC's executive editor added that working with other companies has always been TOC's approach:

"We're always open to collaborating... that's what makes TOC different from the mainstream media... But we've not come to a stage where there's detailed planning and coordination with other media for major stories and events" (O1, personal communication, 6 April 2016).

In contrast to the online news start-ups, most of the ST editors said cooperation with other news companies, even those owned by SPH, was something ST would not consider. The digital editor said that ST is "very competitive - internally, and with everybody" (S1, personal communication, 10 December 2015). He added that ST did not discuss details of how they planned to cover the GE with anyone else as it was not his newspaper's practice. 


\section{CHAPTER 5: DISCUSSION AND CONCLUSIONS}

This study in journalism convergence has two objectives. The first is to empirically examine the extent to which the updated multidimensional news convergence framework explain journalism convergence in both traditional mainstream newsrooms and digital news start-ups, given their differences in business operations and editorial practices (Atton, 2009; Carlson \& Usher, 2016; George, 2012; Usher, 2017). The second objective is to identify new characteristics of convergence in both types of news organisations in relation to the new digital climate.

To this end, this study is guided by a multidimensional framework (Infotendencias Group, 2012) and provides answers to the following research questions:

RQ1: Based on the multidimensional framework, what existing characteristics of journalism convergence may be observed in legacy news organisations and digital news start-ups?

RQ2: What new characteristics are needed to explain journalism convergence in legacy news organisations and digital news start-ups?

The answers to the RQs are based on a multiple-case study that includes indepth interviews with a total of 19 journalists from one legacy newsroom and two online news start-ups, and a content analysis of their online news articles.

\subsection{Relevance of the Multidimensional Framework}

In relation to RQ1, this study has found that except for one characteristic, all the traits identified by the multidimensional framework exist in the legacy news organisation (Table 5.1, next page). This result echoes Larrondo et al.'s (2014) 
observation that journalism convergence follows a similar basic pattern in news companies. 


\begin{tabular}{|c|c|c|c|c|}
\hline Dimension & Characteristic & ST & TMG & TOC \\
\hline \multirow{3}{*}{ 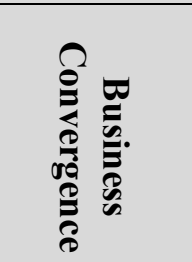 } & Centripetal & $\sqrt{ }$ & $\sqrt{ }$ & $\sqrt{ }$ \\
\hline & Centrifugal (horizontal) & $\sqrt{ }$ & $\sqrt{ }$ & $\sqrt{ }$ \\
\hline & Centrifugal (vertical) & & $\sqrt{ }$ & $\sqrt{ }$ \\
\hline 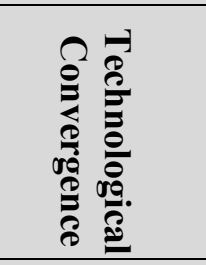 & $\begin{array}{l}\text { Multi-platform news } \\
\text { production and dissemination }\end{array}$ & $\sqrt{ }$ & $\sqrt{ }$ & $\sqrt{ }$ \\
\hline \multirow{2}{*}{ 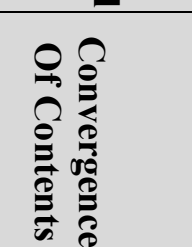 } & Multimedia news & $\sqrt{ }$ & $\sqrt{ }$ & $\sqrt{ }$ \\
\hline & $\begin{array}{l}\text { Sharing of content from } \\
\text { affiliated media brands }\end{array}$ & $\sqrt{ }$ & & \\
\hline \multirow{4}{*}{ 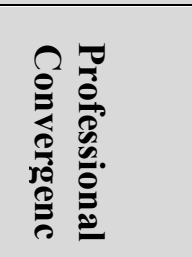 } & Polyvalence: Functional & $\sqrt{ }$ & $\sqrt{ }$ & $\sqrt{ }$ \\
\hline & Polyvalence: Thematic & $\sqrt{ }$ & $\sqrt{ }$ & $\sqrt{ }$ \\
\hline & Polyvalence: Media & $\sqrt{ }$ & $\sqrt{ }$ & $\sqrt{ }$ \\
\hline & Positive towards polyvalence & $\sqrt{ }$ & $\sqrt{ }$ & $\sqrt{ }$ \\
\hline \multirow{5}{*}{ 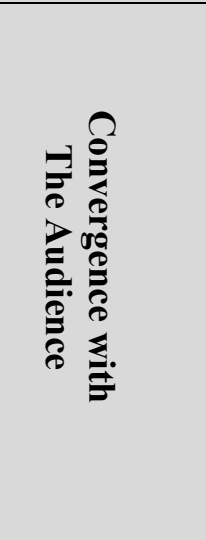 } & $\begin{array}{l}\text { Using social media to involve } \\
\text { readers in news construction }\end{array}$ & $\sqrt{ }$ & $\sqrt{ }$ & $\sqrt{ }$ \\
\hline & $\begin{array}{l}\text { Using social media to directly } \\
\text { engage readers }\end{array}$ & $\sqrt{ }$ & $\sqrt{ }$ & $\sqrt{ }$ \\
\hline & $\begin{array}{l}\text { Including social media sharing } \\
\text { functions on websites' articles }\end{array}$ & $\sqrt{ }$ & $\sqrt{ }$ & $\sqrt{ }$ \\
\hline & $\begin{array}{l}\text { Embedding readers' social } \\
\text { media posts in web stories }\end{array}$ & $\sqrt{ }$, but low & $\sqrt{ }$, but low & $\sqrt{ }$, but low \\
\hline & $\begin{array}{l}\text { Use of analytics as an indirect } \\
\text { audience engagement tool }\end{array}$ & $\sqrt{ }$ & & \\
\hline
\end{tabular}

Table 5.1 Existing Characteristics of Journalism Convergence in ST, TMG and TOC

The findings show that The Straits Times (ST) did not display vertical, Centrifugal Business Convergence, which describes how media conglomerates invest in businesses present throughout the value chain of the media industry (Infotendencias Group, 2012). This thesis suggests that the legacy newspaper did not exhibit this trait because it was not part of its business strategy. Vertical diversification was the responsibility of its parent company Singapore Press Holdings. 
The findings (Table 5.1) indicate that most of the traits outlined by the multidimensional framework were present in both online news start-ups, The Middle Ground (TMG) and The Online Citizen TOC). This runs contrary to the criticisms of the framework that propose news start-ups have little or no similarities with legacy media organisations (Manifred \& Artero, 2014).

However, despite sharing similar characteristics, the findings indicate that there are nuanced differences in certain specific practices. According to Konieczna (2014), online news start-ups have limited resources and thus may display dissimilar norms from established legacy newsrooms. This appears to be the case in this study and may be observed in the following instances: Firstly, although all three organisations displayed Centripetal Business Convergence, ST had the benefit of channelling its financial and human resources from its newspaper operations to its online department and simultaneously expand its digital capabilities. The online-only publishers TMG and TOC, however, focused all their resources on the digital platform from the beginning of their operations. Secondly, even though all three companies exhibited horizontal Centrifugal Business Convergence, ST possessed the resources to publish on both the print and online platforms, while TMG and TOC did not have the financial capability to own traditional media platforms. Instead, they practiced another form of horizontal Centrifugal Business Convergence not explained by the literature by diversifying their online news dissemination channels and increasing the amount of multimedia content they distributed via those channels. Thirdly, despite all three newsrooms exhibiting Technological Convergence, ST introduced an integrated multiplatform publishing workflow, while TMG and TOC only had resources to publish online and hence, introduced a workflow that rationalised and prioritised multiple online news dissemination channels. Fourthly, while all three firms 
demonstrated thematic polyvalence, ST had a sizable newspaper team and as such, afforded each print journalist to only specialise in two or three topics. Contrastingly, TMG hired just six full-time journalists, which meant each reporter had to cover more topics; while TOC had a maximum of four editors and relied on volunteers to produce content.

In relation to using news analytics as an indirect audience engagement tool, it was found that ST's editors relied on both analytics and their editorial judgement when deciding whether readers would be interested in their stories. Both digital news start-ups, however, stressed they only relied on their judgement in determining the importance of stories. This finding is antithetic to studies that have emphasised how analytics is playing an increasingly important role in the editorial work of both legacy newsrooms and news start-ups (Cherubini \& Nielson, 2016).

\subsection{New Characteristics of Convergence}

Scholars and journalists agree that that the future of news will involve a battle between the legacy media and online news start-ups that will be waged on the digital front (Belam, 2010; Gold, 2012; Jewell, 2016). Through investigating the new characteristics of journalism convergence in the news companies that were not identified by this study's framework (Table 5.2, next page), this study found one common theme - a strategic focus on enhancing digital news capabilities. 


\begin{tabular}{|l|c|c|c|}
\hline & ST & TMG & TOC \\
\hline $\begin{array}{l}\text { Proliferation of online news } \\
\text { distribution channels }\end{array}$ & $\sqrt{ }$ & $\sqrt{ }$ & $\sqrt{ }$ \\
\hline $\begin{array}{l}\text { Leveraging on new digital } \\
\text { communication apps in news work }\end{array}$ & $\sqrt{ }$ & $\sqrt{ }$ & $\sqrt{ }$ \\
\hline $\begin{array}{l}\text { Broadcasting live video news on } \\
\text { websites and social media }\end{array}$ & $\sqrt{ }$ & $\sqrt{ }$ \\
\hline $\begin{array}{l}\text { Collaboration I: Co-producing content } \\
\text { with external partners and volunteers }\end{array}$ & & & $\sqrt{ }$ \\
\hline $\begin{array}{l}\text { Collaboration II: Pooling different } \\
\text { media skills to produce multimedia } \\
\text { content }\end{array}$ & & $\begin{array}{l}\text { Keen to } \\
\text { explore }\end{array}$ & $\begin{array}{l}\text { Keen to } \\
\text { explore }\end{array}$ \\
\hline $\begin{array}{l}\text { Collaboration III: Coordination of } \\
\text { coverage with external partners during } \\
\text { major news events }\end{array}$ & & & \\
\hline
\end{tabular}

Table 5.2 New Characteristics of Journalism Convergence in ST, TMG and TOC

The literature highlights that single-medium news organisations are rapidly expanding their operations to include multiple platforms and multiple media (Infotendencias Group, 2012). The findings indicate that all three news organisations, however, were mainly focused on proliferating their news dissemination channels on the digital platform to reach more audiences. The use of channels such as Facebook, Twitter and WhatsApp to distribute news was also an effort by the newsrooms to maximise social media sharing and discussion of their articles and, in turn, boost their online presence and promote audience participation - albeit to different degrees - in their journalism.

The findings show that digital apps that allowed virtual, instantaneous group communication and the sharing of multimedia content featured prominently in the production routines of the three newsrooms. The use of multimedia-enabled, mobile communication apps by journalists in news production was a new aspect of convergence that had transformed the way they coordinated and communicated with 
their team members. It also aided and facilitated the production of simple multimedia content. These virtual chat groups also gave the junior staff an opportunity to conveniently tap on the professional knowledge of the more experienced journalists and editors within the company.

The material shows that all three newsrooms have made attempts to enhance their journalism by live streaming news online. However, their approaches were starkly different. During the Singapore General Election in 2015 (GE2015), the online news start-ups turned to social media's relatively new live online streaming functions (Lewis \& Dahmen, 2017), but the legacy newspaper invested in sophisticated broadcasting equipment that allowed them to live stream high-quality videos via its website.

Scholars observe that news start-ups exhibit a collaborative culture that sees news workers co-produce content with members of the public and other news professionals from other organisations (Deuze \& Witschge, 2017; Naldi \& Picard, 2012). This is the case for TOC and TMG. The findings show that to overcome the challenge of limited resources, both news start-ups collaborated with data visualisation companies to produce interactive electoral maps during GE2015. Furthermore, TOC worked with another media company to co-produce a microsite to host GE2015 news content, and pooled volunteers with different media production skills together to produce multimedia content. The editors of both digital news start-ups also showed interest in coordinating their resources with other news outlets to cover major news events, although this had not happened during the time of this study. In contrast, the legacy news organisation remained mainly protectionistic and guarded when it came to the sharing and coordinating of its resources, even with its own affiliated media brands under SPH. 
Furthermore, the study also shows that characteristics of convergence are not homogenous among online news start-ups. TMG hires full-time journalists and functions like a professional newsroom, whereas TOC relies on volunteers to contribute content and cover news events. During GE2015, they resourcefully gathered volunteers who were proficient in different types of media production and grouped them together to produce multimedia content. The existence of these discrepancies between both online news outfits comply with Menke et al.'s (2016) conclusion that convergence in each newsroom may be different as they are influenced by different cultural and contextual factors.

\subsection{Contributions to Research}

Current literature on convergence largely focuses on legacy news media and gives less attention to news start-ups. Additionally, journalism research on convergence in Singapore newsrooms is relatively under-represented. This study sheds more light on the multifaceted phenomenon of journalism convergence in several ways.

Firstly, it empirically extends our understanding of the multidimensional approach by applying it to the investigation of journalism convergence in online news start-ups and legacy media organisations. It may be concluded that as most of the dimensions of framework may be observed in both types of newsrooms, it remains a relevant approach to guide convergence research and it is not an overly simplistic typology as noted by its critics (Konieczna, 2014; Manfredi \& Artero, 2014). However, convergence processes in every news organisation are complex, unique and not homogenous. As discovered by this study, nuanced dissimilarities exist despite the similar characteristics of journalism convergence shared by the three news 
organisations. As such, future studies would do well to rely on the framework as a potential guide to facilitate research but still allow for the uncovering of subtle differences, plus new and distinctive processes of convergence.

Secondly, it makes a theoretical contribution to study of news convergence by including the dimension of Convergence with The Audience in the multidimensional approach. This dimension is crucial as it analyses the myriad ways that both legacy news organisations and online news start-ups are using digital tools, such as social media and editorial analytics, to understand and engage their online audiences, and promote their journalism.

Thirdly, the new dimensions of journalism convergence that have been observed by this research - and left unidentified by the multidimensional framework bolster our understanding of how both traditional news companies and start-ups are altering their news practices and deploying their resources to meet the demands of the ever-evolving digital news environment. These new characteristics, including the emphasis placed on the proliferation of digital channels of news dissemination; the adoption of new digital communication tools for journalists; a greater emphasis on video and live coverage of news events; and greater collaboration between news startups to overcome staffing and resource limitations, add even more depth to the already multifaceted definition of journalism convergence.

In the application to the profession of journalism, this study contributes to the understanding that journalists and news managers have towards the changes in their field. This enables them to better position their organisations and themselves to navigate the challenges of a digital-first future. It also serves as an important source of information for policy and strategic decision-making in media management, 
particularly on how resources may be best utilised to support the growth of digital capabilities.

\subsection{Limitation and Future Studies}

Firstly, the findings in this study cannot be generalised to all legacy news organisations and digital news start-ups. This research is explorative and largely qualitative in nature, and focused on three newsrooms in one location. Singapore's press system is idiosyncratic (Duffy, Tandoc \& Ling, 2017; Lau, Lin \& Low, 2013) and the dimensions of journalism convergence observed in these three cases may vary across media organisations under different contexts. Despite this limitation, the findings of this study contribute to the limited research done on journalism convergence in digital news start-ups, especially in Singapore. Moreover, the exploratory approach to this study allowed it to uncover additional dimensions of news convergence, providing a richer understanding of the phenomenon.

Secondly, the number of interviewees from each news company varied greatly. The case of ST had 10 interviewees, while TMG had 6 and TOC had 3. This imbalance may be attributed to the small workforce of both online news start-ups. Despite this limitation, the total number of interviewees in this study provides a sufficient sample size to go beyond simple anecdotal evidence and develop adequate analytical power and uncover empirical relationships to understand the phenomenon in detail. For such interview-based research, Kvale's (1996) recommends between 10 to 15 participants.

Thirdly, in researching legacy news organisations, this study only focused on one newspaper and did not include a traditional news broadcaster due to reasons of access. The dynamics of convergence may influence newspapers and broadcast media 
differently. For future research, comparative studies across legacy newsrooms that operate on different mediums can be done to better understand how convergence impacts traditional media organisations.

Another area of study could deep-dive into investigating the similarities and differences in how social media has influenced legacy newsrooms and online news start-ups, which was not fully discussed here. 


\section{REFERENCES}

Anderson, C. W. (2011). Between creative and quantified audiences: Web metrics and changing patterns of newswork in local US newsrooms. Journalism, 12(5), 550566. http://doi.org/10.1177/1464884911402451

Anderson, C. W. (2011b). Deliberative, agonistic, and algorithmic audiences: Journalism's vision of its public in an age of audience transparency. International Journal of Communication, 5, 19. http://doi.org/1932-8036/20110529

Appelgren, E. (2004). Convergence and divergence in media: Different perspectives. Elpub 2004 - 8th International Conference on Electronic Publishing. June 2326, 2004, Brasilia, Brazil, (pp. 237 - 248).

Atton, C. (2009). Alternative and citizen journalism. In Jorgensen, K., \& Hanitzsct, T. (Eds.) The Handbook of Journalism Studies (pp. 265-278). New York: Routledge.

Baxter, P., \& Jack, S. (2008). Qualitative case study methodology: Study design and implementation for novice researchers. Qual Rep, 13(4), 544-559. Retrieved from http://nsuworks.nova.edu/tqr/vol13/iss $4 / 2$

Belam, M. (2010, 14 April). Journalism in the digital age: trends, tools, technologies. The Guardian. Retrieved from https://www.theguardian.com/help/insideguardian/2010/apr/14/journalism-trendstools-technologies

Boczkowski, P. J. (2004), The processes of adopting multimedia and interactivity in three online newsrooms. Journal of Communication, 54(2), 197-213. http://doi:10.1111/j.1460-2466.2004.tb02624.x

Boyles, J. L. (2016). The Isolation of Innovation: Restructuring the digital newsroom through intrapreneurship. Digital Journalism, 4(2), 229-246. http://doi.org/10.1080/21670811.2015.1022193

Bruno, N. \& Nielsen, R. K. (2012). Survival is Success: Journalistic Online Start-ups in Western Europe, (pp. 15-39). Oxford, UK: Reuters Institute for the Study of Journalism. Retrieved from https://reutersinstitute.politics.ox.ac.uk/sites/default/files/Survival $\% 20$ is $\% 20$ Succ ess \%20Journalistic\%20Online\%20StartUps\%20in\%20Western\%20Europe_0.pdf

Carlson, M., \& Usher, N. (2016). News start-ups as agents of innovation. Digital Journalism, 4(5), 563-581. http://doi.org/10.1080/21670811.2015.1076344

Cottle, S. \& Ashton, M. (1999). From BBC newsroom to BBC newscentre: On changing technology and journalist practices. Convergence 5(3), 22-43. 
Cherubini, F. \& Nielsen, R. K. (2016). Editorial analytics: How news media are developing and using audience data and metrics. Reuters Institute for the Study of Journalism Digital News Project 2016. Retrieved from http:/digitalnewsreport.org/publications/2016/editorial-analytics-2016/

Chew, H. H. (2015, September 1). GE2015: Opposition set to challenge PAP in all 29 electoral divisions. The Straits Times. Retrieved from http://www.straitstimes.com/politics/ge2015-opposition-set-to-challenge-pap-inall-29-electoral-divisions

Chua, S. (2017, November 17). Beating the 404 death knell: Singapore news startups struggle to conver costs and find their footing. Nieman Lab. Retrieved from http://www.niemanlab.org/2017/11/beating-the-404-death-knell-singapore-newsstartups-struggle-to-cover-costs-and-find-their-footing/

Chyi, H. I., \& Lee, A. M. (2013). Online news consumption. Digital Journalism, 1(2), 194-211. http://doi.org/10.1080/21670811.2012.753299

Corbin, J. \& Strauss, A. (2015). Basics of qualitative research: Techniques and procedures for developing grounded theory, $4^{\text {th }}$ edition, (pp. 57-84). Thousand Oaks, California: Sage Publications

Dailey, L., Demo, L., \& Spillman, M. (2005). The convergence continuum: A model for studying collaboration between media newsrooms. Atlantic Journal of Communication, 13(3), 150-168. doi:10.1207/s15456889ajc1303_2

Deuze, M. (2017). Considering a possible future for digital journalism. Mediterranean Journal of Communication, 8(1), 9-18. http://doi.org/https://www.doi.org/10.14198/MEDCOM2017.8.1.1

Deuze, M., \& Witschge, T. (2017). Beyond journalism: Theorizing the transformation of journalism. Journalism, 146488491668855. http://doi.org/10.1177/1464884916688550

Dickinson, R., Matthews, J., \& Saltzis, K. (2013). Studying journalists in changing times. International Communication Gazette, 75(1), 3-18. http://doi.org/10.1177/1748048512461759

Domingo, D., Salaverria, R., Aguado, J., et al. (2007). Four dimensions of journalistic convergence: A preliminary approach to current media trends at Spain. In: 8th International Symposium on Online Journalism. Available at: online.journalism.utexas.edu/2007/papers/Domingo.pdf.

Domingo, D. (2008). Inventing online journalism: A constructivist approach to the development of online news. In Paterson, C. \& Doming, D. (Eds.), Making Online News, pp.15-28. New York: Peter Lang.

Doudaki, V., \& Spyridou, L. P. (2014). News content online: Patterns and norms under convergence dynamics. Journalism, 1464884913517657-. doi:10.1177/1464884913517657 
Drula, G. (2015). Forms of media convergence and multimedia content: A Romanian Perspective. Comunicar, 22(44), 131-140. http://doi.org/10.3916/C44-2015-14

Duffy, A., Tandoc, E. C., \& Ling, R. (2017). Frankenstein journalism. Information, Communication \& Society, 4462(April), 1-15. http://doi.org/10.1080/1369118X.2017.1313884

Edge, M. (2004). Pie sharing for food fight? The impact of regulatory changes on media market competition in Singapore. The International Journal on Media Management, 6(3/4), 184-193. DOI: 10.1207/s14241250ijmm0603\&4_7

Erdal, I. (2007). Researching media convergence and cross-media news production: Mapping the field. Nordicom Review, 28, 51-61. Retrieved from http://www.nordicom.gu.se/common/publ_pdf/255_erdal.pdf

Erdal, I. (2011). Coming to Terms with Convergence Journalism: Cross-Media as a Theoretical and Analytical Concept. Convergence: The International Journal of Research into New Media Technologies, 17, 213-223. doi:10.1177/1354856510397109

Eisenhardt, K. M., \& Graebner, M. E. (2007). Theory building from cases: Opportunities and challenges. The Academy of Management Journal, 50(1), 2532. doi: $10.2307 / 20159839$

Fernandez, W. (2015, July 5). Ready to ride wave of change. The Straits Times, Singapore Press Holdings. Retrieved from http://www.straitstimes.com/singapore/ready-to-ride-wave-of-change

García-Avilés, J. A., \& Carvajal, M. (2008). Integrated and cross-media newsroom convergence two models of multimedia news production: The cases of Novotécnica and La Verdad multimedia in Spain. Convergence: The International Journal of Research into New Media Technologies, 14(2), 221-239.

García-Avilés, J. A., Kaltenbrunner, A., \& Meier, K. (2014). Media convergence revisited: Lessons learned on newsroom integration in Austria, Germany and Spain. Journalism Practice, 2786(June), 1-12. http://doi.org/10.1080/17512786.2014.885678

García-Avilés, J. A., Masip, P., Salaverria, R. Sadaba, C., Portilla, I., \& Saad, B. (2007). In Palacios, M., \& Díaz-Noci, J. (Eds.), Online journalism: Research methods. A multi-disciplinary approach in comparative perspective (pp. 111129). Bilbao, Spain: Servicio Editorial de la. Retrieved from http://www.ehu.es/argitalpenak/images/stories/libros_gratuitos_en_pdf/Ciencias_ Sociales/Online Journalism Research methods.pdf

García-Avilés, J. A., Meier, K., \& Kaltenbrunner, A. (2017). Converged media content: Reshaping the 'legacy' of legacy media in the online scenario. In Franklin, B. \& Eldrige II, S. A. (Eds.), The Routledge Companion to Digital Journalism Studies (pp. 556-566). New York: Routledge. 
George, C. (2012). Alternative online media: Challenging the gatekeepers. In Freedom from the press: journalism and state power in Singapore (pp. 158-182).

Singapore: NUS Press.

George, C. (2016). Legal landmines and OB markers: Survival strategies of alternative media. In Tan, T. H., Mahizhnan, A., \& Ang, P. H. (Eds.), Battle for Hearts and Minds: New Media and Elections in Singapore (pp. 201-226). Chicago: World Scientific.

Goh, D. (2017). Country report: Digital news sites and social media services serve as Singapore's primary sources of news, with three-quarters of the country accessing news through smartphone. In Newman, N., Fletcher, R., Kalogeropoulous, A., Levy, D. \& Nielsen, R. K. (Eds.), Reuters Institute Digital News Report 2017 (pp. 124-125). Retrieved from http://www.digitalnewsreport.org/survey/2017/singapore-2017/

Goh, D. \& Pang, N. (2012). Online and ontrack? Political parties' use of websites and Facebook during Singapore's 2011 General Elections. Paper presented at the International Communication Association (ICA), 24 - 28 May, 2012, Phoenix, Arizona.

Gold, K. J. (2012). The future of print in a digital world. PriceWaterhouseCoopers. Retrieved from http://upfront.pwc.com/risk/255-future-print-digital-world

Gordon, R. (2003). The meanings and implications of convergence. In Kawamoto, K. (Ed.), Digital journalism: Emerging media and the changing horizons of journalism (pp. 57-73). New York: Rowman \& Littlefield Publishers Inc.

Hare, K. (2016, May 24). We're starting to see a new blueprint for reinventing legacy newsrooms. Poynter. Retrieved from http://www.poynter.org/2016/were-startingto-see-a-new-blueprint-for-reinventing-legacy-newsrooms/413251/

Henson, B. (2015, June 11). Feet firmly planted on the ground [Blog post]. Retrieved from https://berthahenson.wordpress.com/2015/

Hicks, R. (2015a, December 7). The Online Citizen breaks away from fund-raising arm The Opinion Collaborative. Mumbrella Asia. Retrieved from https://www.mumbrella.asia/2015/12/the-online-citizen-breaks-away-fromfund-raising-arm

Hicks, R. (2015b, February 16). The Online Citizen crowdfunds journalists to cover Singapore elections. Mumbrealla Asia. Retrieved from https://www.mumbrella.asia/2015/02/online-citizen-crowdsources-journalistscover-singapore-elections

Holt, J. (2011). Empires of entertainment: Media industries and the politics of deregulation, 1980-1996, (pp. 165-170). New Brunswick: Rutgers University Press 
Infotendencias Group. (2012). Media Convergence. In Siapera, E. \& Veglis, A. (Eds.), The Handbook of Global Online Journalism, (pp. 21-38). West Sussex, UK: John Wiley \& Sons, Inc.

Jenkins, H. (2004). The cultural logic of media convergence. International Journal of Cultural Studies, 7(1), 33-43. http://doi.org/10.1177/1367877904040603

Jenkins, H. (2006). Convergence culture. New York: New York University Press.

Jenkins, H. (2014). Rethinking "rethinking convergence/culture". Cultural Studies, 28(2), 267-298.

Jewell, J. (2016, 16 February). The future is digital - let's hope the online-only Independent will be part of it. The Conversation. Retrieved from $\mathrm{http}$ ://theconversation.com/the-future-is-digital-lets-hope-the-online-onlyindependent-will-be-part-of-it-54786

Kamalipour, Y., \& Friedrichsen, M. (2017). Introduction: Digital transformation in a global world. In Friedrichsen, M. \& Kamalipour, Y. (Eds.), Digital Transformation in Journalism and News Media: Media Management, Media Convergence and Globalization, (pp. 1-4). Cham: Swizterland: Springer International Publishing

Karlsson, M., \& Sjøvaag, H. (2016). Introduction. Digital Journalism, 4(1), 1-7. http://doi.org/10.1080/21670811.2015.1096595

Keshvani, N. (2000a). The Integrated Newsroom: The changing face <phase $>$ of news journalism as we know it. Paper presented at the International Association of Mass Communication Research (IAMCR) Communication Beyond 2000 Conference, 17 - 20 July, 2000, Singapore.

Keshvani, N. (2000b). Trends in the online newsroom: A study of The Straits Times Interactive. Asia Pacific Media Educator, 1(9), 106-118. Retrieved from $\mathrm{http} / / /$ ro.uow.edu.au/apme/vol1/iss9/8

Karmasin, M., Diehl, S., \& Koinig, I. (2016). Convergent business environments: Debating the need for new business models, organizational structures and management respectively employee competencies. In Lugmayr A. \& Dal Zotto, C. (Eds.), Media Convergence Handbook Vol. 2: Firms and User Perspectives (pp. 49-68). Berlin, Heidelberg: Springer Berlin Heidelberg. http://doi.org/10.1007/978-3-642-54487-3_4

Kolodzy, J., Grant, A. E., DeMars, T. R., \& Wilkinson, J. S. (2014). The convergence years. Journalism \& Mass Communication Educator, 69(2), 197-205. http://doi.org/10.1177/1077695814531718

Konieczna, M. (2013). Do old norms have a place in new media? Journalism Practice, 8(1), 1-16. http://doi.org/10.1080/17512786.2013.793511 
Kumar, K. J., \& Thomas, A. O. (2006). Telecommunications and development: The cellular mobile 'revolution' in India and China. Journal of Creative Communications, 3(1), 297-309.

Kvale, S. (1996). Interviews: An Introduction to Qualitative Research Interviewing (pp. 83-105). Thousand Oaks, California: Sage Publications

Lawson-Borders, G. L. (2005). Media organisations and convergence: Case studies of media convergence pioneers (pp. 43-64). New York: Lawrence Erlbaum Associates

Lau, J. N., Lin T., \& Low, M. M. (2013). Mapping digital media: Singapore (A country report). Open Society Foundations. Retrieved from https://www.opensocietyfoundations.org/sites/default/files/mapping-digitalmedia-singapore-20131017_0.pdf

Larrondo, A., Domingo, D., Erdal, I. J., Masip, P., \& Van den Bulck, H. (2014). Opportunities and limitations of newsroom convergence. Journalism Studies. doi: 10.1080/1461670X.2014.977611

Larrondo, A. Erdal, I. J., Masip, P. \& Van den Bulck, H. (2017). Newsroom convergence: A comparative study of European public service broadcasting organizations in Scotland, Span, Norway and Flemish Belgium. In Franklin, B. \& Eldrige II, S. A. (Eds.), The Routledge Companion to Digital Journalism Studies (pp. 556-566). New York: Routledge.

Lee, T. (2015). The pragmatics of change: Singapore's 2015 General Election. In Lee, T. \& Tan, K. (Eds.), Change In Voting: Singapore 2015 General Election (pp. 925). Ethos Books: Singapore.

Lee-Wright, P. (2010). Culture shock: New media and organizational change in the BBC. In N. Fenton (Ed.), New Media, Old News: Journalism \& Democracy in the Digital Age (pp. 71-86). Thousand Oaks, California: Sage.

Lewis, S. \& Dahmen, N. S. (2017, February 8). What Facebook Live means for journalism. The Conversation. Retrieved from http://theconversation.com/whatfacebook-live-means-for-journalism-72233

Lin, T. (2012). Multi-skilling as a solution? Changing workflow and journalistic practice and the implication for international news. In Clarke, J. \& Bromley, M. (Eds.), International News in the Digital Age: East-West Perceptions of A New World Order (pp. 90-109). New York: Routledge.

Martins, E. (2015). Convergence and transmedia storytelling in journalism: Transformations in professional practices and profiles. Brazilian Journalism Research, 11(2 EN), 168-187. Retrieved from http://bjr.sbpjor.org.br/bjr/article/view/851

Manfredi, J. L., \& Artero, J. P. (2014). New business models for the media: The Spanish case. In E. Psychogiopoulou (Ed.), Media Policies Revisited: The 
Challenge for Media Freedom and Independence (pp. 160-174). London: Palgrave Macmillan UK. http://doi.org/10.1057/9781137337849_12

Meier, K., Bracker, I., \& Verhovnik, M. (2017). Technological innovation and convergent journalism: Case study on the transformation process of Bavaria's public broadcasting service. Mediterranean Journal of Communication, 8, 33-44.

Menke, M., Kinnebrock, S., Kretzschmar, S., Aichberger, I., Broersma, M., Hummel, R., ... Salaverría, R. (2016). Convergence Culture in European Newsrooms. Journalism Studies, 1-24. http://doi.org/10.1080/1461670X.2016.1232175

Mico, J. L., Masip, P., \& Domingo, D. (2013). To wish impossible things: Convergence as a process of diffusion of innovations in an actor-network. International Communication Gazette, 75(1), 118-137. http://doi.org/10.1177/1748048512461765

Mitchelstein, E., \& Boczkowski, P. J. (2009). Between tradition and change: A review of recent research on online news production. Journalism, 10(5), 562-586. doi: $10.1177 / 1464884909106533$

Morse, J. (2004). Theoretical saturation. In Lewis-Beck M. S., Bryman A. \& Liao T. F. (Eds.), The SAGE Encyclopedia of Social Science Research Methods (Vol. 3, pp. 1123-1123). Thousand Oaks, California: SAGE Publications Ltd. doi: 10.4135/9781412950589.n1011

Naldi, L., \& Picard, R. G. (2012). "Let's start an online news site": Opportunities, resources, strategy, and formational myopia in startups. Journal of Media Business Studies, 9(4), 69-97. http://doi.org/10.1080/16522354.2012.11073556

Nurmis, J. (2014). Reporting on international climate negotiations: A test run for global journalism. In AEJMC Midwinter Conference 2014: International Communication Division. Retrieved from https://www.academia.edu/8423739/Reporting_on_international_climate_negotia tions_a_test_run_for_global_journalism

Oliver, S., \& Ostwald, K. (2017). Explaining elections in Singapore: One-party dominance and valence politics. Paper presented at the American Political Science Association (APSA) Conference, 1 - 4 September, 2016, Philadelphia, Pennsylvania. Retrieved from https://ssrn.com/abstract $=2899285$

Pavlik, J. V. (1996). New Media Technology: Cultural and Commercial Perspectives (pp. 120-136). Boston, MA: Allyn and Bacon.

Pavlik, J. V. (1999). New Media and News: Implications for the Future of Journalism. New Media \& Society, 1(1), 54-59. http://doi.org/10.1177/1461444899001001009

Pew Research Center. (2012, March 19). State of the news media 2012. Retrieved from http://www.pewresearch.org/2012/03/19/state-of-the-news-media-2012/ 
Picard, R. G. (2014). Twilight or new dawn of journalism? Digital Journalism, 2(3), 273-283. http://doi.10.1080/21670811.2014.895531

Quandt, T. \& Singer, J. (2009). Convergence and cross-platform content production. In Jorgensen, K., \& Hanitzsct, T. (Eds.) The Handbook of Journalism Studies (pp. 130-144). New York: Routledge.

Raviola, E., \& Hartmann, B. (2009). Business perspectives on work in news organizations. Journal of Media Business Studies, 6(1), 7-36. http://doi.org/10.1080/16522354.2009.11073477

Reuters Institute. (2012). Digital news report 2012: Tracking the future of news. Retrieved from http://reutersinstitute.politics.ox.ac.uk/sites/default/files/Digital\%20News\%20Re port $\% 202012$.pdf

Reuters Institute. (2017). Digital news report 2017. Retrieved from https://reutersinstitute.politics.ox.ac.uk/sites/default/files/Digital\%20News\%20Re port $\% 202017 \% 20$ web_0.pdf

Risen, T. (2014, 21 April). As journalism evolves, start-ups pick up the pieces. U.S. News \& World Report. Retrieved from https://www.usnews.com/news/articles/2014/04/21/vox-thunderdome-and-theevolution-of-journalism-startups

Salaverria, R. (2012, September). Media convergence revisited: Understanding the multi-level impact of digital technologies in news organisations. Paper presented at the International Conference on Matters of Journalism: Understanding Professional Challenges and Dilemmas, Warsaw, Poland. Abstract retrieved from https://www.academia.edu/1933596/Media_Convergence_Revisited_Understandi ng_the_Multi-Level_Impact_of_Digital_Technologies_in_News_Organizations

Saldana, J. (2009). The coding manual for qualitative researchers. Thousand Oaks, California: Sage.

Salleh, N. A. M. (2015, 2 May). Political websites creating a buzz in Singapore. The Straits Times. Retrieved from http://www.straitstimes.com/singapore/politicalwebsites-creating-a-buzz-in-singapore

Samsudin, N. (2017, 11 September). Our shrinking political blogging scene. IPS Commons. Retrieved from https://www.ipscommons.sg/our-shrinking-politicalblogging-scene/

Scolari, C. A., Navarro, H., Pardo, H., \& Mico, J. L. (2007). The new professional profiles and multiskilling of journalists in Catalonia: A map of the situation. Quaderns del CAC, 27(Jan-Apr), 111-120.

Soon, C. \& Samsudin, N. (2016). General Election 2015 in Singapore: What social media did and did not do. The Round Table, 105(2), 171-184. http://doi.org/10.1080/00358533.2016.1154388 
Steensen, S. (2011). Online journalism and the promises of new technology, Journalism Studies, 12(3), 311-327. http://doi.org/10.1080/1461670X.2010.501151

Spyridou, L. P., Matsiola, M., Veglis, A., Kalliris, G., \& Dimoulas, C. (2013). Journalism in a state of flux: Journalists as agents of technology innovation and emerging news practices. International Communication Gazette, 75(1), 76-98. http://doi.org/10.1177/1748048512461763

Spyridou, L.P., \& Veglis, A. (2016). Convergence and the changing labor of journalism: Towards the "super journalist" paradigm. In Lugmayr, A. \& Zotto, C. (Eds.), Media convergence handbook: Media business and innovation (Vol. 1, pp. 249-264). http://doi.org/10.1007/978-3-642-54484-2

Sim, W. (2016, March 3). The Online Citizen now a one-man show. The Straits Times, Singapore Press Holdings. Retrieved from http://www.straitstimes.com/politics/the-online-citizen-now-a-one-man-show

Singer, J. B. (2004). Strange bedfellows? The diffusion of convergence in four news organizations. Journalism Studies, 5(1), 3-18. doi:10.1080/1461670032000174701

Singer, J. B. (2006). Partnerships and public service: Normative issues for journalists in converged newsrooms. Journal of Mass Media Ethics, 21(1), 30-53. DOI: $10.1207 /$ s15327728jmme2101_3

Singapore Press Holdings. (2017). About Singapore Press Holdings Ltd. Retrieved from http://www.sph.com.sg/about-sph/sph-corporate-profile/

Silverman, D. (2014). Interpreting qualitative data, (pp. 57-71). Thousand Oaks, California: Sage.

Staps, F. (2015, August 25). Want to create a more digital newsroom? Find your inner start-up. Nieman Lab. Retrieved from http://www.niemanlab.org/2015/08/wantto-create-a-more-digital-newsroom-find-your-inner-startup/

Tan, T. H. \& Mahizhnan, A. (2016). Not quite an "Internet" Election: Survey of media use of voters. In Tan, T. H., Mahizhnan, A., \& Ang, P. H. (Eds.), Battle for Hearts and Minds: New Media and Elections in Singapore (pp. 201-226). Chicago: World Scientific.

Tan, T. H., Tng, Y., \& Yeo, A. (2015, September 11). [The Angle] Battle for Eyeballs: Online Media in the 2015 Election. Retrieved November 19, 2015, from http://www.ipscommons.sg/battle-for-eyeballs-online-media-in-the-2015election/

Tandoc, E. C. (2015). Why web analytics click. Journalism Studies, 16(6), 728-799. http://doi.org/10.1080/1461670X.2014.946309 
Teng, A. (2016, March 4). A "continuous journey" towards newsroom of the future. The Straits Times, Singapore Press Holdings. Retrieved from http://www.straitstimes.com/singapore/a-continuous-journey-towards-newsroomof-the-future

The New York Times. (2014, March 24). Innovation. The New York Times. Retrieved from https://www.scribd.com/doc/224608514/The-Full-New-York-TimesInnovation-Report

The Online Citizen. (2017, August 9). About Us. The Online Citizen. Retrieved from https://www.theonlinecitizen.com/theonlinecitizen-team/

Tremblay, S. (2017). Are we teaching international media at small liberal arts colleges? In Friedrichsen, M. \& Kamalipour, Y. (Eds.), Digital Transformation in Journalism and News Media: Media Management, Media Convergence and Globalization (pp. 501-518). Cham: Switzerland: Springer International Publishing

Torres, B. P. (2013). Levels of professional polyvalence in Spanish multimedia groups. Recherches En Communication, (39), 31-51. Retrieved from http://sites.uclouvain.be/rec/index.php/rec/article/view/8263/7303

Usher, N. (2017a). Making business news: A production analysis of The New York Times. International Journal of Communication, 11, 363-382.

Usher, N. (2017b). Venture-backed news startups and the field of journalism. Digital Journalism, O(0), 1-18. http://doi.org/10.1080/21670811.2016.1272064

Veglis, A. (2012). Journalism and cross media-media publishing: The case of Greece. In Siapera, E. \& Veglis, A. (Eds.), The Handbook of Global Online Journalism, (pp. 209-230). West Sussex, UK: John Wiley \& Sons, Inc.

Ward, B. (2016, January 15). Should your newsroom act more like a startup? Poynter. Retrieved from https://www.poynter.org/news/should-your-newsroom-act-morestartup

Wengraf, T. (2011). Qualitative Research Interviewing: Biographic Narratives and Semi-structured Methods. London, UK: Sage

Westlund, O. (2013). Mobile News. Digital Journalism, 1(1), 6-26. http://doi.org/10.1080/21670811.2012.740273

Winseck, D. (1998). Pursuing the holy grail: Information highways and media reconvergence in Britain and Canada. European Journal of Communication, 13(3), 337-374.

Yap, D. (2017). Thank you. But we just can't go on any more. The Middle Ground. Retrieved from http://themiddleground.sg/2017/10/28/thank-just-cant-go/ 
Yin, R. K. (2009). Case study research: Design and methods (5 ${ }^{\text {th }}$ Edition). Sage Publications.

Zaccheus, M. (2015). The Straits Times remains most-read English newspaper, in both print and digital. The Straits Times, Singapore Press Holdings. Retrieved from $\mathrm{http} / /$ www.straitstimes.com/singapore/nielsen-report-print-news-a-staple-formost-singaporeans-st-is-most-read-english-daily

Zhang, W. (2016). Social media and elections in Singapore: comparing 2011 and 2015. Chinese Journal of Communication, 9(4), 367-384. http://doi.org/10.1080/17544750.2016.1231129

Zhang, W. \& Pang, N. (2016). The internet and social media. In Lee. T \& Tan, K. (Eds.), Change in Voting: Singapore's 2015 General Election (pp. 232-245). Singapore: Ethos Books.

Zuckerberg, M. (2016, April 6). Launch of Facebook Live (Facebook post). Retrieved from https://www.facebook.com/zuck/posts/10102764095821611 


\section{APPENDIX A: BACKGROUND INFORMATION OF INTERVIEWEES}

\section{TOTAL NO. OF INTERVIEWEES: 19}

\section{The Straits Times}

\begin{tabular}{|c|c|c|c|}
\hline Interviewee & $\begin{array}{c}\text { Years of } \\
\text { working at } \\
\text { The Straits } \\
\text { Times }\end{array}$ & Job title & Job description \\
\hline S1 & 10 & $\begin{array}{l}\text { Digital Editor } \\
\text { (digital desk) }\end{array}$ & Head of digital team \\
\hline S2 & 7 & $\begin{array}{l}\text { Social Media } \\
\text { Editor (digital } \\
\text { desk) }\end{array}$ & $\begin{array}{l}\text { In-charge of ST's social media } \\
\text { platforms and social media related } \\
\text { news. Part of digital team. }\end{array}$ \\
\hline S3 & 7 & $\begin{array}{l}\text { Video Editor } \\
\text { (digital desk) }\end{array}$ & $\begin{array}{l}\text { Head of ST's video team. Part of } \\
\text { digital team. }\end{array}$ \\
\hline S4 & 4 & $\begin{array}{l}\text { Digital sub-editor } \\
\text { (digital desk) }\end{array}$ & $\begin{array}{l}\text { Backend sub for website. Puts text, } \\
\text { video, photo together for online } \\
\text { stories. Does simple video editing } \\
\text { occasionally. Part of digital team. }\end{array}$ \\
\hline S5 & 10 & $\begin{array}{l}\text { Videographer } \\
\text { (digital desk) }\end{array}$ & $\begin{array}{l}\text { Camera man for ST's video team. } \\
\text { Part of digital team. }\end{array}$ \\
\hline S6 & 6 & $\begin{array}{l}\text { Video journalist } \\
\text { (digital desk) }\end{array}$ & $\begin{array}{l}\text { Video journalist for ST's video } \\
\text { team. Does scripting, part of digital } \\
\text { team. }\end{array}$ \\
\hline S7 & 6 & $\begin{array}{l}\text { Reporter } \\
\text { (news desk) }\end{array}$ & ST print reporter, political desk. \\
\hline S8 & 9 & $\begin{array}{l}\text { Associate News } \\
\text { Editor } \\
\text { (news desk) }\end{array}$ & ST associate editor (print). \\
\hline S9 & 16 & $\begin{array}{l}\text { Breaking News } \\
\text { Editor } \\
\text { (digital desk) }\end{array}$ & $\begin{array}{l}\text { ST breaking news editor, digital } \\
\text { desk. In-charge of all breaking } \\
\text { news events for online. }\end{array}$ \\
\hline S10 & 16 & $\begin{array}{l}\text { Deputy Digital } \\
\text { Editor } \\
\text { (digital desk) }\end{array}$ & $\begin{array}{l}\text { Oversees the daily news operations } \\
\text { and running of the digital desk }\end{array}$ \\
\hline
\end{tabular}


The Middle Ground (launched June 2015)

\begin{tabular}{|c|c|c|l|}
\hline Interviewee & $\begin{array}{c}\text { Years of } \\
\text { working at } \\
\text { The } \\
\text { Middle } \\
\text { Ground }\end{array}$ & Job title & Job description /additional Info \\
\hline T1 & 1 & Publisher & $\begin{array}{l}\text { Co-founder; in-charge of business } \\
\text { and operations }\end{array}$ \\
\hline T2 & 1 & Consulting editor & $\begin{array}{l}\text { Co-founder; in-charge of editorial } \\
\text { (former ST journalist for 28 years) }\end{array}$ \\
\hline T3 & 1 & News editor & $\begin{array}{l}\text { Part-time; former ST copy editor } \\
\text { and reporter for 7 years }\end{array}$ \\
\hline T4 & 1 & Freelance journalist & Contributed coverage for GE2015 \\
\hline T5 & 1 & Full-time Journalist & $\begin{array}{l}\text { No particular beat; covered } \\
\text { GE2015 }\end{array}$ \\
\hline T6 & 1 & Full-time journalist & $\begin{array}{l}\text { No particular beat; covered } \\
\text { GE2015 }\end{array}$ \\
\hline
\end{tabular}

\section{The Online Citizen}

\begin{tabular}{|c|c|l|l|}
\hline Interviewee & $\begin{array}{c}\text { Years of } \\
\text { working at } \\
\text { The Online } \\
\text { Citizen }\end{array}$ & \multicolumn{1}{|c|}{ Job title } & \multicolumn{1}{|c|}{ Job description } \\
\hline O1 & 5 & Executive editor & $\begin{array}{l}\text { Writes, and manages editorial and } \\
\text { business aspects }\end{array}$ \\
\hline O2 & 3 & Editor & $\begin{array}{l}\text { Writes and manages editorial; } \\
\text { especially volunteers and } \\
\text { freelancers; has stopped writing for } \\
\text { TOC }\end{array}$ \\
\hline O3 & 4 & $\begin{array}{l}\text { Commentaries } \\
\text { editor }\end{array}$ & $\begin{array}{l}\text { Writes and manages editorial; has } \\
\text { stopped writing for TOC helping } \\
\text { TOC with business transition }\end{array}$ \\
\hline
\end{tabular}




\section{APPENDIX B: INTERVIEW GUIDE}

\section{Section 1: Background/rapport building}

1. Name/age/gender/role/time with company

2. How did you come to work here?

\section{Section 2: Business Convergence}

1. Describe your company's organisational structure (number of departments, number of staff, nature of work of each department).

2. How is your newsroom currently organised, physically?

3. Has it been re-organised? If so, how and why?

4. As far as you know, has your company diversified its business or plans to diversify its business? If so, what types of diversification? (Has it been setting up new platforms, or mediums, or buying out other similar-industry companies?)

\section{Section 3: Technological Convergence}

\section{Multiplatform news distribution}

1. As far as you know, how does your news organisation prioritise the distribution of news on different platforms?

2. As far as you know, how does your news organisation decide on which media was better suited to which platforms?

3. As far as you know, what were the results of your/your organisation's strategy?

News production processes

4. Describe your news production workflow

5. In relation to news production workflow, how has it changed? Why?

6. What types of new IT systems (content management systems, communications software) have been introduced to facilitate news production?

\section{Section 4: Professional Convergence}

1. How important is it for a journalist in your organisation/role to be able to multitask the different parts of the news production process (writing, editing, photography, videography, online publishing; functional polyvalence)?

2. How important is it for a journalist in your organisation/role to be able to report on different news topics (thematic polyvalence)? 
3. How important is it for a journalist in your organisation/role to be able to create news content for different mediums (print, online, video, audio; media polyvalence)?

4. How has new technology been used to aid the three types of polyvalence in your organisation?

5. In relation to the different types of multiskilling (polyvalence), what sort of training does your company provide?

6. In relation to the different types of multiskilling (polyvalence), what sort of training have you attended?

\section{Section 5: Content Convergence}

\section{Multimedia news presentation}

1. As far as you know, how does your news organisation decide on whether a news story needs a multimedia package, or just single or dual media (for example, text only, or text and photo only, infographics)?

2. As far as you know, how does your news organisation decide which stories to place on the main space on your website and which to relegate?

3. As far as you know, how does your news organisation make your website interactive?

\section{Collaboration}

1. As far as you know, how much collaboration is there between news professionals when producing news in your organisation?

2. As far as you know, how do you think multimedia news has news affected the degree of collaboration between journalists in your organisation?

3. As far as you know, how much collaboration is there between news professionals when disseminating news in your organisation?

\section{Coordination}

1. As far as you know, what type of coordination is needed between news professionals when producing news in your organisation?

2. As far as you know, how do you think multimedia news has news affected the degree of coordination between journalists in your organisation?

3. As far as you know, how much coordination is there between news professionals when disseminating news in your organisation?

\section{Section 6: The Audience}


1. How important is it to engage your audience online, personally and for your organisation?

2. How do you think readers share your news from your publishing platforms?

3. As far as you know, how does your news organisation decide when to engage your audience online?

4. As far as you know, how does your news organisation decide who in your company should engage?

5. How have you used comments on the Internet (including social media and your website) in news reporting?

6. As far as you know, how does your news organisation use web and social media analytics?

7. Do you pay attention to web analytics in relation to you work?

8. How important is it to your organisation that you use your own social media platform to promote the news that has reported by your journalists?

\section{$+++\mathrm{END}+++$}




\section{Informed Consent Form}

\section{Please read this consent agreement carefully before agreeing to participate in this research.}

Purpose of the research This research examines journalism convergence in large media organisations and online news start-ups. This study will be used in the Master of Mass Communication dissertation of Mr. Sherwin Chua Kim Hee, which is supervised by Dr. Trisha T. C. Lin, Assistant Professor, Wee Kim Wee School of Communication and Information, Nanyang Technological University, Singapore.

What you will do in this study You will be interviewed by the researcher Mr Sherwin Chua about your work as a journalist with your organisation. The interview will take about 30 to 45 minutes. However, subsequent follow-up questions may be asked of you.

Benefits and Risks Your participation will greatly contribute to journalism research in Singapore and aid the understanding and development of the practice. There are no anticipated risks linked with participating in this study.

Voluntary Withdrawal Your participation in this study is voluntary, and you may withdraw from the study at any time without penalty.

Confidentiality Your personal data and responses in this study will remain strictly confidential and be used only for research purposes. All interviews will be recorded. However, your name will not be recorded with your interview responses.

All data and consent forms will be stored safely and securely.

The research findings may be presented at academic conferences and/or published in journals, books, etc. However, no participants' names will be disclosed during such presentations and publications.

Further Information This study is approved by the NTU-Institutional Review Board (IRB). If you have any questions about the study or your rights as a participant, please contact the researcher, Mr Sherwin Chua, schua018@e.ntu.edu.sg, her supervisor, Dr. Trisha T. C. Lin, trishalin@ntu.edu.sg, or a representative of the IRB (irb@ntu.edu.sg, or at +65 65922495).

Thank you very much for your time and effort. We highly appreciate your help in this research.

Sincerely,

Sherwin Chua

Post-graduate student

schua018@e.ntu.edu.sg

Master in Mass Communication

Wee Kim Wee School of Communication and Information

\section{Agreement:}

The purpose and the nature of this study have been sufficiently explained to me. I agree to participate in this study voluntarily. I understand that I am free to withdraw at any time without giving any reason and without any penalty. If you agree, please select yes.

Yes $\square \quad$ No $\square$

Name:

Signature/Date: 


\section{APPENDIX D: CODES FOR DATA ANALYSIS AND DEFINITION}

\section{Personal information (PI)}

Personal information about the interviewees

1. Interviewees' age (PI-AG)

2. Interviewees' duration of work at company (PI-DU)

3. Interviewees' current title in company (PI-TI)

4. Interviewees' current job description/work responsibilities (PI-JD)

5. Interviewees' experience as a journalist (PI-EX)

\section{Business Convergence (BC)}

Organisational structure (OS)

1. Number of staff (BC-OS-NS)

2. Number of departments (BC-OS-DE)

3. Job scope of each department (BC-OS-JS)

\section{Centrifugal (CF)}

1. Horizontal expansion (BC-CF-HE)

Regarding the expansion of the news business from one platform to multiplatform operations, either through acquisition or internal expansion.

2. Vertical expansion (BC-CF-VE)

Regarding the expansion of the news business to include other parts of the value chain, either through acquisition or internal expansion.

Centripetal $(C P)$

1. Newsroom organisation (BC-CP-OR)

Regarding the current (physical) organization of the newsroom

2. Newsroom integration (BC-CP-IN)

Regarding newsroom reorganization (physical) to merge editorial teams/units

3. Newsroom divergence (BC-CP-DV)*

Regarding newsroom reorganization (physical) to separate editorial teams/units

\section{Technological Convergence (TC)}

Multiplatform news distribution (ND)

1. Prioritisation of platforms for news distribution (TC-ND-PL) Regarding how platforms are prioritised for news distribution

2. Results of organisation's news distribution strategy (TC-ND-RE)

Regarding results organisation's news distribution strategy on multiple platforms 
News production processes (PP)

1. News production processes (TC-PP-CU)

Regarding the organizations' current news production processes (non-physical)

2. Changes to news production processes (TC-PP-CH)

Regarding changes made the news production processes (non-physical)

3. New IT (software and hardware) that facilitate the news production process (TP-PP-IT) Regarding new IT that facilitate news production

\section{Professional Convergence (PC)}

1. Functional polyvalence (PC-FP)

Instances when a news staff must carry out tasks related to the different stages of the news production process

2. Thematic polyvalence (PC-TP)

Instances when a news staff must work on news related to different thematic areas

3. Polyvalence of media for one publication (PC-MP-ON)

Instances when a news staff must produce multimedia content for different mediums, for one publication/brand

4. Polyvalence of media for multiple publications (PC-MP-MU)

Instances when a news staff must produce multimedia content for different mediums, for multiple publications or brand belonging to the media company

5. New technology that was introduced/adopted to assist polyvalence (PC-NT)

Regarding new technology that has been introduced/adopted to facilitate polyvalence

6. Training in polyvalent skills (PC-TR)

Whether journalists were given training by their companies to be professionally polyvalent

7. Attitude towards polyvalence (PC-AT)

Regarding news staff's attitude towards professional polyvalence

\section{Content Convergence (CC)}

Multimedia news presentation (MM)

1. Types of media in a news story (CC-MM-TM)

Regarding types of media (text, video, audio, photos) in an online news story

2. Decisions on commissioning multimedia stories (CC-MM-CM)

Regarding journalists' decision-making process on whether a multimedia story is necessary

3. Decisions on placement of stories on website (CC-MM-PL)

Regarding journalists' decision-making process on placement of stories on their news website

4. Interactive elements* (CC-MM-IN)

Regarding interactive elements in an online news story

5. Hypertextual elements* (CC-MM-HY)

Regarding hypertextual elements in an online news story 
Collaboration (is this different from coordination?)

1. Within-publication collaboration (CC-CB-WC)

Collaboration between news staff from different teams/units within the same publication to produce multimedia news

2. External collaboration (TP-CB-EC)

Collaboration between news staff from different publications within the company/group to produce multimedia news

3. Industry collaboration (TP-CB-IC)

Collaboration between news staff from different companies within the industry to produce multimedia news

\section{Coordination}

1. Within-publication coordination (CC-CD-WC)

Coordination between news staff from different teams/units within the same publication

2. External coordination (CC-CD-EC)

Coordination between news staff from different publications within the company/group

3. Industry coordination (CC-CD-IC)

Coordination between news staff from different companies within the industry

\section{Convergence with The Audience (AA)}

Use of the Internet as platform for engaging audience (EA)

1. Monitors comments about own stories (AA-EA-MC)

Monitors readers' comments about own stories on Social Web platforms but does not respond

2. Respond to comments (AA-EA-RC)

Responds to readers' comments in or present own opinions on Social Web platforms

3. Self-promotion of own stories (AA-EA-SP)

Uses own social media platforms to re-publish and promote own stories written for his/her publication

4. Promotion of other journalists' stories (AA-EA-PP)

Uses own social media platforms to re-publish and promote other co- workers' stories

5. Organisational policy (AA-EA-OP)

Regarding news organisations' Social Web policy or guidelines on engaging readers

Use of analytics as a tool to measure engagement (AN)

1. Personal attitude towards analytics (AA-AN-AT)

Does not care about web analytics at all

2. Organisation's policy towards analytics (AN-OP)

Regarding news organisations' policy on using analytics in news construction

$$
\text { +++END+++ }
$$


Appendix E

ACCOUNTING AND CORPORATE REGULATORY AUTHORITY

(ACRA)

INFORMATION RESOURGES

WHILST EVERY ENDEAVOR IS MADE TO ENSURE THAT INFORMATION PROVIDED IS UPDATED AND CORRECT. THE AUTHORITY DISCLAIMS ANY LIABILITY FOR ANY DAMAGE OR LOSS THAT MAY BE CAUSED AS A RESULT OF ANY ERROR OR OMISSION.

Business Profile (Company) of THE OPINION COLLABORATIVE (LIMITED)

Date: 09/05/2017 (201412054R)

The Following Are The Brief Particulars of :

Registration No

Company Name.

\begin{tabular}{|l|}
\hline 201412054R \\
\hline THE OPINION COLLABORATIVE (LIMITED) \\
\hline
\end{tabular}

Former Name if any

Incorporation Date.

Company Type

Status

Status Date

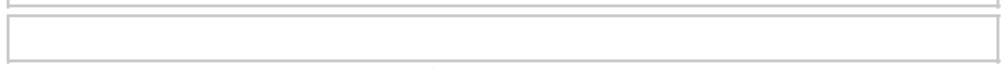

$26 / 04 / 2014$

PUBLIC COMPANY LIMITED BY GUARANTEE

Live Company

$26 / 04 / 2014$

Principal Activities

Activities (I)

Description

NEWS AGENCY ACTIVITIES (63901)

NEWS PUBLICATION FOR GRASSROOT ACTIVITIES

Activities (II)

PRODUCTION OF ADVERTISEMENTS, CORPORATE VIDEOS AND EVENT VIDEOS (59112)

Description

Registered Office Address

PRODUCTION OF DOCUMENTARY FOR EDUCATION PURPOSE

28 SIN MING LANE

\#03-142

MIDVIEW CITY

SINGAPORE (573972)

Date of Address

$20 / 04 / 2015$

Date of Last AGM

Date of Last AR

Date of AVC Laid at Last AGM

Date of Lodgment of $A R, A / C$

$23 / 01 / 2017$

20/02/2017

$30 / 09 / 2015$

$20 / 02 / 2017$

Audit Firms
NAME
Y C TAN \& CO

Charges

Charge No. 
Appendix E

ACCOUNTING AND CORPORATE REGULATORY AUTHORITY

(ACRA)

\section{IIFORMATION RESOUREES}

WHILST EVERY ENDEAVOR IS MADE TO ENSURE THAT INFORMATION PROVIDED IS UPDATED AND CORRECT. THE AUTHORITY DISCLAIMS ANY LIABILITY FOR ANY DAMAGE OR LOSS THAT MAY BE CAUSED AS A RESULT OF ANY ERROR OR OMISSION.

Business Profile (Company) of THE OPINION COLLABORATIVE (LIMITED)

Date: 09/05/2017 (201412054R)

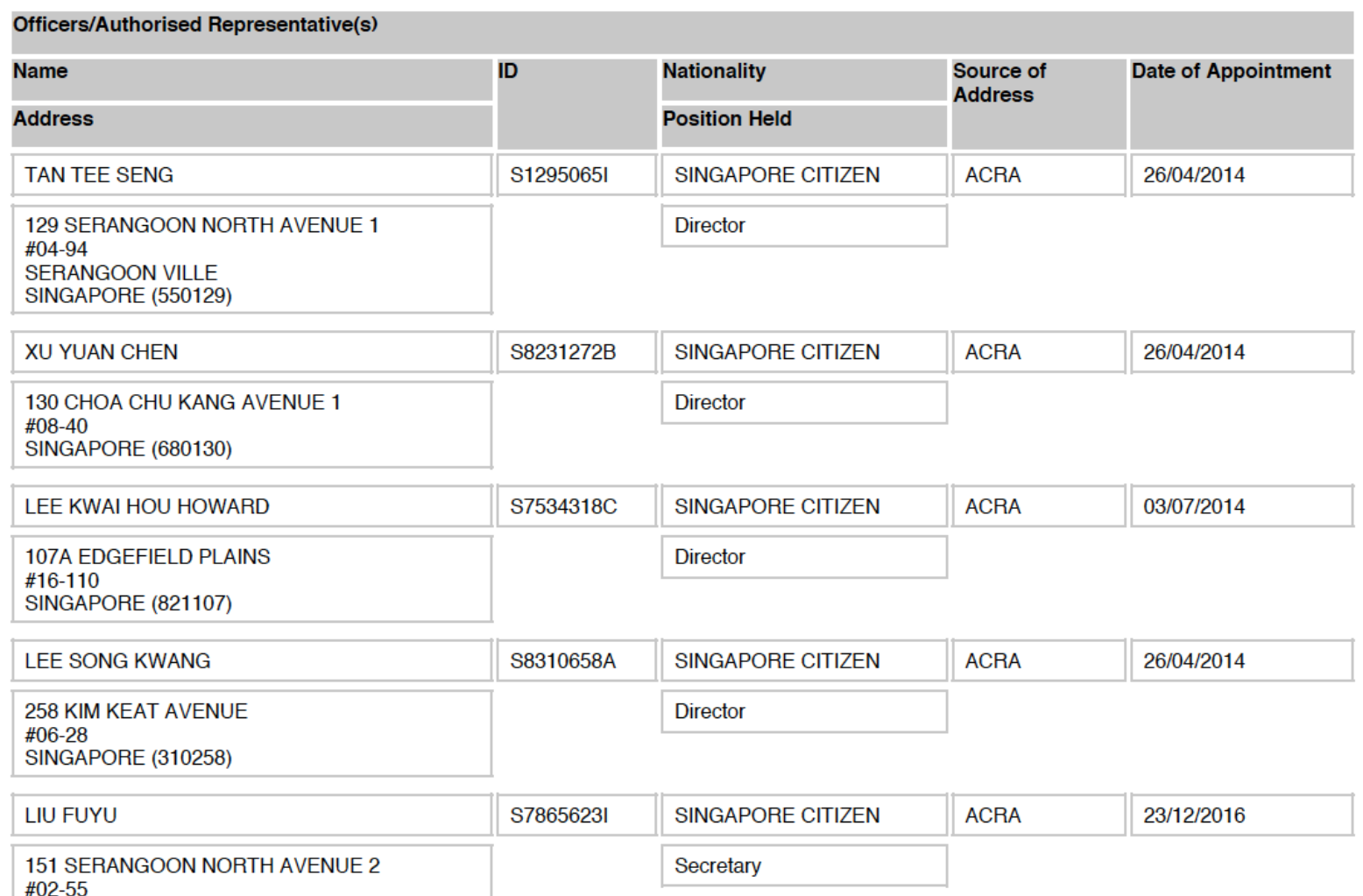

SINGAPORE (550151)

\section{Abbreviation}

UL - Local Entity not registered with ACRA

UF - Foreign Entity not registered with ACRA 
Appendix E

ACCOUNTING AND CORPORATE REGULATORY AUTHORITY

(ACRA)

\section{INFORMATION RESOURGES}

WHILST EVERY ENDEAVOR IS MADE TO ENSURE THAT INFORMATION PROVIDED IS UPDATED AND CORRECT. THE AUTHORITY DISCLAIMS ANY LIABILITY FOR ANY DAMAGE OR LOSS THAT MAY BE CAUSED AS A RESULT OF ANY ERROR OR OMISSION.

Business Profile (Company) of THE OPINION COLLABORATIVE (LIMITED)

Date: 09/05/2017 (201412054R)

PLEASE NOTE THAT INFORMATION HEREIN CONTAINED IS EXTRACTED FROM FORMS/TRANSACTIONS FILED WITH THE AUTHORITY

FOR REGISTRAR OF COMPANIES AND BUSINESS NAMES

SINGAPORE

RECEIPT NO. : : ACRA170509151880

DATE

: 09/05/2017

This is computer generated. Hence no signature required. 